(2) norden 



\section{Working time arrangements and social consequences - What do we know?}

Karen Albertsen

Kaisa Kauppinen

Asbjön Grimsmo

Björg Aase Sørensen

Gudbjörg Linda Rafnsdóttir

Kristinn Tómasson 
Working time arrangements and social consequences - What do we know?

TemaNord 2007:607

(C) Nordic Council of Ministers, Copenhagen 2007

ISBN 978-92-893-1620-0

Print: Ekspressen Tryk \& Kopicenter

Cover: Kjell Olsson

Layout:

Cover photo:

Copies: 200

Printed on environmentally friendly paper

This publication can be ordered on www.norden.org/order. Other Nordic publications are available at www.norden.org/publications

Printed in Denmark

Nordic Council of Ministers

Store Strandstræde 18

DK-1255 Copenhagen K

Phone (+45) 33960200

Fax (+45) 33960202

www.norden.org

\section{Nordic Council}

Store Strandstræde 18

DK-1255 Copenhagen K

Phone (+45) 33960400

Fax (+45) 33111870

\section{Nordic co-operation}

Nordic cooperation is one of the world's most extensive forms of regional collaboration, involving Denmark, Finland, Iceland, Norway, Sweden, and three autonomous areas: the Faroe Islands, Greenland, and Åland.

Nordic cooperation has firm traditions in politics, the economy, and culture. It plays an important rol in European and international collaboration, and aims at creating a strong Nordic community in a strong Europe.

Nordic cooperation seeks to safeguard Nordic and regional interests and principles in the global community. Common Nordic values help the region solidify its position as one of the world's most innovative and competitive. 


\section{Acknowledgements}

This report has been written as part of network collaboration between researchers from the Nordic countries. The project was supported with a grant from The Nordic Council of Ministries. Grant no. 411050-05079.

We would like to acknowledge Professor Torbjörn Åkerstedt, Karolinska Institutet, Stockholm, Associate professor Carina Bildt, National Institute for Working Life, Sweden and Research Director Otto Melchior Poulsen, The National Research Centre for the Working Environment in Denmark, for their support and contributions in the upstart period of the project.

Further, we would like to acknowledge the following persons, who have kindly assisted the project: Ms.Tarita Tuomola from The Finnish Institute of Occupational Health (FIOH) assisted with data collection. From the National Research Centre for the Working Environment in Denmark, the Secretaries Bodil Holst, Lone Bösewetter, Pia Gøtterup and Pia Dukholm have proff-read and revised the manuschript and made the layout. The Librarians; Rikke Nielsson, Elizabeth Bengtsen and Elisabeth Frederiksen have collected the large amount of literature to the project. 



\section{Content}

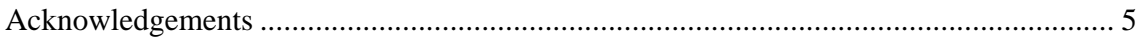

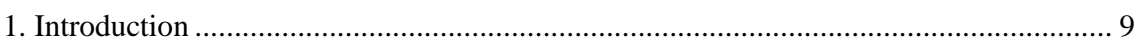

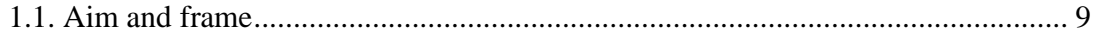

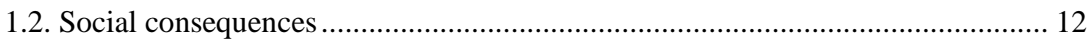

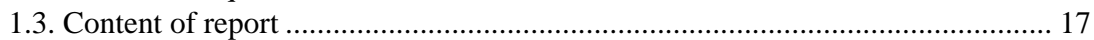

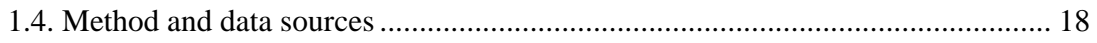

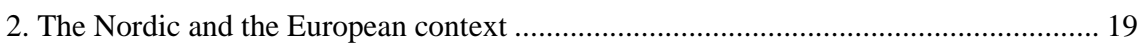

2.1. Working hours in the Nordic countries .......................................................... 21

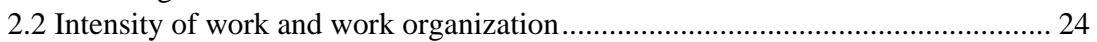

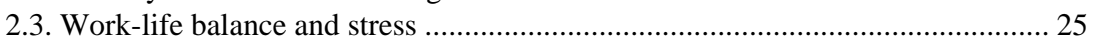

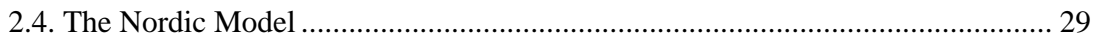

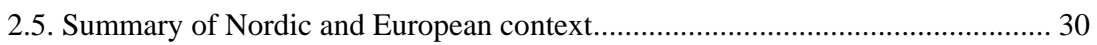

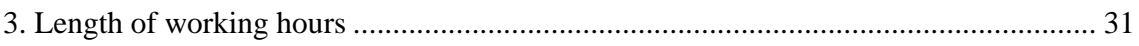

3.1. Consequences of working hours on work-life balance ...................................... 31

3.2. Consequences of working hours on stress and wellbeing..................................... 41

3.3 Summary on working hours, work-life balance and psychological

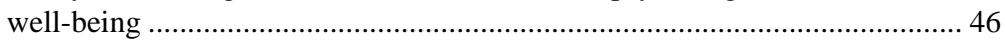

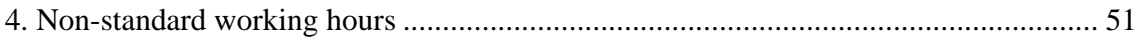

4.1. Consequences of non-standard working hours on work-life balance.................... 51

4.2. Consequences of non-standard working hours on stress and wellbeing ............... 56

4.3. Summary - non-standard working hours, work-life balance and stress

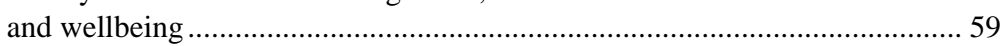

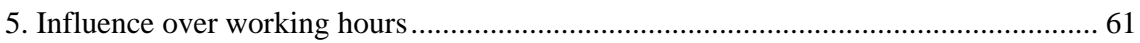

5.1. Consequences of influence over working hours on work-life balance .................. 61

5.2. Consequences of influence over working hours on stress and wellbeing ............. 65

6. Results concerning health consequences of long and irregular working hours...............69 69

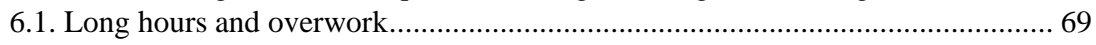

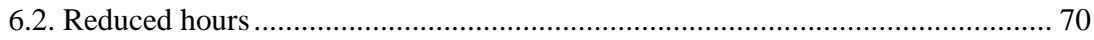

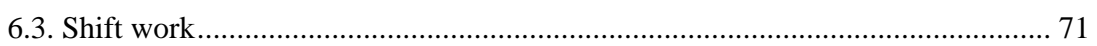

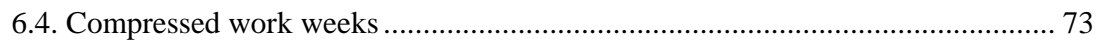

7. Examples of interventions in working time arrangements................................................ 75

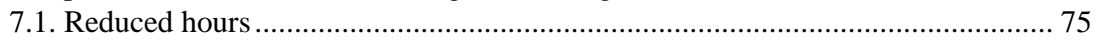

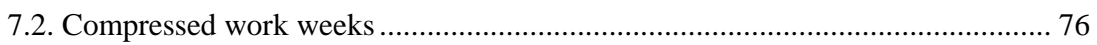

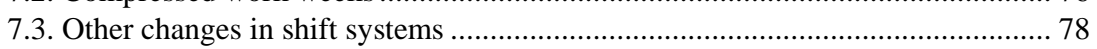

7.4. Increased influence over working hours ................................................................ 79

7.5. Summary on experiments and interventions in working

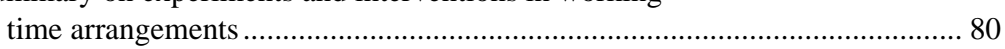

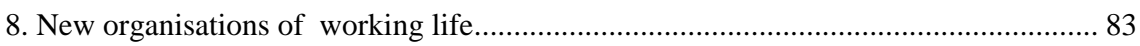

8.1. Trust hours - work based on results and performance.............................................. 85

8.2. Teleworking - via telecommunications equipment ............................................ 85

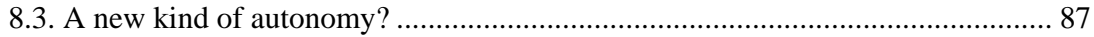

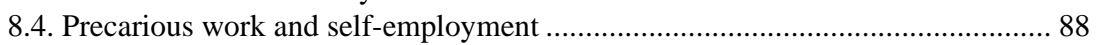

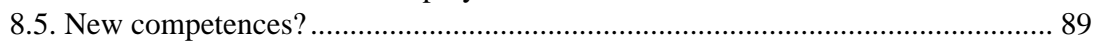

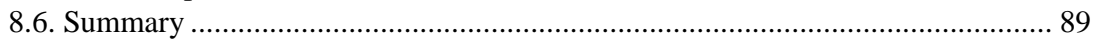

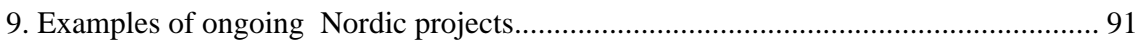

9.1. Work/Life Balance - a research and development program ................................ 91

9.2. Work hours impact on health .............................................................................. 93 


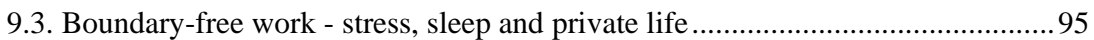

9.4. Working hours and parents' experience of stress ............................................... 96

9.5 Shift work; employees attitudes and expectations................................................... 98

9.6. The work-life balance: Integrating Family well-being and working life research........................................................................... 99

9.7. Nordic Study on working hours in nursing ....................................................... 100

9.8. Reciprocity is an asset - a study on flexible working time arrangements.

10. Summary from Seminar on long and irregular working hours at the National Institute of Occupational Health (NIOH), Denmark ................................ 103

10.1. "Working time, demands at work and developments in fatigue, sleep and heart disease"

10.2. "Work-family Conflict and Fatigue: The role of Working

Time Arrangements".

10.3. "Stress and Workload: Health Promoting and Health

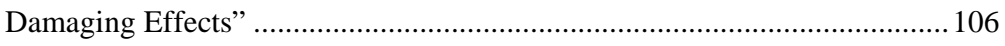

10.4“Health and long/irregular/flexible work hour” ............................................... 108

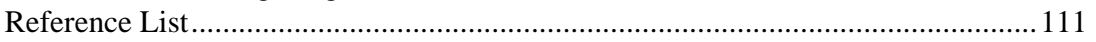

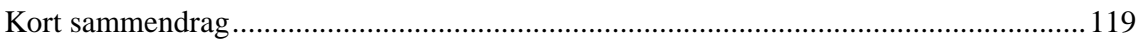

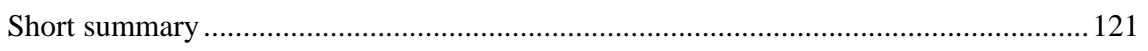

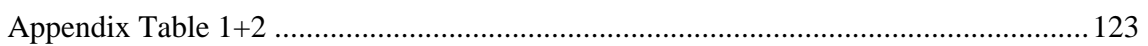




\section{Introduction}

\subsection{Aim and frame}

Within the latest decades, working life has been subjected to a lot of changes. The global 24-hours economy has significantly influenced the way working life is organized. Increased globalization and competitive pressure have forced organisations to expand their capacity of operation. Communication and transportation takes place across national borders and across time zones. "Just in time delivery" of the right amount at the right place, has been requested within the industry. Within the domestic sector, services are requested at all times of the day, evenings, weekends and holidays.

Flexibility in production, in delivery and in the organisation of working hours has been part of the solution to these requests. But flexibility in work hours can take many forms and have many different meanings. For a discussion and overview see the report from the SALTSA project (Costa et al., 2003). It is at least important to differentiate between company-based flexibility on the one hand, referring to the needs of employers to modify, extend or reduce work hours according to production needs, and on the other hand individual flexibility that meets the needs of employees, providing them more or less influence over own schedule (Härmä, 2006).

In parallel with these changes, also private life and the structure of a family life have undergone dramatic changes from thirty years ago where long lasting couple and parent relationships were the norm toward changing family constellations and network-families where parenthood is no longer necessarily connected to the intimate partner relationship. Children may live in diverse and changing constellations of biological parents and step-parents; with a single parent or two parents (maybe of the same gender) (Rones \& Matthiesen, 2006; Allvin, Aronsson, Hagström, Johansson, \& Lundberg, 2006).

The new organization of working life places high demands on the employees. On the one hand increased independence, influence on and responsibility for the organization and execution of work, on the other hand increased demands in the form of tight deadlines, high demands to documentation, coordination, collaboration and flexibility, and often less social support and feedback from supervisors.

In parallel with these developments, problems such as stress, depression and conflicts between work and private life have become more and more common in the latest decades. 
The organisation of work hours is one of the major factors in the work environment influencing our private life. The new organisation of working life demands more flexible and more variable working time arrangements, including long hours, overwork with or without compensation and different kinds of compressed work hours. Also the time for work; at days, evenings, nights and weekends has a tendency to increase in the new and so called 24-hours global economy.

All these tendencies may have social consequences both for the individual and for the family. The whole rhythm of life is dependent on the organization of work hours: time for paid work, time for home work, time for care and being together with children friends and relatives, time for relaxation and for leisure. The organizations of work hours influence both our biological and social rhythm: sleep, hormones, recovery and circadian rhythm is highly influenced by the organization of work hours. It influences the lifestyle, e.g. the possibilities of physical activities and a regular diet. The organisation of work hours also influences other aspects of the work environment: the possibilities of contact with colleagues, communication and in some cases, such as 24-hours open gasoline stations, the risk of exposure to work-related violence and robberies.

The tendencies seem to be present all over the world, but there is, however, large national differences in the way in which both working life and private life is organized.

In the near future the Nordic countries may face an increased shortage of both skilled and unskilled labour on the market. One of the consequences could be that employers have to compete in recruiting and keeping the right manpower in their businesses. Different arrangements for optimal work-life balance might become an important factor and knowledge about what contributes to work-life balance should therefore be in the interest of all parties in the labour market.

Compared to the rest of the world, the Nordic countries have all succeeded in combining high employment rates for both men and women with relatively high fertility rates. Island is the absolute top score with a fertility rate of about two. This is a large advantage in light of the challenges to maintain welfare and productivity in societies with increasing populations of elderly people. The combination of high employment rates and high fertility rates may to a high degree be ascribed to wellfunctioning child-care and parental leave systems. The challenge is to maintain a system in the future, which secures a sustainable balance between work and private life.

There seems to be many similarities between the societies in the Nordic countries. In some cases, the "Nordic Model" is discussed as if it was a single and uniform model shared by the Nordic countries. The similarities between the countries make it obvious to summarize experiences and discuss perspectives for the future development within a Nordic context. 
This should, however, not exclude the knowledge from the rest of the world.

This report describes Nordic and international research-based knowledge about the consequences of different forms of working hour arrangements on work-life balance and wellbeing.

The knowledge in this field is far from complete. Some areas are intensively researched and a lot of documentation exists, while in other areas there is a lack of research and/or contradictory findings due to methodological problems or lack of theoretical models or clearly stated hypotheses. Some topics or problem areas are relatively new and still need much more exploration.

The purposes of this report are:

1. To summarize the international scientific knowledge with regard to social consequences of long and irregular working hours and employee influence on working hours.

2. To describe the context of the labour market in the different Nordic countries and to describe and give examples of Nordic studies of the social consequences of the organisation of working hours.

The focus of the report is on the direct social consequences of working hours in the form of psychological well-being, stress and work-life balance including social relationships between the employee and his or her environment outside work; that is, children, spouse, other family members, friends, leisure time activities, society and community activities.

Physiological and physical health consequences and consequences in the form of pain, fertility and pregnancy problems are not included in this report. There is of course no clear cut demarcation line between physical health and social well-being. Both are included in the comprehensive definition of health by WHO:"health is a state of complete physical, mental and social well-being and not merely the absence of disease or infirmity" (http://www.searo.who.int/ ). Physical, social and psychological health is related and influences each other in many different ways. There exist, however, already good reviews with regard to the physical health consequences of the organisation of working hours, so we have here chosen to focus on the social and psychological aspects as work-life balance, stress and psychological well-being, and give a brief overview of the results with regard to health (see chapter 6).

There may as well be other relevant consequences and secondary consequences of many of these. For example may accidents or disease caused by long working hours have consequences for the family and for the social life of the victim, and poor work-life balance may have secondary consequences in the form of poor health, absence, low productivity etc. These kinds of secondary consequences are not included in the report, but are nevertheless very important. 
Productivity, efficiency and attention or concentration at work is not included; neither are accidents or absence as consequences of long and irregular working hours or secondary consequences in the form of exposure to violence or other traumatic events. Wage reduction or reduced career opportunities as a result of reduced hours or flexible work-family policies is only included if they have been part of studies focusing on work-life balance or well-being.

\subsection{Social consequences}

\section{The balance between work and private life}

The relationship between working life and private life has been a topic for discussion and research since women in a larger scale started to enter the labour market after the middle of the former century. The process has taken different forms and speed in different countries. Before that time, there was a common, traditional solution to the work-family conflict: a breadwinner and a housewife (see e.g. Hochschild or Højrup (Højrup, 1989; Hochschild, 1997; Hochschild, 1989; Hochschild, 1995).

This traditional form of organizing family life still exists, and in some countries it is still the most common form. However, in many cases, the solutions to the problem of balancing work and private life demands have changed. Dual-earner couples have become the most common type of family, and only few men can nowadays rely on a house-wife. Only very few women have ever had the opportunity to rely on a back-stage husband who took care of home and children, and single parents of both gender have, by definition, never had it.

Also the stability of the partner relationships have changed: "Network families" have become more and more common; describing families in which marriage and parenthood are two separate functions. Focus has changed from the family as the important entity and to the individual. This does, however, not mean that families have lost their importance for the individual, but the family as an entity does not have the same stability (Allvin et al., 2006). The continuity and stability of the workplace may in some cases be higher than of the family (Hochschild, 1997).

This disability in combination with the tendencies at the labour market, where more and more groups experience a de-regulation of time and place for the performance of work and increased demands to selfregulation and self-organisation of work, has placed considerable challenges to the families and the efforts to combine work and family life.

In general terms, work-family conflicts can be described as "a situation in which fulfilling the roles in one of the two domains (work and family) conflict with fulfilling the role in the other." (Kristensen, SmithHansen, \& Jansen, 2005). 
To keep it simple, the development can be described as a tendency toward more and more people assimilating a career life-form (Højrup, 1989). At the same time, the traditional solution to the work-life balance within this life form, a back-stage wife, has become more and more rare. Dual career families as well as single parents - without stable and well functioning solutions to the work-family conflict - have become the norm.

The problems associated with this development have been described as early as in 1957 by the Swedish politician and intellectual Alva Myrdal. In her book "Kvinnans två roller”(Myrdal \& Klein, 1957), she argued for the right of women to combine the role as a mother with the role of a wage earner. She also described the double burden for working women, and labled a long list of suggestions for societal changes that could make it more possible for women to combine work and family. Among other things, she argued that men should participate more in the household- and childcare work.

The American Sociologist Arlie Hochchild emphazised with her book "The second shift" how the burden of domestic work at home was still very unequally shared between men and women in the 1980's (Hochschild, 1989). And further she described the change in the meaning and content of a family in her book "The time bind. When work becomes home and home becomes work" (Hochschild, 1997).

There exists a lot of different and to some degree overlapping concepts to describe the connection between work and family life. Two main traditions can be distinguished: a tradition around the concept of workfamily conflict and a tradition around the concepts of work-life balance. The tradition of work-life balance can be associated with a "best practice" approach not only with focus on families but on the whole life span and the different phases in life. The work-family conflict tradition is more closely associated with a tradition focusing on "poor health consequences", and the focus is more directly on families, and particular on families with children. In practice, research within these two traditions describes, however, pretty much the same kinds of problems and solutions, and a whole range of partly overlapping concepts have appeared: "work-family" or "work-home" or work-life" and "interference" or "interaction" or "spill over", only to mention a few.

In the tradition of "conflicts", it is most usual to distinguish between conflicts generated from lack of time, from lack of energy and from differences in expected behaviour. It is further in the tradition of spill over or interference common to distinguish between work-to family spill over and family to work spill over and between positive and negative spill over. This may all together leave 6 different dimensions. Both positive and negative aspects are included in the concept of work-life balance. For a review over concepts and theoretical frames, see Geurts and Demerouti (Geurts \& Demerouti, 2003). 
In recent years, there has been a lively discussion about the new tendencies in the organization of working life, and how they influence the work-life balance. Instead of a picture where work intrudes the family and the private life as a negative aggressor, the weight is in this discourse on the positive side; people love both family and work, but have difficulties in prioritizing their passions. Particularly in relation to borderless work, work where the amount and quality of work is unlimited, the prioritizing may cause troubles. Among others, the book "Competing devotions: career and family among women executives” (Blair - Loy, 2003) focus on this dilemma. Also the concept of "navigation" has been introduced as a mean to learn to prioritize and set goals in private life as well as working life (Kring, 2005). The devotion or passion toward work, sometimes taking the form of dependence, is also touched upon by the concept of "workaholics", people who are addicted to the kick they get out of working hard, perform well and experiencing the adrenaline in the body (Ng, Sorensen, \& Feldman, 2007). This addiction may also, in parallel with alcohol addiction, take form of an escape from emotional demands and troubles in private life (Rasmussen, 2005).

In this context where literature will be reviewed from the whole range of different traditions, we will not go into details with definitions, but include all kinds of studies focusing on the connections between work and home and use the terms of "conflict", "imbalance" and "interference" interchangeably and the concepts of "family", "private life" and "home" interchangeably and dependent on what is most appropriate and relevant in the actual context.

\section{Stress, recovery and wellbeing}

The European Agency for Safety and Health at Work has estimated that work-related stress affects more than 40 million of the 710 million Europeans every year, and that it costs more than 20 billions in absence and health costs every year. After back pain, stress is the most reported workrelated health problem in Europe (Parent-Thirion, Macías, Hurley, \& Vermeylen, 2007). Both stress and backache has been associated with poor psychosocial work environment (Gunnarsdóttir, Rafnsdóttir, Helgadóttir, \& Tomasson, 2003; Feveile, Jensen, \& Burr, 2002).

This report focuses on stress as one of the most important individual consequences of working time arrangements. Stress as such is not necessarily a social consequence, but may have very serious consequences for health, individual behaviour, social life, and family life.

The concept of stress is, however, not very precise. Sometimes stress refers to exposures in the environment, other times to individual reactions and sometimes to the whole individual-in-context system. Here we will use the term 'stressor' to characterize the exposures or events that the individual experiences, and the term 'stress' to characterize the individual's reaction to the stressor. 
Stress reactions cover a spectre of different kinds of bodily, psychological and behavioural signs. Stress can influence the level of certain hormones as cortisol, adrenaline and noradrenaline, blood pressure, pulse and temperature; it can give rise to anxiety, irritability, sleeping problems or behavioural problems such as alcohol use, aggressive behaviour, absence or accidents.

Stress is a normal and healthful reaction to threatening events and experiences. Stress has helped us to mobilize all resources to survive in a lot of threatening situations. When stress is followed by recovery in the form of sleep or rest periods, it is not harmful to health. When stress continues over a longer period, without enough recovery in between, the stress reaction can be more or less chronic, and disturb the functioning of the whole organism, both psychological and biological. In the long run this can be harmful to health. It has been shown that stress can increase the risk of heart disease, infections and depression (Groth \& Rosbjerg, 2006b).

Stress can be caused by stressors at many different levels and of different size; from daily hassles to major life events. Some are acute and short-term, e.g. to break a leg, others are more or less chronic, e.g. to care for an ill family member or to work in shifts. There is no simple relation between a stressor and a stress reaction. What is stressful to one person is not necessarily stressful to another. People have different perceptions of a situation and they have different resources to cope with different stressors (Lazarus, 1991). Some situations will, however, be stressful to most people. The classical stressors in the work environment are related to industrial work: repetitive, monotonous work, fast speed, low control. Later, new stressors, associated to work with people, clients, costumers or patients were identified. This encompassed stressors as high, emotional demands and conflicts at work. In the latest decades new stressors related to knowledge-work has become more in focus: endless demands, unpredictability, high competition, deadlines and individualization of work. Particularly in relation to the 'new' stressors, it seems to be obvious that some situations are stressful to one person, while the same situation seems to be stimulating to another.

We will not here focus on individual differences, but concentrate on work environmental stressors, particularly working time arrangements generally associated with stress.

The organisation of working time constitutes the structure around the work, it set the limits for work and for non-work and is particular important for the possibilities for recovery from work-related stress.

The different aspects of working hours are also closely related to the psychosocial factors in the work environment. The job-strain model suggests the combination of demands and control in work as the important factors in relation to stress and health (Karasek \& Theorell, 1990). Overtime and long hours are more common in jobs with high job demands. Influence over working hours may further be positively associated with 
the dimension of work control, and shift-work can be associated with less work control over work (Härmä, 2006).

In this context we will include not only studies with focus on the association between working hours and stress, but also studies with focus on other outcomes related to the broader concept of psychological wellbeing, including e.g. anxiety and life satisfaction.

\section{A gendered issue}

The employment rates as well as the participation in unpaid household work differ for men and women. The gender differences are among other things dependent on national and social class traditions as well as age and children in the household. Accordingly, the consequences of working time arrangements, and particularly the social consequences, differ for men and women.

A report from the European Agency for Safety and Health at Work has recently reviewed gender differences in occupational safety and health (Kauppinen, Kumpulainen, \& Houtman, 2003). With regard to gender differences in working time arrangements, they summarize findings from the third European survey on working conditions:

- That women in general work nine hours less than men per week.

- That $32 \%$ of women and $7 \%$ of men work part-time

- That men are more likely than women to have the possibility of determining when they want to start and stop working.

The authors further stress that the division of household work is still far from evenly distributed between women and men, and that employed women on average spend more time in total on paid and unpaid work, particularly when they work full-time. The results based on the Fourth European Working Conditions Survey confirm these observations. A much higher proportion of working women than working men devotes time outside work to domestic responsibilities, such as caring for children, housework or cooking. On average, men work longer hours than women in their paid jobs; however, when paid and unpaid hours are added together, it is the women, who work the longest number of hours (Parent-Thirion et al., 2007).

Gender differences and gender issues will be identified and discussed where it is judged relevant through this report.

\section{A Comprehensive model}

Work-life balance and psychological well-being are influenced by a lot of factors at different societal levels: Individual and personal factors, factors related to private life, socioeconomic conditions and work environmental factors. Work-life balance and psychological well-being further influence each other and in turn influence factors as health, productivity and ab- 
sence. The figure below shows some of the areas of importance, the interconnections between them and, marked with bold, the focus areas for this report.

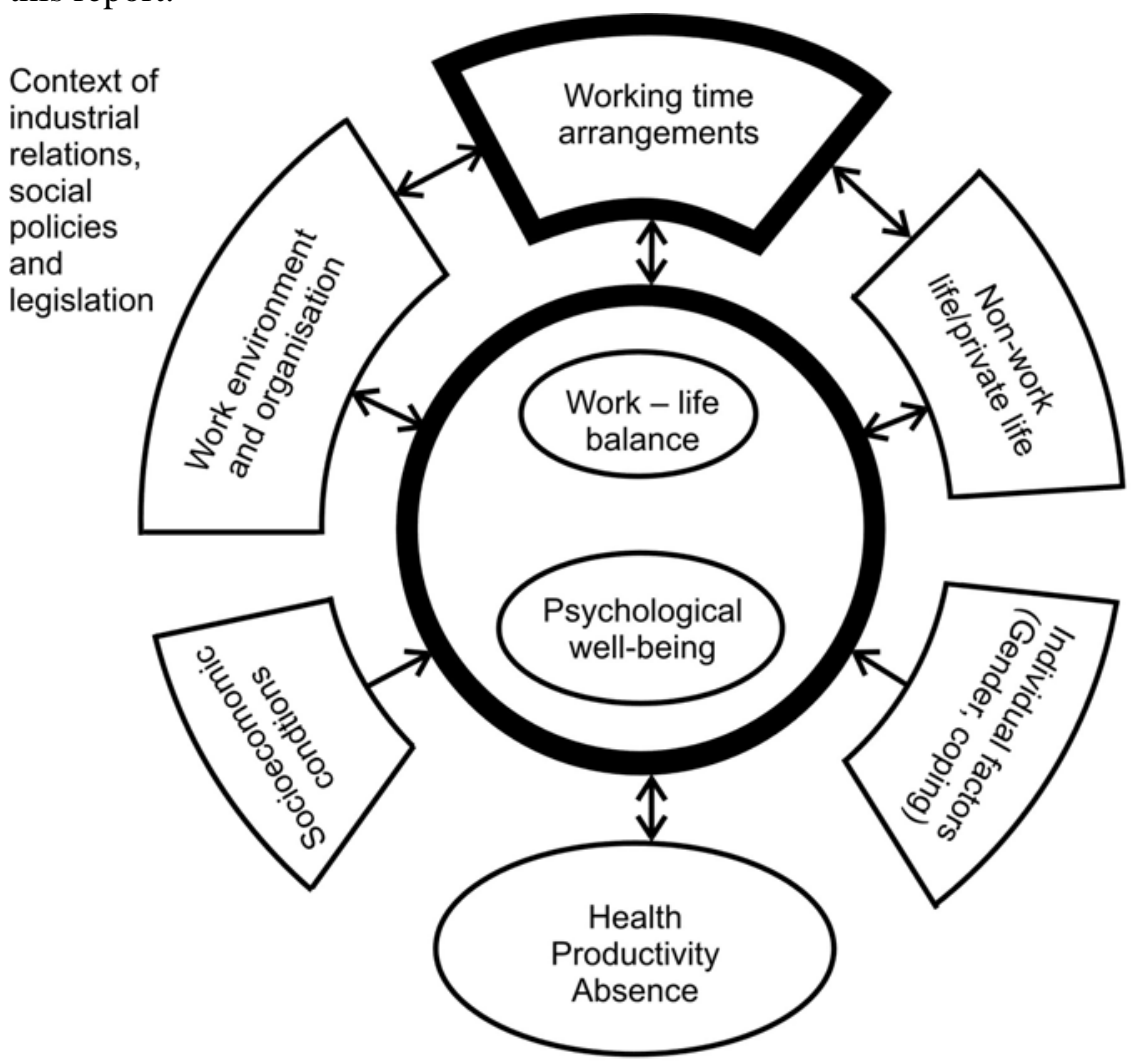

Figure 1: Societal, social and individual antecedents of work-life balance and psychological well-being.

\subsection{Content of report}

The main parts of the report contain a review of studies of social consequences of different working time arrangements. Appendix A table 1 provides a systematic presentation of design and results from the epidemiologic studies. Appendix A table 2 provides a systematic presentation of design and results from the intervention studies.

The second chapter in the report gives a short presentation of the national contexts in the Nordic countries. This chapter is mainly based on statistics from the EU. Facts about employment rates, working hours, part-time work, and shift work, intensity of work, work-life balance and stress in the Nordic countries are presented.

In the next three chapters, the international literature on different aspects of the social consequences of organisation of working hours are presented and discussed. 3) Social consequences of long working hours, overtime work and reduced work hours 4) Social consequences of work 
at non-standard hours 5) Social consequences of influence on work schedule.

Chapter 6 gives a brief overview of the scientific knowledge about health consequences of working time arrangements. This chapter is primarily based on reviews and not on original empirical articles.

Chapter 7 presents some examples of research on interventions in working time arrangements, and in chapter 8 , some aspects of 'the new organization of working life' is briefly discussed.

In chapter 9 a few examples of ongoing Nordic projects in the field are provided and chapter 10 contains a summary from a seminar about long and irregular hours held at The National Institute of Occupational Health in Denmark, as part of this Nordic collaboration project.

\subsection{Method and data sources}

Literature has been searched in the large databases, PSYC-info and Pub Med and supplemented with references from the relevant literature.

Inclusion criteria:

Primary empirical literature. Including as minimum

- One measure of working time arrangements.

- One measure of work-family balance or stress or well-being

- Published between 1990 and 2005 in English or Scandinavian languages

\section{Exclusion criteria:}

Publications without primary empirical data

Studies with measures of workload or work stressors where working time arrangements (e.g. satisfaction with working hours or overwork) are only included as inseparable part of the measure.

Besides primary empirical research published in international journals, we also included relevant reviews, and from the Nordic countries, research published in reports, serials, thesis etc.

The review of literature does not aim at being complete, and relevant studies may have been neglected. We do, however, think that the main conclusions in the report are rather stable and would not change, even if more references were included. 


\section{The Nordic and the European context}

Resent reports from the European Foundation for the Improvement of Living and Working Conditions have focused on the issue of working time and work-life balance in EU (2005; Riedmann, Bielenski, Szczurowska, \& Wagner, 2006; Fagan, 2003; Anxo, Fagan, Smith, Letablier, \& Perraudin, 2007; Kummerling \& Lehndorff, 2007; Riedmann et al., 2006; Parent-Thirion et al., 2007).

http://www.eurofound.eu.int/ewco/surveys/EWCS2005/index.htm

In 2005, a new round of the European Working Condition Survey was conducted (Parent-Thirion et al., 2007) and in 2003, a round of the Labour Force Survey was launched (2003).

http://epp.eurostat.cec.eu.int/cache/ITY_OFFPUB/KS-BP-03-001/EN/KS-BP-03-

001-EN.PDF

We will briefly try to summarize some of the results from these studies concerning working time and work-life balance in the Nordic countries. Unfortunately, Iceland and Norway are only covered in some of the statistics.

It is always difficult to make cross-national comparisons and to compare working hours and organisation of working time across countries with different structures and different labour markets and combinations of jobs, education levels and kind of employments. The definitions, e.g. of shift-work, may vary from country to country, and it is almost impossible to secure the "same" understanding of a question in different cultural contexts. In addition to this, some of the population samples may be relatively small, and not fully representative. There may therefore be relatively large uncertainty related to the numbers given in the tables below. We did, however, find that the statistics could give some impressions of differences and similarities, and that it was better than nothing and better than presenting numbers from each country based on national statistical sources. Even though these statistics may be more accurate, they may be even more impossible to compare across nations.

According to the EU report about Working-time preferences (Fagan, 2003), the development in working time was in the end of the former century characterised by a reduction in working hours and of more diversity in working time schedule. Now some newer trends in the develop- 
ment in regulation of working time are identified and described in the report:

- Development of specific measures to guarantee equal treatment of part-time and other atypical workers. This pertains particularly to the south of Europe and to The Netherlands where options for individuals to request part-time were implemented in collective agreements.

- Employer's resistance upon union demands for working-time reductions unless they are accompanied by increased working time flexibility and/ or wage cuts. Flexibility in this context means flexibility for the employer, e.g. just-in-time production methods, working hour's flexibility or the reduction of bonuses for 'unsocial' hours and over-time.

- Decentralisation of working time regulation, where the law now sets the default standard to be filled in by collective agreements and bargaining.

- Flexibility to suit the needs of workers, the work-life balance. This includes childcare services, parental leave and a variety of working time adjustments options (Fagan, 2003).

- Finnish researchers have further indicated a tendency toward more diversity: a lengthening of work hours among white-collar workers and a shortening of work hours among blue collar workers (Härmä, 2006). These tendencies have been present in U.S.A. in a longer period (Jacobs \& Gerson, 2004) and seem now to spread to Europe.

When the focus is on working hours among employees, it is important to know the actual employment rate for the specific country. Data from The Forth European Working Conditions Survey 2005 (Parent-Thirion et al., 2007) show high employment rates for women in all the Nordic countries: $65 \%$ in Finland, $70 \%$ in Sweden, $72 \%$ in Denmark and $73 \%$ in Norway. Data from The European Union Labour Force Survey, 2002, showed an employment rate at $82 \%$ among women in Iceland. Compared to the rest of the European countries, all the Nordic countries have higher employment rates for women. Among men, the rates are high in Iceland (88\%), in Denmark (79\%) and in Norway (78\%), while it is more moderate in Sweden (73\%) and Finland (69\%) compared to the other European countries (Parent-Thirion et al., 2007).

The proportion of temporary employees as percent of total employees was in 2005, 9\% in Denmark, 10\% in Norway and 15\% in Sweden and Finland (Parent-Thirion et al., 2007). According to the European Labour Force Survey, it was 5\% in Iceland in 2002. In EU15 there were 13\% of temporary employed out of totally employed (2003).

Employees in Norway and Sweden have the legal right to paid vacation in 25 workdays per year, while employees in Finland and Denmark have the right to paid vacation in 30 workdays per year (in Finland only 
after 1 year of employment). In addition, Denmark and Finland have legal right to 9 paid holidays per year and Norway has 2 paid holidays (Ray \& Schmitt, 2007).

\subsection{Working hours in the Nordic countries}

In all the Nordic countries, legislation enacts that the working time shall be arranged so that during every 24 hours, counting from the beginning of the working day, workers shall receive at least 11 hours continuous rest.

The maximum weekly working hours adopted by legislation or concluded by agreement between the organisations of the social partners differ a lot from country to country. In Denmark the limit is 48 hours/week, and a 13 hours working day, while Norway, Sweden and Finland have a 40 hours limit. Norway has a limit for a maximum working day of 9 hours and Sweden and Finland of 8 hours (Fagan, 2003). In Iceland, most of the labour unions have concluded an agreement about 40 hours working week and 8 hours working day. After that employees have to pay for "overtime".

The average actual weekly hours of work for employees also differ. Data from the European Labour Force Survey (se table 2.1.) show Iceland as the absolute European top-score with $50.4 \mathrm{hr} /$ week among full-time employed (or self-employed) men, followed by Sweden, Finland and Denmark with approximately 40 hours, and Norway with $39 \mathrm{hr} /$ week. Among full-time employed (or self-employed) women, the average weekly hours of work is 42,5 in Iceland, 39,6 in Sweden, and about 38 in Denmark, Finland and Norway. Except from the higher level in Iceland, this is approximately at the same level as the other EU15 countries (2003).

Table 2.1.1.: Average self-reported usual weekly hours of work in main job for all employees

\begin{tabular}{lcccccc}
\hline Weekly hours in main job & EU15 & DK & FI & SE & NO & IS \\
\hline Full-time males & 40,8 & 40,1 & 40,0 & 40,1 & 39,0 & 50,4 \\
Full-time females & 38,6 & 37,7 & 38,2 & 39,6 & 37,6 & 42,5 \\
Part-time males & 19,0 & 13,6 & 19,7 & 19,0 & 19,8 & 18,7 \\
Part-time females & 19,9 & 20,4 & 21,0 & 23,6 & 22,5 & 22,8 \\
\hline
\end{tabular}

Source: European Labour Force survey 2002

\section{Long hours}

According to data from the European Working Conditions Survey 2005, almost the same number (15-16\%) of employees in Denmark, Sweden and Finland work long days (more than 10 hours a day more than 5 times per month), whereas the level is a little lower in Norway (13\%). The proportion working long weeks (more than 48 hours) is between 8 and $10 \%$ in Denmark, Sweden and Finland, while it is slightly smaller in Norway. 
It is particularly among self-employed and higher educated full-time employees that the actual working hours per week are increased (Fagan, 2003). As Fagan express is:

"Yet, in nearly every European country the percentage of full-timers who work 45 or more hours per week has risen since the mid 1980s associated with a spread in unpaid over-time and a growing proportion of people with working-time arrangements that are 'self-determined' with little direct collective regulation. Most of these full-timers are highly qualified managerial and professional employees working to ever-tighter deadlines and time pressures yet are usually considered to 'selfdetermine' their own working hours, and the self-employed for whom long hours of work are also common.” (Fagan, 2003).

\section{Part-time work}

With regard to the proportion working part-time, there are marked national differences (see table 2.1.2.). In Finland, only $17 \%$ of the employed women worked part-time in 2002, while it was between $31 \%$ and $45 \%$ in the other Nordic countries. Among men, the numbers were more alike with $8-13 \%$. In Netherlands as many as $73 \%$ of the employed women worked part-time, while in the other end of the spectre, only $8 \%$ worked part-time in Greece.

Table 2.1.2.: Part-time employment as percent of total employment, and involuntary part-time in percent of total part-time

\begin{tabular}{lrrrrrr}
\hline Part time work & EU15 & DK & FI & SE & NO & IS \\
\hline Males and females & 18 & 21 & 12 & 21 & 26 & 27 \\
Males & 7 & 11 & 8 & 11 & 11 & 13 \\
Females & 34 & 31 & 17 & 33 & 44 & 45 \\
Involuntary part-time males & - & 11 & 27 & 20 & 11 & 10 \\
Involuntary part-time females & - & 18 & 34 & 23 & 8 & 9 \\
\hline
\end{tabular}

Source: European Labour Force Survey 2002

Not all part-time workers have chosen to work part-time voluntarily. In Finland, 34\% of the women working part-time reported that they worked part-time because they could not find another job, and in Sweden it was $23 \%$. This, in combination with a high rate of part-time working people in Sweden, leaves a relatively large group of people with involuntary part-time employment in this country.

Almost $80 \%$ of the Swedish establishments use part-time work, while only $71 \%$ of the Danish and $53 \%$ of the Finnish establishments do. Further $30 \%$ of the Swedish establishments use part-time work for fathers, while the corresponding numbers for Denmark is $21 \%$ and for Finland 26\% (Anxo et al., 2007). 


\section{Shift work and variable hours}

The number of people working in shifts is very different in Denmark and in the rest of the Nordic countries. Denmark has the lowest level in Europe with 5\% working in shifts. In the rest of the Nordic countries almost a quarter of the employees work in shifts, and in average in EU15 it is $16 \%$ (table 2.1.3.). Data from the European Working Conditions Survey, 2005, show however a little increase in Denmark (9\%) and in Sweden a little decrease (16\%). Data from the National Work Environment Cohort Study in Denmark 2005, shows that 9\% work outside regular daytime (7 AM- 5 PM) at least $1 / 4$ of the time. (http://www.arbejdsmiljoforskning.dk/NationaleData/NAK2005/Tidsudvikling/ ).

The percentage of people working in the evening and night is a little higher in Denmark, Finland and Sweden (23-25\%), than in Norway and Iceland (16\%). Almost the same percentage in the Nordic countries (20-25\%), and a little less than the European mean work on Saturdays, and almost the same percentage (13-18\%), and a little more than the European mean work on Sundays.

Table 2.1.3.: Population usually working shift work, in the evening, at night, on Saturday or on Sunday, as percentage of the total employment

\begin{tabular}{lrrrrrr}
\hline Usually work & EU15 & DK & FI & SV & NO & IS \\
\hline ...shift work & 16 & 5 & 24 & 24 & 23 & 24 \\
...in the evening & 18 & 23 & 25 & 23 & 16 & 16 \\
....at night & 7 & 7 & 9 & 8 & 5 & 5 \\
...on Saturday & 29 & 22 & 25 & 20 & 22 & 21 \\
...on Sunday & 12 & 17 & 17 & 18 & 13 & 16 \\
\hline
\end{tabular}

Source: European Labour Force Survey 2002

For employees who have to work changing hours, it is of great importance whether they are given notice of changes in the schedule well in advance. According to the Establishment Survey on Working Time 2004-2005 (Kummerling et al., 2007), only few companies in Sweden and Finland with at least $20 \%$ of the workers deployed at changing hours have short notification periods. In Finland, only 3\% of these companies have notification periods below 3 days, and in Sweden it is 6\%. In Denmark, $27 \%$ of these companies have notification periods below 3 days.

In some countries, the inconvenience of shift-work is compensated in different ways, e.g. by reduced hours to higher wages. This is for example the case in Norway.

Norwegian collective wage agreements often have a distinction between working shifts and in "turnus". If the working hour's arrangement includes at least 539 working hours at night and 231 hours on Sundays, it is called permanent (helkontinuerlig) shifts. People working permanent shifts, mainly men in manufacturing and other industries in the private sector where the production requires the same manning all hours throughout the week, usually have collective agreements stating a maxi- 
mum of 33.6 working hours per week, and a shorter working week is compensated through higher wages. If the amount of inconvenient working hours does not reach the norms mentioned above, the working hour's arrangement is called either rotating/altering shifts or "turnus". For those working in "turnus", mainly women within the health care sector, the Norwegian Work Environment Act sets a maximum of 38 working hours per week, and the irregular working hours are compensated through collective agreements. On a societal level this distinction in collective wage agreements between working shifts and in "turnus", reproduces a genderbiased wage difference.

\section{Flexibility}

The number of daily and weekly working hours seems to vary for more people in the Nordic countries than for the average in Europe (table 2.1.4.). Also the number of people with limited flexibility in the schedule is lower in the Nordic countries than the average in Europe.

Table 2.1.4.: Percent experiencing different working time exposures, in the Nordic countries compared to average for the EU15 countries.

\begin{tabular}{lccccc}
\hline Working time & EU15 & DK & FI & SV & NO \\
\hline \% with more than one job & 6 & 15 & 10 & 11 & 16 \\
Work same nuber of hours each day & 59 & 34 & 48 & 45 & 55 \\
Work same number of hours each week & 75 & 70 & 71 & 66 & 64 \\
Work fixed starting and finishing times & 61 & 56 & 49 & 60 & 67 \\
\% with less flexible schedules & 64 & 49 & 53 & 41 & 58 \\
\hline
\end{tabular}

Source: European Working Conditions Survey 2005

According to the European Establishment Survey on working time 20042005 (Riedmann et al., 2006), more than $60 \%$ of the establishments in Sweden, Finland and 50\% in Denmark offer different kinds of flexible working time arrangements. About a quarter of the establishments offers possibilities to use accumulated hours for longer periods of leave. This was only the case for $13 \%$ of the establishments in the EU as average.

\subsection{Intensity of work and work organization}

According to the job-strain model by Karasek and Theorell (Karasek et al., 1990), high job demands can lead to stress, particularly if the job decision latitude is low. The stress produced may carry over to non-work situations and influence how the person acts in the family or towards friends. Data from the European Working Conditions Survey, 2005, indicate that employees in the Nordic countries experience higher intensity and higher control at work than their colleagues in the EU15 (Figure 6.12, p. 60, http://www.eurofound.europa.eu/pubdocs/2006/98/en/2/ef0698en.pdf ). 
As it appear from table 2.2.1., a higher number of employees in the Nordic countries is working at a very high speed and a higher number is working with tight deadlines. At the same time more people are teleworking from home and can take breaks when needed. In Denmark, Finland and Norway, a higher number is further able to choose or change the speed of work. This does not seem, however, to be the case in Sweden, where less people can choose or change the speed of work. Almost the same number as in the other European countries has enough time to get the job done.

Table 2.2.1.: Percent experiencing different characteristics regarding organization of work and place of work, in the Nordic countries compared to average for the 27EU countries

\begin{tabular}{lrrrrr}
\hline Place of work and work organization & EU15 & DK & FI & SV & NO \\
\hline Teleworking from home $1 / 4$ of the time or more & 8 & 16 & 13 & 11 & 12 \\
Working with computers & 50 & 62 & 62 & 70 & 56 \\
Working at very high speed & 61 & 76 & 78 & 85 & 78 \\
Working to tight deadlines $1 / 4$ of the time or more & 62 & 69 & 74 & 72 & 65 \\
Can choose/change speed of work & 69 & 81 & 74 & 66 & 77 \\
Can take breaks when wishes & 45 & 58 & 63 & 60 & 51 \\
Has enough time to get the job done & 69 & 68 & 68 & 68 & 69 \\
Can choose/change methods of work & 68 & 81 & 73 & 89 & 82 \\
Can choose/change order of tasks & 64 & 85 & 81 & 85 & 78 \\
Has influence over choice of working partners & 23 & 36 & 27 & 30 & 30 \\
\hline
\end{tabular}

Source: European Working Conditions Survey 2005

\subsection{Work-life balance and stress}

In the European Working Conditions Survey, 2005, a higher proportion of the respondents in the Nordic countries (43-55 \%) than in EU15 (30\%), reports that their health is affected by their work.

Table 2.3.1.: Percent experiencing that work affects health in the Nordic countries compared to average for the EU

\begin{tabular}{lrrrrr}
\hline & EU15 & DK & FI & SV & NO \\
\hline Does your work affect your health? & 31 & 44 & 43 & 57 & 48 \\
\hline Source: European Working Conditions Survey 2005 & & & &
\end{tabular}

Table 2.3.2, shows the percentages of all respondents (both those who answered yes and no to the question about how their work affects their health) who mentioned stress, overall fatigue, sleeping problems, anxiety and/or irritability as health symptoms. 
Table 2.3.2.: Percent experiencing that work affects different health outcomes in the Nordic countries compared to average for the EU

\begin{tabular}{lrrrrr}
\hline Work affects health & EU15 & DK & FI & SV & NO \\
\hline ..stress & 20 & 27 & 25 & 38 & 29 \\
...overall fatigue & 18 & 17 & 22 & 16 & 12 \\
...sleeping problems & 8 & 10 & 13 & 19 & 10 \\
...anxiety & 8 & 2 & 7 & 17 & 10 \\
$\ldots$...ritability & 10 & 14 & 15 & 15 & 13 \\
\hline
\end{tabular}

Source: European Working Conditions Survey 2005

Health problems like stress, sleeping problems, irritability and partly anxiety from work, seem to be more common in the Nordic countries, particularly Sweden, than in the EU15. This result is contradictory to what is expected from the Karasek model mentioned above. One explanation could be a higher willingness to report this kind of symptoms among Nordic self-employed and employees than those within EU15. Another explanation could be that the Nordic white- and blue-collar workers to a greater extent just attribute the cause of their health problems to their work. A third and statistical explanation is that the differences between EU15 and the Nordic countries in intensity and autonomy at work are so small that the predictive value of Karasek's model in explaining differences in stress becomes close to zero. A forth explanation may be that the level of autonomy in general is so high in the Nordic countries that it may no longer buffer for health damaging effects of high demands and intensity at work.

Even though the Nordic countries score so high on these psychological health outcomes, data from the same survey show that compared to the rest of Europe more employees in Norway, Finland and Denmark find that their working hours fit family or social commitments well or very well (table 2.3.3.). However, Sweden is at the European mean. At the same time, more employees in the Nordic countries are contacted about work outside normal working hours, cares for or educate children (Norway is particularly high on this), and more people (men) take part in cooking and housework.

The relatively good work-life balance reported in the European Working Conditions Survey in the Nordic countries is in accordance with the results from the European Quality of Life Survey 2003 (2005) showing that $19 \%$ of the Swedish employees experience to be too tired to do household work several times a week, $16 \%$ in Denmark and $14 \%$ in Finland, compared to 23\% as average in Europe. Only 8\%, 5\% and 5\% 
Table 2.3.3.: Percent experiencing different work and family life exposures, in the Nordic countries compared to average for the EU

\begin{tabular}{|c|c|c|c|c|c|}
\hline Work and family life & EU15 & DK & $\mathbf{F I}$ & sv & NO \\
\hline Working hours fit family /social commitments well or very well & 81 & 88 & 86 & 79 & 88 \\
\hline $\begin{array}{l}\text { Contacted about work outside normal working hours (a couple } \\
\text { of times a month or more) }\end{array}$ & 22 & 34 & 44 & 45 & 49 \\
\hline $\begin{array}{l}\text { Caring for or educating your children every day for an hour } \\
\text { or more }\end{array}$ & 27 & 37 & 28 & 31 & 47 \\
\hline Cooking and housework (every day for one hour or more) & 47 & 57 & 50 & 55 & 60 \\
\hline
\end{tabular}

Source: European Working Conditions Survey 2005

from Sweden, Denmark and Finland, respectively, experience difficulties in fulfilling family responsibilities several times a week compared to $10 \%$ as average in Europe. The same survey lists Denmark, Finland and Sweden as the highest ranking countries with regard to all round life satisfaction (Norway and Iceland are unfortunately not represented).

Based on the results from the fourth European working condition survey. table 2.3.4 below, shows the distribution of types of households within EU15 and the Nordic countries.

Table 2.3.4.: Distribution of types of households within EU15 and the Nordic countries in percentages

\begin{tabular}{lrrrrr}
\hline & $\begin{array}{c}\text { EU15 } \\
\text { (- DK, } \\
\text { FI,SW) }\end{array}$ & DK & FI & SW & NO \\
\hline Single person household & 14 & 18 & 22 & 17 & 16 \\
Two persons household & 26 & 28 & 29 & 29 & 27 \\
Couple w/at least 1 child <10 y & 21 & 28 & 22 & 21 & 24 \\
Couple w/at least 1 child 10-18 y & 12 & 11 & 10 & 17 & 12 \\
Single parent with at least one child under 10 years old & 2 & 4 & 5 & 2 & 5 \\
Single parent with at least one child between 10-18 & 2 & 2 & 4 & 4 & 3 \\
years & & & & 10 & 13 \\
Household with three or more adults without children & 24 & 9 & 8 & 10 \\
\hline
\end{tabular}

Source: European Working Conditions Survey 2005

There are fewer single person households and single parent households, but quite a few more households with three or more adults within the EU15 than in the Nordic countries. The last type of household consists of three larger groups; 1) young adults living together with their parents, brothers and sisters, 2) parents with grown-up children, and 3) middleaged adults living together with elderly parent(s) or other relative(s).

Employees and self-employed from households with small children are least satisfied with how working hours fit with family or social commitments outside work (Table 9.1, p. 72, http://www.eurofound.europa.eu/pubdocs/2006/98/en/2/ef0698en.pdf ). People from households consisting of three or more adults are also significantly more dissatisfied with their work-life balance. This might indicate that some of the people belonging to this kind of household have i.e. elderly or disabled persons 
to take care of at home. The fact that households with three or more adults are much more common in the EU15 than in the Nordic countries, partly explains the difference in the overall satisfaction with work-life between the two sets of countries in table 2.3.3.

Compared to most countries in Europe, the Nordic countries all have very comprehensive public childcare service systems, public eldercare systems and paid parental leave (Crompton \& Lyonette, 2006).

This does, however, not mean that there is full coverage of the needs for child care in these countries. Care for sick children is e.g. still a serious problem to many employees.

In Denmark, most but not all (2007) people are covered by labour agreements that gives access to at least one day of paid leave at the child's first day of illness. After that, it is in most cases up to the parents to find other options for child care. Also the possibilities for family members to take leave to care for older family members are still sparse.

In Finland, it is concluded in the labour contract agreement whether an employee (a man or a woman) can stay at home if the child suddenly becomes ill. In this case, the employee can stay at home to look after a sick child or to arrange alternative care for one or maximum three days. It is concluded in the labour contract whether this absence is paid by the employer. In most cases, the first days are paid leave. The Gender Equality Barometer (2004) indicates that both male and female employees with a child under the age of 12 have stayed at home to look after a sick child: $50 \%$ of both women and men have stayed at home a few times during the last two years to look after a sick child, while $18 \%$ of women and $14 \%$ of men have stayed at home numerous times (Melkas, 2005).

For many employers, this is a costly arrangement. New legislation in Finland allows employers to offer childcare to their employees in circumstances such as sudden illness of a child. The service is free for the employee and tax-deductible for the employer. The system has proved to be a successful social innovation and beneficial to both individual families as well as employers. One of the aims of this benefit is to help balancing work-life demands, since in most Finnish families both partners are employed outside of the home (Neményi et al., 2006). (Employment in social care in Europe, 2006. www.eurofound.ei.int ).

Managing both multiple care giving and employment roles is characteristic of those who belong to the 'sandwiched generation'. They are caught between the needs of their children and their parents and typically of their own jobs. The "Work and Health in Finland 2006” survey asked: Do you care for a person who needs help because of his/her illness, disability or age? According to the results, $20 \%$ of employed women and 17 $\%$ of employed men answered that they provided some care at least once a month. Their average age was 47 years (Kauppinen \& Toivanen, 2006). These results are in line with other results based on EU samples representing working aged populations across the EU. Women make more 
work-related accommodations than men when sandwiched between their multiple roles (Neményi et al., 2006). (Employment in social care in Europe, 2006. www.eurofound.ei.int ).

The options for parental leave are, compared to the rest of Europe comprehensive in the Nordic countries, but national differences exist both in length, degree of compensation and flexibility of the systems.

In a recent report from the Ministries of Social Affairs and Health in Finland (Piekkola \& Ruuskanen, 2006), pros and cons of the specific Finnish child home care system are discussed. Within this system, mothers are compensated for being home with children until they are three years old. It is also described that only $25 \%$ of the Finnish children under three were in outside care, while it was 50\% in Sweden and 70\% in Denmark.

\subsection{The Nordic Model}

The welfare states and the labour market systems in the Nordic countries have sometimes been described as one shared system or a model called the Nordic or the Scandinavian Model, and indicating very 'encompassing' welfare states. It has been demonstrated, "that a 'societal' effect, in respect of the quality of working life, would seem to be in operation in the Scandinavian countries" (Gallie 2003, here cited after Crompton et al., 2006).

In a study including Finland and Norway together with Britain, France and Portugal, Crompton and Lyonette (Crompton et al., 2006) found evidence of a 'societal effect' on work-life conflicts in Finland and Norway. These countries reported significantly lower levels of work-life conflict even after control for working hours, sex, children in household, age and social class. The authors suggest that work-family and 'women-friendly' policies in Finland and Norway have had a positive impact on reducing levels of work-life conflicts in the countries. In the same study, the level of work-life conflict in France is as high as in Britain and Portugal, even though France also has a comprehensive child care system and other supports for working mothers. Further data analyses showed that the division of domestic labour differed between the countries, with the most equal share between men and women in Norway, followed by Finland, then Britain, France and Portugal with significantly lower scores. A traditional division of the domestic labour was a significant predictor of work-life conflict in France. The authors conclude that the lower level of work-life conflicts in Norway and Finland is due both to more comprehensive welfare states and to a more equal share of caring and domestic work between men and women.

Thus, equality seems to be an important parameter in relation to worklife balance and well-being (see also chapter 3.1). 


\subsection{Summary of Nordic and European context}

Taken together, the European statistics point at high employment rates among women in the Nordic countries, average or little below average number of working hours, except from Iceland with a very high number of weekly working hours, higher intensity at work, and more influence on speed and schedule. More people experience stress, sleeping problems and irritability, but at the same time more people experience a good work-life balance. Studies suggest that this may on the one hand be due to comprehensive welfare states with good child care and elderly facilities and parental leave systems, and on the other hand to a higher level of gender equality and a more equal share of the domestic work between men and women.

Although the Nordic countries are rather similar in a lot of respects, there are also some differences between the countries.

Iceland is exceptional with respect to very high employment rates for both gender and very high levels of weekly hours worked. This, combined with relatively many employees working part-time, could reflect many Icelanders with two or more employments at the same time. Unfortunately, many data are missing from Iceland.

Norway has, together with Finland, a high level of education among employees. There are, compared to the other Nordic countries, more women working part-time, few people working long days, few people experiencing tight deadlines and they have a short average annual leave period. A high number of people in Norway spend time on child care and child education.

In Sweden, compared to the other Nordic countries, a higher proportion experience working at a very high speed, and a smaller proportion can choose or change the speed of work. More people in Sweden experience stress, sleeping problems and anxiety, and at the same time, fewer people experience a good work-life balance.

Finland has a higher proportion of people working long hours and fewer people working part-time. The experience of working hours adapted to family /social commitments are, however, only slightly lower in Finland than in Denmark and Norway, but fewer people spend time on child care or education of children than in Denmark and Norway.

In Denmark, relatively few people work in shifts; however, night and evening work are at the same level as in Finland and Sweden. Slightly more people are teleworking from home, and slightly more people can choose or change the speed of work, and fewer people work the same number of hours each day. A high number report good work-life balance.

However, these cross-national differences should be taken with some caution. They may, at least to some degree, be due to uncertainty in the statistics, and may also have changed in the past years since the surveys were conducted. 


\section{Length of working hours}

This chapter gives a review of studies that deal with the question how the length of working hours influences work-life balance, stress and wellbeing. In the first part of the chapter, studies of the effect of long hours, overtime work and part-time work in relation to the employee's experience of work-life balance are reviewed. Secondly, studies of consequences for the family as entity and for children's well-being are reviewed. Thirdly, aspects of gender, job and cultural differences are discussed. In the second part of the chapter, studies of the consequences of long hours, overtime work and total workload in relation to stress and well-being are reviewed.

We try in this chapter to focus on the effect of working hours and to separate this effect from other work environmental effects. Working hours are, however, highly associated with other aspects of the work environment. Long hours are often associated with high demands at work, high responsibility, high skills discretion and high possibilities for development. Further there is a selection into jobs with long hours of healthy people, highly educated people and people who prioritize work highly. The effect of these associated factors cannot totally be disentangled from the effects of long hours, and these methodological problems will be touched upon through the chapter.

\subsection{Consequences of working hours on work-life balance}

\section{Long working hours}

Long working hours in most studies mean working hours more than the ordinary level at 37-40 hours per week. Many studies do not differentiate between long hours and overwork. In this chapter we have included all studies focusing on the effect of longer hours as compared to shorter hours, but not defining the long hours as overwork. Further, many studies treat working hours as a continuous variable and do not specify a threshold between long and ordinary hours. The definitions used in each study will so far it has been possible appear from table 1, appendix A.

The majority of the studies reviewed found higher number of working hours associated with lower levels of different measures of work-life balance. Thus a higher number of hours were associated with less balance, while part-time or reduced hours were associated with more balance.

The measures of work-life balance included both measures of work to family interference or conflict and of family to work interference or con- 
flict (abbreviations explained below the table 1 in appendix A). The associations were most consistently found among women.

Thus, a higher number of working hours were associated with worse work-life balance in 9 female samples (Grzywacz \& Marks, 2000; Hill, Märtinson, \& Ferris, 2004; Jansen, Kant, Nijhuis, Swaen, \& Kristensen, 2004; Jansen, Kant, Kristensen, \& Nijhuis, 2003; Batt \& Valcour, 2003; Higgins, Duxbury, \& Johnson, 2000; Kinnunen \& Mauno, 1998; van Rijswijk, Bekker, Rutte, \& Croon, 2004; Grönlund, 2007b; Grönlund, 2007a), from U.S.A., Canada, Sweden, Finland and Netherlands.

Negative associations between working hours and work-life balance were further supported in 16 gender mixed samples (Hill, Hawkins, Ferris, \& Weitzman, 2001; Baltes \& Heydens-Gahir, 2003; Tausig \& Fenwick, 2001; Batt et al., 2003; Fu \& Shaffer, 2001; Major, Klein, \& Ehrhart, 2002; Voydanoff, 2004; Grönlund, 2004; Albertsen, Kristensen, \& Pejtersen, 2007; Brough, O’Driscoll, \& Kalliath, 2005; Crompton et al., 2006; Berg, Kalleberg, \& Appelbaum, 2003), from U.S.A., Canada, Hong Kong, Sweden and Denmark. The study of Crompton and Lyonette covers 5 samples from UK, France, Finland, Norway and Portugal.

Two male samples, from Sweden and U.S.A., respectively (Grzywacz et al., 2000; Grönlund, 2007b) found a higher number of working hours associated with poor work-life balance.

No association between working hours and work-life balance was found in four other male samples (Jansen et al., 2004; Jansen et al., 2003; Batt et al., 2003; Kinnunen et al., 1998) from U.S.A., Netherlands and Finland and in one mixed sample (Grosswald, 2004) from U.S.A.

Only a single study from the Netherlands had a prospective design. In a gender mixed sample, full-time work and more than 30 minutes commuting time predicted work home interference over 8 months compared to part-time and lower commuting time (Jansen et al., 2004). In another, but overlapping sample, work family conflicts after a year were predicted by more than 30 minutes of commuting time for women. Commuting time was not predictive for men (Jansen, 2003).

In a rather small female sample of nurses from U.S.A., Fox and Dwyer (Fox \& Dwyer, 1999) found interaction processes: long work hours were associated with high work family conflict in connection with low support from supervisors and marital conflicts, while high work time was associated with low work family conflict in connection with high support from supervisors and no marital conflicts.

In summary, there is high evidence that a higher number of working hours are associated with a lower level of work-life balance among women. The findings seem to be stable across different western cultures, both in female and in gender-mixed samples. There is only limited evidence (from U.S.A. and Sweden) for an association between number of working hours and lower work- life balance among men. 


\section{Overtime work}

The distinction between long working hours and overtime work can be difficult to make. In some studies, the authors have, however, made clear that they focused on overtime work, understood as hours worked above contracted hours. Results from these studies are summarized below. Overtime work is often characterized by unpredictability while long hours may be planned and scheduled. The effect of overtime work on work-life balance could therefore be anticipated to be worse that the effect of long hours.

Eight of the reviewed studies explored the association between working overtime and different measures of work-life balance. All of these studies found that overtime work was associated with decreased work-life balance measured as feelings of neglecting home matters (Kandolin, Härmä, \& Toivanen, 2001), work family conflicts (Jansen et al., 2003; Voydanoff, 2004), work home interference (Jansen et al., 2004; van der Hulst \& Geurts, 2001; Geurts, Rutte, \& Peeters, 1999) work family facilitation (Voydanoff, 2004) and workers perception of company help to balance work and family life (Berg et al., 2003). The studies were conducted in the U.S.A., Finland and the Netherlands.

Only two studies from the Netherlands (with partly overlapping study populations) differentiated between men and women. Prospectively over 1 year of follow-up, overtime work was in one of these studies not predictive of work family conflicts among men, while it was among women (Jansen et al., 2003). In the other study, overtime work was crosssectional associated with work-home interference both among men and women, and prospectively in a gender-mixed sample over an 8 months period, and after control for baseline work home interference (Jansen et al., 2004).

In summary, there is high evidence that overtime work is associated with lower work-life balance. There are few studies differentiating between men and women, and the results with regard to men are mixed, so no firm conclusions with regard to gender can be drawn.

\section{Part-time work}

Part-time work is defined as work below the ordinary weekly number of hours. Usually only work below $35 \mathrm{hr} /$ week is counted as part-time work. The exact definition varies from study to study. As far as possible, the definitions used in the specific studies are given in the table 1, appendix A.

In seven female samples, part-time as compared to full-time work was associated with (different measures of ) better work-life (Grzywacz et al., 2000; Grönlund, 2007b; Hill et al., 2001; Jansen et al., 2004; Higgins et al., 2000; Kinnunen et al., 1998; van Rijswijk et al., 2004). The studies were conducted in the U.S.A, Canada, Netherlands, Sweden and Finland.

In male samples, three studies from Sweden, the Netherlands and Finland failed to find any association between part-time work and better 
work-life balance (Grönlund, 2007b; Jansen et al., 2004; Kinnunen et al., 1998).

The findings in a few of the female samples are also contradictory.

In one study, women with high part-time work (26-35 hours/ week) did not experience lower levels of work interference with home, while women in low part-time jobs ( $<26$ hours/week) did benefit of the reduced hours (Jansen et al., 2004).

In another sample, career women in part-time employment did not experience lower levels of family work interference or role overload, while wage-earning mothers did, however, both groups experienced lower levels of work family interference (Higgins et al., 2000).

In one study in a mixed sample, part-time work was associated with worse work-life balance than full-time work, when work hours were controlled. Thus, a high number of work hours were associated with lower work-life balance, and when this was taken into account, part-time work was associated with worse work-life balance than full-time (Tausig et al., 2001). This finding is in accordance with the finding of Jansen et al.(Jansen et al., 2004), who found that a decrease in working hours on own request within the last year was associated with higher levels of work interference with home and with the finding of Artazcoz et al. also found that part-time work was associated with more demands at home (Artazcoz et al., 2004). Thus, choosing part-time can be a strategy to reduce unbalance between work and family, when it is already high, and does not necessarily guarantee that the unbalances will disappear.

Part-time job may under some conditions have other negative sideeffects as well. In career jobs, it may increase the intensity of work, thus making the workload higher while working and it may reduce the future career opportunities and possibilities for development. It may simultaneously be associated with more low-control household task at home, which is in turn associated with distress (Barnett, 1998).

Barnett has further in different studies (see chapter 3.2) emphasized the importance of the fit of working hours rather than the simple number of working hours. People may be more or less satisfied with the number of hours they work, and part-time work is not always voluntarily chosen. As mentioned in chapter 2, there are e.g. in Sweden a relatively large group of people, who are part-time employed, but who would prefer a full time employment. In the large Swedish project, HELA, relevant aspects of involuntary part-time is examined. One of the working papers from this project describes explanation models and statistics (Forssell \& Jonsson, 2005). In another qualitative study, some of the subjective consequences of involuntary part-time among female employees in the retail industry are illuminated and discussed (Mulinari, 2004), and in a third working paper the effects of a community-wide offer of full-time employment to all are evaluated (Bildt \& Nordh, 2004). 
In one study, at special kind of part-time work, called New Concept Part-time was explored. This part-time employment option was targeted toward professional women, and aimed at enhance job prestige, job satisfaction, and career opportunities associated with reduced-hours employment. Women employed in this kind of part-time work (average 30 hr/week) reported compared to full-time (average $50 \mathrm{hr} /$ week) women less work to family conflict and more success in managing the demands of their work and family. They did, however, not report less family to work strain and not less difficulty in managing work and family demands. They reported less career optimism and work success, but not less job performance, job satisfaction and commitment (Hill et al., 2004).

In summary, there is evidence that part-time work is associated with better work-life balance among women, while there is no evidence for such an association among men. The reason for this result is probably that many women use part-time as a strategy to improve work-life balance, while part-time is only chosen voluntarily by few men as a strategy to improve work-life balance. Part-time among men may more often be associated with work disabilities. So, given that part-time is voluntarily chosen, it may help to improve work-life balance.

\section{Work hours load for individuals or families?}

Jacobs and Gerson (Jacobs \& Gerson, 2001; Jacobs et al., 2004) have argued that it is necessary to focus more on the combined work schedules of family members than on changes in individual work patterns. They argue that with an increasing number of dual-earner couples, the shared work weeks have also increased significantly even without changes in the individual working time. They compared working hours of 32676 married couples from the U.S.A. in 1997 with 27494 couples in 1970. The results showed the largest increase in working time among dual-earner couples, and mainly due to a growing working time for the wives. They calculated that $80 \%$ of the growth in working time among married couples is due to growth in dual-earner households.

In addition, the proportion reporting very long work weeks $(+100$ hours/week) rose sharply from between 1970 and 1997 from $9.5 \%$ to $16.5 \%$ for couples without children and from $8.2 \%$ to $12.8 \%$ for couples with children below 18 years (Jacobs et al., 2001). Further, they found two segments of employees: One segment of highly educated workers who are putting in more and more hours at work and another segment of workers who have too little to do. They argue that increases in family time deficits should not be explained by changes in individual working time, but derive from demographic transitions in family compositions and gender relations.

All though it seems obvious that the effect of working hours on family life will depend on the total workload of the parents, and not only on the workload for each of the parents as individuals, most studies are con- 
ducted at the level of the individual employee, and do not take into consideration the total workload for the whole family.

Only three of the studies reviewed have examined the effect of the combined working hours for two spouses.

In one study from the U.S.A. dual career couples were compared to single career couples, and it was found that dual career couples experienced higher levels of stress, overload, role-conflicts, role-ambi-guity and family conflicts, but not significantly higher levels of work family conflicts than single career couples (Elloy \& Smith, 2003).

Another study from the U.S.A. compared different combinations of working hours among spouses. When either one or both spouses worked long hours (more than $45 \mathrm{hr} /$ week), both men and women reported high levels of work-life conflict, stress and overload. When both spouses worked regular hours (39-45 hr/week) or one worked reduced hours (less than $39 \mathrm{hr}$ /week), both men and women reported lower levels of worklife conflict, stress and overload. Reduced hours for one of the spouses were, however, not associated with less work-life conflict, stress or overload compared to the situation where both worked regular hours (Moen \& $\mathrm{Yu}, 2000)$.

In a single study from the Netherlands, the effect of spouses overtime work was explored (Geurts et al., 1999). It was found that work home interference was increased when the spouse worked overtime.

Grönlund (Grönlund, 2004) found in a Swedish study that it was associated with less work family conflicts among women when men worked full-time and women worked part-time in a couple (compared to both in full time). For men, it was not associated with less conflicts, neither when they themselves or when there partner worked part-time.

In summary, it is supported, that long hours and overtime work has a negative influence also on the partner's experience of work-life balance. The results give mixed evidence whether it is associated with better balance, when one of the partners in a couple works part-time and the other full time, compared to both working full-time.

\section{Working hours and children's well-being}

It is well-known that combined paid work and family is associated with good health among women (Ala-Mursula, Vahtera, Pentti, \& Kivimaki, 2004), and the well-being of parents may of course influence children in a positive way. There are, nevertheless, few studies documenting the effects of parent's working time arrangements on children's well-being.

The Nordic study "Inequal Childhood: A comparative Study in the Nordic Countries" examined those psychosocial factors, according to which children are at risk with respect to their wellbeing and health. The data were collected in 2002 in Tampera (Finland), Trondheim (Norway) and in Uppsala (Sweden) among pupils ( $\mathrm{n}=925)$. One of the main results of the study was that in each country the risk of ill-health among the chil- 
dren was related to the time spent with their parents: the more time, the better health, and the less time, the poorer health. Among the Finnish children, the risk for ill-health increased if the mother worked outside the home. The risk was further intensified if the mother felt overloaded by work, which reflected in the emotional atmosphere in the family. (Järventie, 2007; Unequal Childhood: a Comparative study in the Nordic Countries https://tutkii.uta.fi/cris/).

In a resent Danish report, where 1000 children in the 5th grade were asked about there everyday life, one third of the children thinks that one or both of there parents are stressed. The children suggest that the parents work less and are more together with the family in the weekdays. They want more time for play and talk together in the family (www.boerneraadet.dk ).

In a Finnish sample of adolescents, Sallinen et al explored the relationship between well-being and the perception of parents' work. Their results showed that parents' negative work experiences (reported by the adolescents) were associated with adolescents' depression, especially among girls. The association was partially mediated by adolescents' perception of less autonomy granting in parenting and increased conflicts. They further found that adolescents typically complained about parents' fatigue and bad mood, and not so often about parents' lack of time due to work (Sallinen, Kinnunen, \& Ronka, 2004).

Three studies from the U.S.A. have focused on the effect of the parents' working hours on children's well-being and behaviour. In their study from 1993, Parcel et al. found that mothers' low part-time work (1$19 \mathrm{hr} /$ week) in 1986 compared to regular hours was predictive of increases in behavioural problems for 6-8 years old children between 1986 and 1988. Also in cross-sectional analyses, mothers' low part-time was associated with higher behavioural problems for children (Parcel \& Menaghan, 1993).

In another study, the same researchers found that verbal facility was higher for 3-6 years old children whose mothers worked moderate parttime (21-34 hr/week) compared with full time. When mothers worked low part-time, verbal facility was higher, but not significantly higher than full time (Parcel \& Menaghan, 1990). Mothers long working hours (> 40 $\mathrm{hr}$ /week) were associated with more behavioural problems for children in cross-sectional analyses, but not prospectively (Parcel et al., 1993), and it was associated with lower verbal facility for 3-6 years old children (Parcel et al., 1990).

In a third study, the occupational complexity of mothers work was found positively associated with children's home environment, while hours worked per week were not (Menaghan \& Parcel, 1991).

Together the results from the American studies suggest that long working hours among mothers may have a negative effect on children's behaviour and verbal facility, but long-term effects have not been docu- 
mented. They may further suggest that mother's part-time work may be beneficial for the verbal development of smaller children. Mother's parttime work was, however, also associated with behavioural problems among school-aged children. Low part-time work among mothers of school-aged children may in many cases not be voluntarily chosen, but associated with poor health and low occupational complexity, while long working hours are highly associated with high occupational complexity. Even though thorough statistical adjustment was made, it may be difficult to disentangle the effect of working hours form the effect of occupational complexity. These studies are all from the U.S.A., and it is doubtful whether the results can be transferred to countries with highly different child care facilities.

The results from the European studies suggest that it is very likely that children suffer from their parents' negative work experiences and lack of time together with parents and the other way around that they benefit from the parents positive work experiences and time spend together with parents. The field is, however, not well explored. There is a lack of studies, exploring the effect of parents' working conditions on children's well-being.

\section{Gender differences}

Most studies report no gender differences in the frequency of reported work-life balance.

In some studies, men report higher work-home interference than women (Jansen et al., 2004), while in others women report higher interference (Duxbury, Higgins, \& Lee, 1994), higher work overload, stress and conflicts than men (Lundberg, Mårdberg, \& Frankenhaeuser, 1994).

In some studies, equal levels of work-life balance have been found when the raw score among men and women was compared, while differences appeared, when numbers of work-hours were controlled (Tausig et al., 2001; Albertsen et al., 2007; Grönlund, 2004; Grönlund, 2007b). So, when men and women work equal amount of hours, women report more work-family conflicts. These results support the findings suggesting that work hours have different effect on the perception of work-life balance for men and women.

Many studies report different gender effects, e.g. the study by Galambos and Walters finding negative effect of wives' working hours and inflexible schedules on the wellbeing of their husbands, while no effect was found of the husbands' work hours and schedule inflexibility on the wellbeing of there wives (Galambos \& Walters, 1992).

In summary, both men and women experience conflicts between work and family, and they do it almost to the same degree. Men work, however, in average more hours than women in paid work and women more hours in unpaid, household work (se chapter 3.2.), and accordingly the 
impact of number of hours in paid work on work-life balance differ for men and women.

Some of the results further suggest that an equal share of both paid work and household work between a man and a woman in a couple is most likely to support work-life balance for both partners.

The importance of gender equality in relation to work-life balance and well-being at work is acknowledged in an ongoing research project at The Finnish Institute of Occupational Health, the Monikko project ( http://ec.europa.eu/employment_social/equal/practical-examples/opport06-fi-monikko_en.cfm), an important component of the "Work/life balance research and development programme" described in chapter 9.1.1. The project examines gender equality, differences and similarities.

\section{Job differences}

Not only working hours are important for work-life balance and wellbeing. Other factors in the psychosocial work environment are important for the work-life balance as well; and other factors are associated with the length of the working hours.

In a recent review article, Härmä (Härmä, 2006) gives an overview over associations between work hours and psychosocial work characteristics. He points out that work hours are closely related to the three major work-stress models. That overtime is more common in jobs characterized by high job demands and higher possibilities to influence the work situation. In relation to the effort-reward imbalance model, overtime work could be an indicator of over commitment (as part of the 'effort'dimension), while control over work hours and good home-work balance could be viewed as rewarding elements. According to the effort-recovery model, the possible negative consequences of long work hours will depend on the possibilities for recovery during the day and after work.

Grönlund (Grönlund, 2007a; Grönlund, 2007b) found in a Swedish sample that work family conflicts were associated with long hours. However, much more of the variation in work family conflict was explained by job demands, and high job control also contributed to the variation. Long hours were in this study associated with high job demands, but not with high job control.

Pressure at work (Grzywacz et al., 2000), high quantitative work load (Geurts et al., 1999), low decision latitude (Grzywacz et al., 2000), lack of social support from colleagues (Carlson \& Perrewé, 1999; Grzywacz et al., 2000), a problematic dependency of supervisor (Geurts et al., 1999) have all been associated with more work-family conflicts.

High work role conflict, role ambiguity and job stressors as doubts about competence, problems with clients, bureaucratic interference, lack of stimulation and collegiality together with organisational restructuring, downsizing and job-insecurity are also found to be associated with a high 
level of work-family conflict in a review by Geurts and Demerouti (Geurts et al., 2003).

On the other hand, resources at work may be associated with lower levels of work-family conflict. Higher perceived control (Duxbury et al., 1994), job autonomy (Grosswald, 2004) as well as other measures of higher decision latitude and social support together with promotion opportunities and social value of work have shown to be associated with less work-family conflicts (Geurts et al., 2003).

An Icelandic survey among personnel in the bank branches found an association between supervisors' supportiveness and a better work-life balance among women and men (Fridriksdóttir 2004).

The effect of working hours on work-life balance may further be mediated by other work environmental factors.

For example, the effect of high work hours on work-family conflict have shown to be lower when social support from supervisors are high, (Fox et al., 1999). In another study, overtime work did only have a negative effect on work-home interference when rewards were low. When rewards were high, no negative effects of overtime work was found. Low rewards in combination with high pressure had an even worse effect (van der Hulst et al., 2001). In other studies, compensation for working overtime (Jansen et al., 2004) and positive evaluation of work time schedule (Geurts et al., 1999) were associated with less work home interference.

On the other hand, work-family conflicts can partly explain the effect of work environmental factors on well-being. Geurts et al (Geurts et al., 1999) found that work home interference mediated the impact of work and home characteristics on psychological health indicators. Work home interference did partly explain the negative effects of a poor work time schedule, quantitative workload, dependency of supervisor and overtime work by partner on psychological health of the employee. Grönlund (Grönlund, 2007a) also found that work family conflict mediated the effect of job demands and control on psychological well-being.

In summary, working hour arrangement is far from the only important factor in the work environment in relation to work-life balance. Psychosocial factors as job-demands, work-load, influence and social support also play important roles. The effect of long hours and overtime work also seems to be moderated by e.g. pressure and reward to do overtime work, and the experience of work-life balance seems to mediate the effect of the work-environment on psychological well-being.

\section{Cross-national differences}

Although the above reviewed studies derive form many different countries and cultures, and seems to be rather consistent in their findings across countries, important cultural differences may exist. Very few studies have made cross-national comparisons. 
A study of Spector et al (Spector et al., 2004) did, however, compare work-family stressors and working hours across 15 countries divided into three regions: The Anglo Region ( Australia, Canada, England, New Zeeland, and U.S.), the Chinese region (Hong Kong, China and Taiwan) and the Latin American Region (Argentina, Brazil, Colombia, Ecuador, Mexico, Peru and Uruguay). This study supported the hypothesis that there was a stronger relation between the number of hours worked and workfamily pressure in the Anglo region than in the Chinese and Latin regions. The authors speculate that Anglos may view long hours as taking time away from their families, while people in China and Latin America view long hours differently. The lower association between hours worked and work-family pressure in the Chinese and Latin regions may also be due to lower household income. It is less obvious to experience work as a burden taking time from family life, when work is experienced as the only means for the family to survive. Further, the more extended family support in the Chinese and Latin regions may result in less experience of work-family pressure.

A recent study from Britain compared work-life conflicts in Britain, France, Portugal, Finland and Norway. Work-life conflicts were lowest in Finland and Norway and highest in Britain and Portugal. Work-life conflicts were in all countries associated with working hours, highest association in France (0.31) followed by Norway, Britain, Finland and Portugal (0.12). As also mentioned in chapter 2.4., the study also found national differences in the division of domestic labour between men and women, with the most equal share in Norway, followed by Finland, Britain, France and Portugal. France had, regardless of good child care facilities, a high level of work-life conflicts. This may, according to the authors be explained by relatively liberal gender role attitudes in France in combination with a traditional division of the domestic labour (Crompton et al., 2006).

Thus, these few cross-national studies suggest that working hours impact on work-life balance in all countries and that the size of the effect may depend on factors such as. the division of domestic labour, gender role attitudes, child care facilities and family support, income and attitude toward long hours.

\subsection{Consequences of working hours on stress and wellbeing}

\section{Long working hours}

A range of studies have explored the effect of working hours on different measures of well-being. The definition of long working hours, the number of hours worked and the measures of well-being or stress do, however, vary a lot from study to study, and reasonable conclusions are not 
obvious to draw. Here we will try to summarize results from studies of prolonged working days, not described as overtime work, meaning that is should be within the limits of an ordinary working week (35-45 hours).

Associations between long working hours and decreased well-being or stress were supported in six studies conducted on female samples (Artazcoz et al., 2004; Ezoe \& Morimoto, 1994; Higgins et al., 2000; Shields, 1999; van Rijswijk et al., 2004; Väänänen et al., 2004). The studies were conducted in the U.S.A., Canada, Japan, Spain, Finland and the Netherlands.

Two studies from U.S.A. (Barnett \& Gareis, 2002) and Sweden (Grönlund, 2007a; Grönlund, 2007a; Grönlund, 2007a; Grönlund, 2007b) found associations in the opposite direction in female samples.

In male samples, only two studies, one from Japan (Ezoe et al., 1994) and one from Finland (Väänänen et al., 2004) found associations, while three studies from Spain (Artazcoz et al., 2004), Canada (Shields, 1999) and Sweden (Grönlund, 2007b; Grönlund, 2007a) did not.

In mixed samples, 3 studies from the U.S.A. (Barnett, Gareis, \& Brennan, 1999; Fenwick \& Tausig, 2001; Moen et al., 2000) and one from Iceland (with 85\% women in the sample) (Fridriksdóttir, 2004) confirmed associations, while 3 from Sweden (Kecklund, Dahlgren, \& Åkerstedt, 2002; Åkerstedt et al., 2004) and Canada (Marchand, Demers, \& Durand, 2005)did not. A study from Sweden found an association between long hours and less absence (Kecklund et al., 2002).

Two studies, one from Sweden (Grönlund, 2007b; Grönlund, 2007a) and one from Japan (Ezoe et al., 1994), found reduced hours associated with decreased psychological well-being in male samples

Among women, working more than $40 \mathrm{hrs} /$ week compared to parttime was associated with poor self-rated health, psychosomatic problems and more medical visits in a Spanish study (Artazcoz et al., 2004). In a study from Finland, 41-50 hrs/week as compared with part-time $(<38)$ were associated with more psychological distress, while working more than 50 hrs/week was not (Väänänen et al., 2004). Working more than 40 hr/week as compared to 35-40 hours was predictive of subsequent depression (Shields, 1999),

In one study, long working hours were associated with higher marital quality after control for work-family interference. This was explained by a more equal share of low-schedule control tasks between wife and husband (Barnett et al., 2002). Another study from Sweden found longer hours as compared to full time among women associated with better psychological well-being (Grönlund, 2007b; Grönlund, 2007a).

Part-time as compared to full time was associated with higher lifesatisfaction (Higgins et al., 2000) and improved well-being (mediated by work family interference) (van Rijswijk et al., 2004) and less hours were associated with less psychological distress and less social dysfunction (Ezoe et al., 1994). 
However, two studies from Sweden and Canada, respectively, did not find part-time work among women as compared to full-time work associated with better well-being (Grönlund, 2007b; Grönlund, 2007a) or less stress (Higgins et al., 2000), whereas it was related to higher life satisfaction in the study by Higging et al.

A Finnish study found in a large, male sample, work hours of 41-50 hrs/week associated with psychological distress. More than 50 hours were not associated with psychological distress. Long domestic work hours and long total work hours were also related both to psychological distress and sickness absence among men (Väänänen et al., 2004).

A study from Japan found in a male sample that working more or less than $9 \mathrm{hr} /$ day was associated with more somatic symptoms (Ezoe et al., 1994). In the same study, working less than 9 hrs/day was associated with increased social dysfunction among men. In a study from Sweden, working less than 40 hours was also associated with lower psychological wellbeing among men (Grönlund, 2007a).

Three studies failed to show any associations between long working hours and measures of self-rated health, psychosomatic problems, medical visits (Artazcoz et al., 2004), depression (Shields, 1999) and psychological well-being (Grönlund, 2007a) in male samples, while the same studies did show associations in female samples.

In mixed samples long working hours were associated with burnout (Barnett et al., 1999; Barnett \& Gareis, 2000; Fenwick et al., 2001), distress (Fenwick et al., 2001) and with distress mediated by work interference with family (Major et al., 2002). Two studies failed to show associations between working hours and psychological distress (Marchand et al., 2005; Väänänen et al., 2004) and one between working hours and mental fatigue (Åkerstedt et al., 2004), one study found no association between long working hours and stress and at the same time they found less absence among those working long hours (Kecklund et al., 2002).

In the study of Åkerstedt et al. (Åkerstedt et al., 2004), mental fatigue was not predicted by working hours, but by high work demands and high immersion (thinking of work while home).

In summary, the majority of studies support an association between long working hours and decreased psychological well-being in female samples, while one study supported the opposite association and another did find a negative association up to $50 \mathrm{hrs} /$ week whereas none was found for hours more than 50 hrs/week. These two studies were conducted in Sweden and Finland, respectively.

In male and in mixed samples, the results are mixed with regard to an association between longer working hours and decreased well-being. Further, some studies have found reduced hours associated with reduced well-being among men. The results seem to support that gender differences are obvious also with regard to the association between working hours and well-being. As suggested by Keeklund 2002 and Grönlund 
2007, the mixed finding may suggest an association between long hours and more skilled work and more positive work characteristics in general.

\section{Overtime work}

Six of the studies in the review explored the effect of working overtime (defined as such) on different measures of psychological wellbeing (Hughes \& Galinsky, 1994; Kandolin et al., 2001; van der Hulst et al., 2001; Beckers et al., 2004; Jansen et al., 2004; Beckers et al., 2004; Bildt \& Michelsen, 2002). Four of the studies were conducted in gender mixed samples, while one was primarily male. The studies were conducted in Finland, the Netherlands, Sweden, and the U.S.A.

None of the studies could support a general association between working overtime and decreased well-being. In one study from the U.S.A., less extended time (overtime, weekend work, travel) was associated with increased psychological symptoms (Hughes et al., 1994).

In two studies, overtime work interacted with circumstances surrounding the overtime work. Kandolin et al. found in a study of Finnish wage and salary earners that company-controlled flexibility (overtime work, weekend-work and night-shift work) was not associated with well-being among employees with low time pressure in their work, but it was for employees who often or constantly experienced time pressure and who didn't have individual flexibility in time scheduling (Kandolin et al., 2001).Van der Hulst and Geurts (van der Hulst et al., 2001) studied overtime in a sample of primarily male, Dutch postal service employees. The combination of low rewards (incl. job insecurity) and overtime work was associated with elevated risk on five out of six indicators of adverse psychological health (poor recovery, exhaustion, cynicism, negative workhome interference and negative home-work interference) compared to no overtime and high rewards. Overtime under high reward conditions was not associated with adverse outcomes, but low reward was also without overtime associated with three adverse outcomes. They further studied the effect of pressure to work overtime, and found again, that low rewards in combination with both high and low pressure to work overtime had adverse health effects. Particularly low rewards in combination with high pressure had adverse effects.

Some studies discussed the fact that employees working overtime are in general workers with jobs characterised by high decision latitude, high job demands and high skills discretion. It is often highly motivated workers. Beckers et al (Beckers et al., 2004) studied overtime hours in a sample of full-time Dutch workers selected from a random study population. They found no general association between overtime and fatigue. Overtime workers were in general employees with jobs characterised by high decision latitude, high job variety and high job demands, and they had high work motivation. Fatigued and non- motivated workers reported 
worse psychosocial work environment regardless of number of overtime hours.

Kecklund et al.(Kecklund et al., 2002) did not find any relationship between long working hours (> 50 hours /week) and stress among 480 Swedish employees in a trade union, most of them working "trust hours", meaning no formal regulation of the working hours. Those working long hours also had jobs with high demands, high rewards, high influence and high skills discretion; indicating that working long hours in a good psychosocial work environment doesn't have negative consequences in the form of stress.

Jansen et al. also discussed the fact that job demands and other work environmental factors associated with working time arrangements and do additionally affect wellbeing and work-life balance. These factors must therefore be adequately controlled for, if the effect of working time arrangements should be studied. Also factors in the private life situation such as degree of responsibility for childcare and household must be included to give an adequate picture (Jansen et al., 2004).

In a large gender mixed study using data from the Third European Survey on Working Conditions, Costa et al. (Costa, Sartori, \& Akerstedt, 2006) found that after age (40-54 years), time pressure was the most important factor associated with self-reported stress and after age (40-54 years) lack of flexibility was the most important factor associated with irritability.

In summary, in gender mixed and in male studies, there is no evidence that overtime work in general has a negative impact on psychological well-being. There is evidence that the effect of overtime work depend on factors as time pressure, degree of flexibility and rewards for overtime work. There is a lack of studies differentiating between men and women on this issue.

\section{Total workload}

Some studies have explored the effect of the total workload for men and women as a sum of paid and unpaid work. Lundberg and Frankenhaeuser found no difference between men and women among Swedish managers and professional specialists on time spend on paid work (49.1 hrs/week for women and $49.8 \mathrm{hrs} /$ week for men), but women spend twice as much time on unpaid home and household work (16.2 hrs/week for women and $8 \mathrm{hrs} /$ week for men).Women assumed main responsibility for almost all duties at home, and women perceived more stress than men from home and household work. In women but not in men, epinephrine and nor epinephrine were significantly elevated after work (Lundberg \& Frankenhaeuser, 1999).

In a Finnish sample Väänänen et al found that long domestic and total work hours (paid and unpaid) were related to an increased number of sickness absences and psychological distress among men. Among women 
long domestic and total work hours were related to psychological distress, and total work hours to suboptimal health. After control for work family and family work spill-over, the associations were no longer significant (Väänänen et al., 2004).

These studies suggest that a counting of paid working hours is too simple a measure of the total workload in that both paid and unpaid work must be included. The quality of the work (both paid and unpaid) also plays an important role. Barnett et al. found that time spent on lowschedule control household tasks (but not total time or high-control household tasks) was related to psychological distress (Barnett \& Shen, 1997).

Other studies have pointed out that the effect of working hours on well-being is a question of fit of working hours, rather than number of hours. Needs and preferences differ, and optimal working hours vary accordingly. Kecklund et al found that dissatisfaction with working hours was associated with burnout, pain and poor sleep quality (Kecklund et al., 2002), and Barnett et al found that the degree of subjective assessment of fit of the working hours, mediated the effect of working hours on burnout. So the relationship between number of hours worked and burnout depends on the extent to which work schedules meet the needs of the worker and his or her family (Barnett et al., 1999). Further on, difficulty of trade-offs associated with reduced hours was a stronger predictor of job-role quality, turnover intention and psychological distress than number of hours worked (Barnett et al., 2000). In another study, Barnett and Gareis showed that the division of low-schedule-control tasks between man and wife was very important for the effect of the wife's work hours on marital quality (Barnett et al., 2002).

In summary, there is some evidence that a high total level of workload is associated with decreased well-being for both men and women. In addition, there is some evidence that the subjective assessment of fit of working hours is important for whether the effect of long hours is negative or not. Further, studies suggest that trade-offs associated with reduced hours and the division of labour between man and wife is important for the effect of working hours on well-being.

\subsection{Summary on working hours, work-life balance and psychological well-being}

The results from the review strongly supported that a higher number of working hours were associated with a lower level of work-life balance among women, and that part-time work was associated with better balance among women. It was also supported that long working hours were associated with decreased psychological well-being among women, and that part-time work was associated with better psychological well-being. 
However, in two studies, long hours were not associated with decreased well-being.

Among men, the results were more inconclusive. Two studies supported that a higher number of working hours were associated with lower work- life balance, while other studies could not support it. An association between long working hours and decreased well-being was supported in two studies, while other studies could not confirm any association. In addition, there was some evidence that reduced hours were associated with reduced well-being in male and in mixed samples.

In gender mixed samples, it was strongly supported that overtime work is associated with lower levels of work-life balance, while there was no evidence that overtime work should be associated with reduced wellbeing. There was some evidence that the effect of overtime work depends on factors such as time pressure, degree of flexibility and rewards for overtime work. There is a lack of studies differentiating between men and women on this issue, so no firm conclusions with regard to overwork and gender can be drawn.

There was evidence that a high total level of workload is associated with decreased well-being for both men and women. In addition, there was some evidence that the subjective assessment of fit of working hours is important for whether the effects of long hours are negative or not. Some of the results further suggest that an equal share of both paid work and household work between a man and a woman in a couple is most likely to support work-life balance for both partners.

With regard to children's well-being, some American results suggested that long working hours among mothers may have negative effect on children's behaviour and verbal facility, but long term effects have not been documented. It is doubtful whether the results can be transferred to other countries, but it can be concluded that there is a lack of studies exploring the effect of parents working hours on children's well-being.

Results from two cross-national studies suggest that working hours have an impact on work-life balance in all countries and that the size of the effect may depend on factors at the social level as such as the division of domestic labour, gender role attitudes, child care facilities and family support, income and attitude toward long hours.

With regard to part-time work or reduced hours, it was strongly supported that part-time work is associated with better work-life balance among women, while there was no evidence for such an association among men. The reason for this result is probably that many women use part-time as a strategy to improve work-life balance, while part-time is only chosen voluntarily by few men as a strategy to improve work-life balance, part-time among men may more often be associated with work disabilities. Based on the few studies on the effect of the partners working time arrangement, it is not conclusive whether it is associated with better balance, when one of the partners in a couple works part-time and the 
other work full time, compared to both working full-time. Studies also suggest that the trade-offs associated with reduced hours and the division of household labour between husband and wife are important for the effect of reduced hours on well-being.

In total, the results suggest that longer working hours do not necessarily have a negative impact on psychological well-being; the effect may vary dependent on the work environmental and individual context. An important part of the individual context is the family, and domestic demands and obligations may strongly interfere with long working hours. Women are in most countries and in most cases still taking the main responsibility for children and housework, and accordingly, well-being and work-life balance are more often disturbed by long working hours among women than among men.

A more equal share of the household work as well as paid work between men and women may lead to better balance, higher fertility rates and increased female participation in career jobs. This could imply reduced hours for both men and women with small children.

\section{Methodological considerations and future perspectives}

This overview has included studies conducted in a range of different countries, primarily in the U.S.A., Canada and the West and North Europe. It is always difficult to draw conclusions across different cultures and countries. Many of the conclusions seem, nevertheless, to be rather consistent across countries. More strong recommendations for practice and prevention must, however, be adjusted to the specific national context.

The measurements of weekly hours are by no means simple, and many studies are not very precise in their description of particular questions used and of the validity of the measures. Depending both on question formulations and individual tendencies, some respondents may answer according to their actual, weekly hours worked, while others may refer to the negotiated general level of working hours. It is not always obvious whether extra-jobs are included or not. Particular, in jobs without fixed weekly maximum hours, it may be difficult to ask people to recall the average number of hours worked. In some jobs, particularly associated with new organizations of working life (se chapter 8) it may even be difficult to find out what should be regarded as part of work and what should not.

In the study of the effect of working hours on work-life balance and well-being it seems to be very important to differentiate between men and women. Not all studies have stratified on gender, and there is a particular lack of gender- stratified studies on the effect of overtime work.

Further there is a need for studies focusing on the consequences of working hours for the wellbeing of partners and children, and there is a 
lack of studies focusing on the total workload on the individuals and couples.

The studies are performed in a lot of different countries, and results may be difficult to generalize across countries. Cross-cultural studies therefore seem to be a promising route for further exploration of the field.

Multivariate analyses with control for other possible influential work and family factors are applied in most studies, and are certainly also necessary in this field with many interacting and mediating mechanisms. Long hours are further associated with certain types of jobs and other work environmental factors as high demands, high responsibility and high skills discretion. It is of course important to control for these factors in the analyses, but it is not likely that the problems can be fully solved by statistical methods.

- In the study of overtime work and part-time work it seems to be particularly important to consider factors surrounding the part-time or overtime work:

- To what degree is both overtime and part-time voluntarily chosen? How do the hours fit to needs of the employee and his or her family? Is part-time chosen because of poor health, poor psychological wellbeing or work-life conflicts?

- Is overtime compensated or rewarded? Is it conducted under time pressure? How flexible is the schedule? How is the support from supervisors?

- Does part-time work have trade-offs such as costs in the form of giving up professional responsibilities, career opportunities etc. 



\section{Non-standard working hours}

In non-standard working hours, we have included all kinds of working time arrangements different from regular Monday to Friday 8AM-6PM. The main part of the studies focuses on different kinds of shift work arrangements, but also other arrangements of non-standard working hours are included. There may of course be important differences in the social consequences of the different kinds of arrangements, but the number of studies are far from enough to divide the results into different kinds of non-standard working time arrangements.

In a review from 1990, Colligan and Rosa (Colligan \& Rosa, 1990) outlined some of the different kinds of complications associated with different shifts. They stress the point that a particular schedule may be disadvantageous for the worker in some respects (e.g. physiological disruption) while advantageous in other respects (e.g. social). They summarize that fixed day work is the most advantageous seen both from a physiological and a social point of view. However, working afternoon and night shifts or rotating shifts may give better opportunity for solitude day-time activities as gardening, fishing etc. Fixed afternoon shifts may give fewer physiological problems than fixed night shifts and rotating shifts, while it is disruptive on social activities and family life, particularly for time with children. Fixed night work is associated with a lot of physiological disadvantages as sleep disturbances and digestion problems, but it may allow more time for family interaction than afternoon schedules do. However, the demand of adjustment of the family lifestyle to the schedule may also produce strain on the family. Workers on rotating shifts experience some of the best advantages and worst disadvantages of each of the fixed shifts. They conclude that the knowledge up to now have been "quite sketchy".

\subsection{Consequences of non-standard working hours on work-life balance}

In eleven studies, different kinds of shift work arrangements were consistently associated with worse work-life balance, measured as work-home interference (Jansen et al., 2004), work-family conflicts (Albertsen et al., 2007; Jansen et al., 2003) family satisfaction (Grosswald, 2004), workhome balance, work-home conflicts (Fenwick et al., 2001), work-family conflicts, social life conflicts, hobby conflicts (Grönlund, 2004) and time for family and personnel pursuits (Jaffe, Smolensky, \& Wun, 1996; Por- 
tela, Rotenberg, \& Waissmann, 2004). Further three studies supported that the kind of shift-system and the subjective evaluation of it was of importance (Geurts et al., 1999; Jaffe et al., 1996; van Amelsvoort, Jansen, Swaen, van den Brandt, \& Kant, 2004). The studies were conducted in the U.S.A., Brazil, the Netherlands, Denmark, Iceland and Sweden, and all in gender mixed samples, except from the studies by Jaffe and Portela, conducted in a male and in a female sample, respectively.

Studies supporting an association between non-standard hours and decreased work-life balance

In a single, very large study using data from the Third European Survey on Working Conditions, Costa et al. (Costa et al., 2006) found in multivariate analyses that night-work (as one of the three most important factors) was associated with the feeling of a poor fit between working hours and family and social commitment. Shift-work was not among the three most important factors with respect to the feeling of fit between working hours and family and social commitment. Beside night-work, a poor fit of working hours to work and family commitment was associated with lack of flexibility (influence over working hours) and high variability in working hours (not fixed working times).

Jansen et al. found in a large Dutch sample that shift work (as compared to day work) was associated with higher work-home interference among both men and women. Prospectively, shift work was in a mixed sample related to higher work-home interference over an 8-month-period (Jansen et al., 2004) and to more work family conflicts over 1 year (Jansen et al., 2003).

Albertsen et al. (Albertsen et al., 2007) found shift work (all kinds of non-regular day-time work as compared to regular day-time work) associated with poor work-life balance in a representative sample of 3517 Danes. Eiriksdóttir et al (Eiriksdóttir, Rafnsdóttir, Sveinsdóttir, \& Gunnarsdóttir, 2006) found the same results in a survey among 820 shiftworkers in Iceland, and so did Antonsdóttir et al. (Antonsdóttir, Rafnsdóttir, Sveinsdóttir, \& Gunnarsdóttir, 2006) in an Icelandic focus group study. According to the study by Eiriksdóttir, 33\% of the shift working employees felt it was difficult to combine work and family life. Among those with children at pre-school age, $46 \%$ found the work-life balance difficult (Eiriksdóttir et al., 2006).

The study of Grosswald was conducted in a large representative sample of US employees not living alone, and the results showed that employees working in shift work were less likely as those working regular daytime to report family satisfaction. The lowest level of family satisfaction was found in the group working in night shifts, followed by evening shifts. Employees working in rotating shifts were also less likely than 
day-workers to experience family satisfaction, but more likely than those working evening and night shifts (Grosswald, 2004).

Fenwick and Tausig found in their study of another representative sample from U.S.A. that workers with regular Monday-Friday work reported less work-home imbalance and less work-home conflicts compared to overall mean. The whole groups of workers without regular Monday-Friday work reported more work-home imbalance and conflicts compared to overall mean. The sub-groups working non-day and those in rotating shifts did not differ significantly from overall mean (Fenwick et al., 2001; Tausig et al., 2001).

In a sample of Brazil health care workers, Portela et al. (Portela et al., 2004) found that working nights more than four times per 2-weeks was related to complaints about insufficient time for children and rest/leisure.

In a Swedish study, Grönlund explored the effect of the combination of day and non-day work among spouses. She found that when men worked non-day and when both partners worked non-day, it was associated with more work-family conflicts for men, while this was not the case for women (Grönlund, 2004).

\section{Studies of the effect of different kinds of shift work}

Van Amelsvoort (van Amelsvoort et al., 2004) compared in a sample from The Netherlands the effect of forward (morning to evening shifts) and backward (evening to morning shifts) rotating shifts, and found that backward rotating shifts were prospectively related to more work-family conflict than forward rotating shifts.

In a study among male workers in a petrochemical company in Texas, Jaffe et al. (Jaffe et al., 1996) found less time for family and personal pursuits, lower sleep quality and worse physical well-being in the group of workers in 8-hours backward rotating shifts compared to both day workers and workers in 12 hours shift.

A study among 465 U.S. nurses found that afternoon shift workers compared to day, night and rotating shifts had the highest participation in solitary activities and the lowest in voluntary participation. Difficulty in family relations was not related to kind of shift work (day workers were not included) (Skipper, Jr., Jung, \& Coffey, 1990).

In a review of Smith et al. (Smith, Folkard, Tucker, \& Macdonald, 1998) the results pointed at better family relations associated with 12hours shifts than 8-hours shifts. The result is, however, not confirmed in all studies e.g. in a study from Iceland, where the employees pointed out that the family-work balance was more difficult when working 12-hours shifts than 8-hours shifts (Antonsdóttir et al., 2006). Further twelve hours shifts may have negative consequences in the form of increased sleepiness, accidents and less time for restitution (se chapter 6.3 and 6.4). 


\section{Consequences for children}

In three studies, shift work was associated with different kinds of adverse outcomes for the children.

Heymann \& Earle found in a study from the U.S.A. poorer cognitive stimulation in the home environment for children of parents having evening work; particularly evening work among the mothers had an adverse effect (Heymann \& Earle, 2001).

Strazdins et al. found in a Canadian sample higher odds for children having emotional or behavioural difficulties when one or both parents worked non-standard schedules (Strazdins, Korda, Lim, Broom, \& D’Souza, 2004).

Barton et al. (Barton, Aldridge, \& Smith, 1998) found in a sample from the U.K. that daughters of shift working fathers reported poorer perception of their own academic performance, greater discrepancies between perceived and ideal level of competence, more depressive symptoms and lower levels of self-esteem. No such effects were found for the sons of shift-working fathers. The authors suggest that this may be due to the nature of the variables studied, e.g. that externalizing behaviour, which is more common among boys, is not measured in the study.

Not only does shift-work influence family life. Family life also seems to influence the consequences of shift work. Thus it was found in a study from the U.S.A. among female nurses, that the average sleep duration per 24-hours was almost one hour less for nurses who combine shift work, partner and parent roles (Clissold, Smith, Accutt, \& Di Milia, 2002).

\section{Consequences for partners' psychological well-being and marital quality and stability}

A study from the U.K. found that partners of shift workers reported being unhappy with their spouse's shift work and that their lives were disrupted substantially by it. They further reported that shift work had a significant negative impact upon the lives of the partners (Smith \& Folkard, 1993).

Three studies found shift work related to lower marital quality and divorce.

Presser found in a study from the U.S.A. that marital instability was increased by night and rotating shifts for couples with children. For men married less than 5 years, working nights increased the likelihood more than six times compared to fixed day work. For women married more than 5 years, working nights increased the likelihood by three times. No effects of non-standard work schedules on marital stability were found for couples without children (Presser, 2000).

In the study of White and Keith from the U.S.A., shift-work was cross-sectional associated with lower marital happiness, higher sexual problems and child-related problems. Prospectively, respondents in marriages where one of the spouses started to work shifts showed increased 
disagreements. Respondents in couples where one of the spouses dropped shift work showed increase in interaction and decrease in child-related problems. Shift work increased the probability of divorce by 57\% (after adjustment for other factors)(White \& Keith, 1990).

Shields found in a study from Canada that evening shifts for married men were associated with the experience of problems with partner (lack of understanding, affection and commitment) and for single men with difficulties finding a partner. Rotating and irregular shifts were not associated with problems. No associations were found for women (Shields, 2002).

\section{Shift work as the choice}

Shift work is, however, not always involuntarily chosen. Some parents choose shift work as a strategy to obtain balance (Grönlund, 2004; Eiriksdóttir et al., 2006). According to a population based Canadian study, $65 \%$ of men and $53 \%$ of women who worked evening shifts did so, because they had no other choice, while $11 \%$ of the women and $3 \%$ of the men had chosen shift-work because it is easier to care for their family. However, more than $90 \%$ of those working in rotating shifts did so because they had no other choice, and very few did so because of family reasons (Shields, 2002).

In a qualitative study from the U.S.A., Hattery explored the costs and benefits of using non-overlapping shifts as a strategy for balancing and weaving work and family (Hattery, 2001). She found that the main reason given for choosing non-overlapping shifts was that it could save child care costs and that all child care could be provided by the parents. Of negative effects were mentioned: difficulties with scheduling, sleep deprivation, lack of marital couple time, and experiences of being "solo parent".

\section{In summary}

The results do very consistently support that work outside regular daytime has a negative influence on perceived work-life balance, children's well-being and performance and marital quality. A single prospective study suggests that shift work in fact predicts marital instability, and that the causation is not the other way around.

Some but few studies have explored which kind of non-standard working time arrangements is most favourable seen in relation to social activities. These studies suggested forward rotating schedules as preferable to backward rotating. Some studies also suggest that night and evening work is more detrimental to work-life balance than rotating shifts. A single study found that afternoon shifts were the most detrimental to voluntary social activities. 
There is a lack of studies comparing different kinds of shifts with regard to the effect on work- family balance.

\subsection{Consequences of non-standard working hours on stress and wellbeing}

It is generally agreed that shift work is a major work environmental stressor. In a lot of studies, shift work has been associated with different kinds of adverse health outcomes, impaired circadian rhythms and disturbed sleep (se chapter 6.3). Stress is suspected to be one of the linking mechanisms (Theorell et al., 2006).

Probably due to the more hard-core health outcomes used in the studiers of the health effects of shift work, there are not so many studies focusing on shift work and self-reported stress or well-being.

Shift work has been shown to be associated with other work stressors as low job control and low compatibility (job satisfaction) (Harada et al., 2005). Thus the effect of these stressors should be controlled in order to determine the effect of shift-work on stress and well-being.

With regard to the influence of irregular working hours on psychological well-being for the employee, seven out of 10 studies found decreased well-being associated with non-Monday-Friday daytime work schedules, two of these seven studies showed mixed results, and three out of the 10 studies could not support an association.

\section{Studies finding shift-work associated with decreased well-being}

In data from the Third European Survey on Working Conditions, Costa et al. (Costa et al., 2006) found in a very large European and gender mixed sample that variability of working hours (no fixed working times) was associated with stress, irritability and anxiety (it was, however, not among the three most important factors). Shift-work was associated with stomach ache and skin problems (as one of the three most important factors). Night work was associated with sleeping problems and heart disease.

In one of the very few longitudinal studies Shield found in a large, population-based sample from Canada of both sexes that evening shifts were associated with increases in psychological distress levels over two years. After control for diverse individual and work-related factors, men who worked in evening, rotating or irregular shift had increased odds of reporting having been diagnosed with a chronic condition over a fouryear period. In cross-sectional analyses, men who worked evening shift were more likely than those with regular daytime schedule to report low sense of mastery and to have relationship problems. For women, an irregular shift was related to high personal stress, and a rotating shift, to a low sense of mastery. The author speculates that the apparently greater 
ability for women to cope may be because they are more likely to work shifts to cope with care for family. Particularly evening shifts are more often a choice for women (Shields, 2002).

Marchand et al found in a very large gender-mixed sample from Canada non-standard working schedules (measures by a single item) associated with psychological distress (Marchand et al., 2005).

Ahlberg et al. (Ahlberg et al., 2003b; Ahlberg et al., 2003a) found in a gender mixed sample of workers from a Finnish Broadcasting Company (journalists, broadcasting, program production, technical support and administration) that those with irregular shifts were more often dissatisfied with their current work shift schedule than those in daytime work, and that irregular shift work was significantly associated with more frequent stress, but not with self-reported bruxism (frequency of tooth grinding). In multivariate analyses, frequent bruxism was significantly associated with dissatisfaction with current work shift schedule. They concluded that dissatisfaction with one's work shift schedule and not merely irregular shift work may aggravate stress and bruxism.

Janssen et al found in another large, gender mixed, Dutch sample, high variability of working hours associated with increased impairments in health and social well-being. Influence over working hours was consistently associated with less impairment, but did not compensate for the effect of variability (Janssen \& Nachreiner, 2004).

\section{Studies with mixed findings}

In a gender mixed study from the U.S.A., employees working on nonMonday to Friday shifts reported higher levels of burnout compared to general mean, while non-day workers and workers on rotating shifts did not report increased levels of psychological distress. Workers with regular Monday to Friday work reported lower levels of dissatisfaction, but more minor physical problems compared to general mean (Fenwick et al., 2001).

A study among 465 U.S. nurses found that rotating shift workers reported highest level of self-reported stress and lowest level of jobperformance compared to day, night and afternoon shifts. Shift work was not found to be significantly related to either the nurses' physical health or mental depression (Skipper, Jr. et al., 1990).

\section{Studies not finding shift-work associated with decreased well-being}

Matthews and Power did not find any association between unsocial working hours and psychological distress in a study of 33 years old British women (Matthews \& Power, 2002). 
Åkerstedt et al. also missed to find any association between shift work and mental fatigue in an gender mixed, Swedish sample (Åkerstedt et al., 2004).

In a study among Brazil health care workers, Portela et al. (Portela et al., 2004) found that mild emotional disorders were less frequent among night and ex-night workers than among day workers who never had worked in night job. The possible role of exposure by day workers to some risk factors such as work-related stress, was suggested as an explanation for the surprising results.

\section{Studies of the effect of different kinds of shift arrangements}

A Dutch study was performed among male three-shift workers. A backward rotating shift was compared with a forward rotating shift prospectively related to an increased need for recovery (RR 2.88), poor general health (RR 3.21) and poor sleep quality (RR > 7.32) (van Amelsvoort et al., 2004).

The study by Skipper et al found that rotating shift workers reported highest level of self-reported stress and lowest level of job-performance compared to day, night and afternoon shift workers (Skipper, Jr. et al., 1990).

Kandolin found in a study among Finnish nurses that female nurses in three-shift work reported more stress symptoms and had ceased to enjoy their work more often than women in two shifts (without nights). For male nurses, no differences were found (Kandolin, 1993).

A special case of non-standard hours is work, where the employees are requested to be on-call. This is not unusual in professions like medicine, engineering, midwifery, and junior pilots. To be on-call is connected with interruptions of sleep or social and family life and with unpredictability. A review over 16 studies about the health consequences of being on-call was conducted by Nicol and Botterill (Nicol \& Botterill, 2004). They found support for increased stress, disturbed sleep, depression and anxiety. Only a single study explored the consequences for social and family life, and found it disturbed by the on-call duty. The authors conclude that on-call work has received significantly less research attention than other work patterns such as shift work and overtime, and that there are critical gaps in the literature; lack of studies of a lot of possible health consequences, accidents, social life and gender aspects.

Predictability of the working hours schedule is a topic of obvious importance for work-life balance and not only for 'on-call' workers. It is, however, an issue barely touched upon within the work-life balance research. An "unpredictable schedule" sounds like a paradox, but many employees have to change their working hours on short notice because of different circumstances at work. An estimate form the Fourth European Working Condition Survey says that about one fourth (26\%) of those who 
have their working hours arrangements set by the organisation (63\%) are informed less than a week in advance about changes in their work schedule. About $40 \%$ of those with very short notice about changes in their work schedule (the same day or the day before the changes occur) say their working hours do not fit well or do not fit at all with their family or social commitments. Between $17-26 \%$ of those who do not experience these kind of changes or are informed several weeks in advance, experience a poor fit of working hours with family and social life.

\subsection{Summary - non-standard working hours, work-life balance and stress and wellbeing}

There was strong evidence that different kinds of non-standard working hours had a negative influence on work-life balance, wellbeing of children and marital quality.

In summary, it is strongly supported that shift work and other nonstandard working time arrangements are associated with worse work-life balance than regular day-time work. This seems to be the case for both men and women, or at least in gender mixed samples. One study supported that forward rotating shifts gave better work-life balance than backward rotating shifts, one study suggested that evening and night work is more detrimental to work-family balance than rotating shifts, and a review study suggested that 12-hours shifts were superior to 8-hour shifts, with regard to family consequences. In addition to this, there was some support from American, Canadian and a single British study that irregular working time arrangements among parents are associated with child-related problems and with lower marital happiness and stability.

There were more contradictory results regarding the effect of nonstandard work hours on psychological well-being and stress. Six out of ten studies supported an association.

One study found variability of working hours (not necessarily shift work) associated with impairment in health and social well-being. And although influence on working hours was associated with less impairment, results suggested that this could not compensate the negative effect of variability.

\section{Methodological considerations and future perspectives}

The mixed results with regard to effects on stress and well-being of shiftwork may, at least in part, be due to some of the many methodological problems associated with studies of shift work (for discussion of this, see Knutsson, 2004). Among these problems is the serious question of selection into and out of shift work. People with difficulties in accommodating to shift work will rarely stay very long in such jobs. 
Another serious methodological problem is the clustering effect. Shiftwrk is associated with other work environmental factors also associated with poor health and well-being. These effects are, even with complicated statistical methods, almost impossible to disentangle from each other.

There is particularly a need for more well-designed and wellconducted studies of the consequences of non-standard hours for children's development, performance and well-being and for marital quality.

Studies comparing the effects of different kinds of non-standard work arrangements are also needed.

More studies with "hard-core" outcomes as divorce, delinquencies, number of friends, social network, participation and memberships of voluntary organisations have been requested (Colligan et al., 1990).

Also more longitudinal studies may add valuable knowledge. In the field of social consequences of working hour arrangement, there are, however, no reason to believe that many of the effects will show up long time after exposure. Almost immediate reactions on perceived work-life balance and well-being can be anticipated. Longitudinal studies, particularly of changes into and out of e.g. shift work may anyway be valuable to enlighten the direction of causality where possible (e.g. in relation to marital quality and children's performance and development). 


\section{Influence over working hours}

Influence over working hours can also be named employee work time control or employee or individual flexibility. It can be defined as the employee's possibilities to control the duration, position, and distribution of his/her work time, i.e. autonomy with regard to work time (Härmä, 2006).

Influence over working hours does only in few cases imply total influence over number of hours and when to place the hours. In most cases, it means that the employee has some degree of influence on when to place the hours.

When the concept of 'flexibility' is used here, it is in the meaning of employee control or influence over working hours. 'Flexibility' can also be used in the meaning of company-based flexibility, referring to the needs of employers to extend, modify, or reduce work hours according to client or production needs (Härmä, 2006). If this is indented, the term 'company-flexibility' is used. Aspects of company -flexibility are discussed in chapter 4 under the term "variability".

\subsection{Consequences of influence over working hours on work-life balance}

In 13 out of 17 studies different measures of employee control and flexibility over work schedule were associated with better work-life balance. Two studies showed mixed findings and four studies could not support any association.

\section{Studies supporting a positive association}

As part of the SALTSA project, Costa et al conducted a study on a very large sample of 21505 European workers from the Third European Survey of Working Conditions (2000). They distinguished variability and flexibility. They measured variability by asking whether respondents worked the same number of hours each day and each week and whether they had the same start and finishing point. Flexibility was measured by the responses as to whether respondents could take breaks when whished, holidays when wished and whether they could influence working hours. They found that flexibility was positively and variability negatively associated with family and social commitment (Costa et al., 2003; Costa et al., 2006).

In a sample of 6451 IBM employees from the U.S.A., Hill et al found a strong positive association between perceived flexibility and work- 
family balance. Both flex-time and flex-place (possibility to work from different places) added positively to better work-family balance.

Among those working between $40-50$ hours per week, $28 \%$ of those with both flex-time and flex-place experienced difficulties with workfamily balance, compared with $46 \%$ of those with neither flex-time nor flex-place (Hill et al., 2001).

Kandolin et al. explored company controlled and individual flexibility in a sample of 1790 Finnish employees. They found that employees with individually flexible working hours experienced less feelings of neglecting of home matters compared to those without individual flexibility (Kandolin et al., 2001).

Major et al explored in a sample of 513 employees in a Fortune 500 Company in the U.S.A. the effects of schedule flexibility on workinterference with family. They found that schedule flexibility, measured as the ability to take time off from work during prime working hours (8 AM-5 PM) was negatively related to work-interference with family. They further examined whether schedule flexibility could moderate the negative effect of long working hours on work interference with the family, but this could not be supported (Major et al., 2002).

Some studies have focused particularly on influence among employees working in shifts.

Folkard studied 2093 British aircraft maintenance engineers, predominantly male shift workers. He found that days of notice of schedule, degree of control over specific shifts and degree of control over specific start and finishing time were all associated with experience of lower interference of schedule with leisure time (Folkard, 2003).

In two studies among shift workers from Iceland (only available in Icelandic), it was shown that the employee's possibility to have some influence over their own work-schedule improved the work-life balance (Antonsdóttir et al., 2006; Eiriksdóttir et al., 2006).

Some studies have not only explored the effect of influence on own schedule, but in addition looked at the effect of other family friendly policies at work.

In a sample of 398 employed men and women from 23 large organizations in New Zeeland, Brough et al examined the relationship between use of organizational "family friendly" resources and work-family conflict and job and family satisfaction. Family friendly resources were measured by questions about workplace crèche facility, flexible working hours, family-friendly policies, job sharing, assistance with child care/eldercare, a family insurance/savings plan, and general support to meet family needs. They found that the use of family friendly resources in the organization predicted both family satisfaction and job satisfaction three months later. To the surprise of the researchers, the utilization of family friendly policies was also cross-sectional associated with higher levels of family-work interference. An obvious explanation may be that 
those families experiencing the highest demands from family life are also those who make most use of the family friendly possibilities. It is also most important for those families to seek a job with these opportunities (Brough et al., 2005).

In a sample of 398, primarily female health professionals from the U.S.A., Thomas and Ganster examined the effect of family-supportive organisational policies and practices. They found that flexible scheduling, assessed as the possibility to change work schedule on a daily, weekly or biweekly basis, had directly positive effects on employee's perceptions of control over work and family matters, which was in turn associated with lower levels of work-family conflict, job dissatisfaction, depression, somatic complaint and cholesterol. Flexible scheduling had in addition also a direct positive effect on somatic complaints. Supervisor support showed similar associations, while dependent care services and information referral services did not (Thomas \& Ganster, 1995).

Voydanoff evaluated in a large US sample the effect of so-called 'boundary-spanning' resources at work: parental leave, possibility for time off for family, supportive work-family culture and supervisor workfamily support. She found that all these kinds of boundary spanning resources were negatively associated with work-family conflict and positively associated with work-to family facilitation (Voydanoff, 2004).

Some few studies have explored the spill over effects among spouses and flexibility in working hours.

In a sample of 96 dual earner couples from Canada, Galambos and Walters explored the role of working hours and schedule inflexibility for both partners. They found that wives' schedule inflexibility was positively correlated with both wives' and husbands' feelings of role strain. Husbands' schedule inflexibility was associated with their own role strain but was unrelated to the well-being of the wives (Galambos et al., 1992).

\section{Studies with mixed findings}

In a sample of 3402 full time employed men from The Netherlands, Jansen et al found that flexible work hours, familiarity with roster and ability to take a day off was associated cross-sectional with less workhome interference. Among the 494 full-time working women, the associations could not be confirmed. In a 8 month follow-up period in a gender mixed sample of 3422 full-time employed, familiarity with roster and ability to take a day off predicted less work-home interference, while flexible work hours did not (Jansen et al., 2004).

Tausig and Fenwick examined whether alternate work schedules affected perceived work-life imbalance in a sample of 2958 US employees taken from a representative sample of 3381 employees. They found that work-life balance was not associated with a measure of 'availability of flexible schedule options', while a measure of 'perceived schedule control' was positively associated with work-life balance. They argue that the 
lack of association between availability of flexible schedule options and work-life balance may be because some people who have availability of flexible schedule options do not use it and others with inflexible, but regular Monday - Friday daytime schedules may achieve balance through the regularity of these schedules, even though they are not flexible. They further argue that there might exist a reversed causation between perceived schedule control and perceived work-family balance, so by balancing family demands one perceives greater control over own schedule (Tausig et al., 2001).

\section{Studies not supporting an association}

One of the studies with no effect was a prospective study conducted in a large, Dutch sample (Jansen et al., 2003). They did not find flexible work hours predictive of work family conflict over one year, while many other work characteristics were predictive. The authors argue that "flexible working hours do not provide a solution for employees with structural time conflicts between work and family, because the actual hours that need to be spend at work still remain similar."

Another study from the U.S.A., conducted in a sample of professional and managerial employees in dual earner couples did not find any association between access to flexible schedule policy and work-family conflict (Batt et al., 2003). They found, however, that supervisor supportiveness was associated with lower levels of work-family conflict and turnover intentions among women and that flexible policy was associated with lower level of turn-over intentions among men.

A third study from the U.S.A. in a sample of 179 employees also missed to find an association between temporal flexibility (flexibility to set one's own working hours) and family functioning and home satisfaction (Clark, 2001), while operational flexibility (flexibility to alter one's work) was associated with increased work satisfaction and increased family well-being in the same study.

In a Swedish study, Grönlund (Grönlund, 2004) found that employee flexible work hours was not associated with less work family conflict, while it was associated with less social life and less hobby conflicts. In the same study, a moderate degree of flexibility was associated with less work-family conflicts than total flexibility. However, when control was made for social class and company flexibility, the association disappeared, meaning that higher work family conflict for those with total flexibility could be explained by higher social class and more company flexibility.

\section{Summary}

In summary, although a majority of studies support a positive effect of flexible schedule options on work-life balance, the picture is not totally clear. All the four studies that did not support an association were ad- 
justed for a range of work environmental factors that might interact with the role of flexibility; particularly job autonomy or decision latitude and supervisor supportiveness. Only few of the studies with positive effects had adjusted for these factors, while the rest did not have adequate adjustment of these factors. It may, in other words be difficult to disentangle the effect of schedule flexibility from the effect of general job autonomy and decision latitude.

In one study, a moderate degree of employee flexibility was positively associated with less conflict, while more flexibility had a negative effect. This was due to more company flexibility and higher social class associated with more flexibility.

There was no evidence that influence over working hours can compensate for or moderate the negative effect of long working hours on work-life balance.

\subsection{Consequences of influence over working hours on stress and wellbeing}

In 9 out of 10 studies, different kind of employee control and flexibility over work schedule were associated with better psychological wellbeing. In a single study, no association was found, and in another study associations were found among women but not among men. Studies were conducted in gender mixed samples from the EU, the U.S.A., Finland, Germany and Sweden, in a gender stratified sample from Finland, in a female sample from the U.S.A. and in couples in a Canadian study.

In the large sample used in the SALTSA project (see description above or in table), Costa et al found that flexibility was positively associated with work satisfaction, ability to do same job when 60, and negatively to trauma, overall fatigue, irritability, and headache. Variability was negatively associated with family and social commitments, stress, hearth disease, anxiety, stomach-ache, irritability, sleep problems (Costa et al., 2006).

In a prospective study among 4218 full-time and permanently fulltime Finnish employees Ala-Mursula et al found low level of work time control prospectively related to higher odds for psychological distress, poor self-rated health and medically certified sickness absence among women. The health effects were most evident among women with families. Among men, low level of work time control predicted sickness absences among those with dependent children and those with manual occupations. It was not associated with self-rated health or distress. The analyses are controlled for occupation but not for other work environmental factors (Ala-Mursula et al., 2006).

Kandolin et al. found in their sample of 1790 Finnish employees that employees with individually flexible working hours experienced less 
feelings of stress compared to those without individual flexibility (Kandolin et al., 2001).

Janssen and Nachreiner examined in a German sample of 660 employees, impairments in health and social life under different kinds of flexible working hours. They found increased impairments in health and social well-being associated with high variability and a lack of influence over one's working hours. Influence over working hours were consistently associated with less impairment, but did not compensate for the negative effect of variability (Janssen et al., 2004).

Folkard studied 2093 British aircraft maintenance engineers, predominantly male shift workers. He found that self-reported health was better and perceived risk lower the more control over shifts and over starting and finishing times. Notice of schedule did not have impact on these outcomes (Folkard, 2003).

In a sample of 398, primarily female health professionals from the U.S.A., Thomas and Ganster examined the effect of family supportive organisational policies and practices. In addition to the findings mentioned above, they found that flexible scheduling also had a direct positive effect on somatic complaints. Supervisor support showed similar associations, while dependent care services and information referral services did not (Thomas et al., 1995).

Kecklund studied a sample of 480 Swedish employees in a trade union. Most of them worked "trust" hours, meaning that there was no formal regulation of the working hours. Employees with trust hours were more satisfied with working time and reported advantages for social life.

Influence over work hours was negatively associated with measures of burnout, pain and sleep.

Influence over work hours did, however, not explain as much of the variance as dissatisfaction with work, high demands and low rewards (Kecklund et al., 2002).

In the study by Tausig and Fenwick (see description above or table Appendix A), workers with high schedule control reported less burnout, distress and dissatisfaction, better general health and less minor physical health problems. There was no evidence that schedule control mediated any of these associations (Tausig et al., 2001)

A single study has explored the spill over effects among spouses of flexibility in working hours.

In a sample of 96 dual earner couples from Canada, Galambos and Walters explored the role of working hours and schedule inflexibility for both partners. They found that wives' schedule inflexibility was associated with increased anxiety among their husbands, while husbands' schedule inflexibility was unrelated to the wellbeing of their wives (Galambos et al., 1992).

In a study from the U.S.A. including 161 women and 126 men with full-time employed spouses and 142 men with non-employed spouses, 
Hughes and Galinsky (Hughes et al., 1994) found no association between control over working hours and psychological symptoms.

\subsection{Summary - influence over working hours, work-life balance, stress} and well-being

Employee control over work schedule was rather consistently associated with better work-life balance and improved psychological well-being. Many different kinds of influence have been explored with a positive result.

The picture was, however, not totally clear. Some large studies with adequate control, did not find any associations and other studies that found associations did not make adequate control for other work environment factors. Without adequate control, it may be impossible to disentangle the effect of schedule control from the effect from general autonomy and supervisor support at work.

There was no support for the assumption that influence over working hours could compensate for the adverse effects of long, irregular and variable working hours.

As the results from Grönlund suggest, it may be that a moderate degree of employee flexibility decreases the work-family conflict level compared to no flexibility, and particularly in jobs with high demands. Total flexibility is associated with high demands and high company flexibility. Even though such flexibility is positive for the employee, it can not compensate for the negative effects of high demands and company flexibility. Therefore it may be that it is rather the lack of flexibility in situations with very high demands (from job and/or from family), that is a problem (Grönlund, 2004). In groups with very low influence over working hours, and particularly in groups with high demands, more influence may be needed in order to balance work and family demands. In groups that already have some influence over working schedule, it may be doubtful, whether more control can solve the problems of balancing work and family life.

If the demands are high, it may be difficult to fulfil them all regardless of how much influence you have on when to do the work. 



\section{Results concerning health consequences of long and irregular working hours}

The focus of this report is on social consequences of long and irregular working hours. Physical health consequences are not reviewed systematically but only included when they were linked to social consequences. Health consequences have been dealt with in a lot of previous reviews and some of the results from these are briefly summarized below. Not all of the reviews presented below are, however, systematic and few encompass a quality assessment of the included studies.

\subsection{Long hours and overwork}

In a review over long work hours and health, van der Hulst (van der Hulst, 2003) describes two different pathways in the relationship between long work hours and adverse health: insufficient recovery and poor lifestyle. She found that the most consistent pathway from long work hours to health was related to an adverse association between long work hours and sleep. This assumption is supported in a recent review by Geurts and Sonnentag (Geurts \& Sonnentag, 2006) in which they conclude that a chronic situation of sustained physiological activation and incomplete recovery is an important pathway to chronic health impairment.

Long and very long working hours are more common in the U.S.A. and Japan than in the rest of the Western world, except from Iceland maybe. The research on working hours in these countries have focus on the negative health effects effect of long working hours, often described as working 45 or more hours pr week.

A review report from STAMI concludes that overwork (work in excess of the official weekly hours) was associated with reduced sleep quality, different health problems, psychological health and accidents and injuries (Veierstedt \& Boix, 2004).

The National Institute of Safety and Health in the U.S.A. has made a review of 52 studies (mainly from Asia, Europe and the U.S.A.) that examine the associations between long working hours and extended shifts and illnesses, injuries, health behaviours and performance (Caruso, Hitckhock, Dick, Russo, \& Schmit, 2004).

They found that overtime (without specification) was associated with poorer self-perceived general health, increased injury rates, more illness 
and increased mortality. Findings for hypertension were inconsistent across four studies. Furthermore, overtime work was in some studies associated with unhealthy weight gain, increased alcohol use and increased smoking. Four studies on extended shifts between 9 and 12 hours had found associations with feelings of decreased alertness, increased fatigue, lower cognitive function, and decline in vigilance on task measures and increased injuries. Six studies examined 12-hours shifts combined with long working hours (more than 40 hours per week). They reported increases in health complaints, deterioration in performance and slower work pace.

Based on a review of 27 recent empirical studies, van der Hulst concluded that long work hours are associated with adverse health outcomes such as: cardiovascular disease, diabetes, disability retirement, subjectively reported physical health and subjective fatigue. In addition she mentioned evidence for an association with physiological changes as cardiovascular and immunologic parameters. The results also supported a negative association between long work hours and sleep. Mixed evidence was found with regard to alcohol consumption, smoking and Body mass index, while no association was supported with regard to use of psychotropic drugs, eating habits and exercise (van der Hulst, 2003).

Kodz has made a review of the findings of research in the area. She found that up to 40 hours a week there are more positive than negative health consequences of work. For working hours more than 41 per week, higher blood pressure correlated with higher number of hours. Very long working hours (above 10 hours per day) were also correlated with indirect health problems; for example higher alcohol consumption, smoking and overweight. She concluded that long working hours (more than 48 hours per week) increase the risk of poor health, particularly among workers with low work motivation and among women with double work shifts (Brynja \& Bildt, 2005).

Mozurkewich et al. found no association between long working hours and adverse pregnancy outcome in a meta-analysis of 10 studies (Mozurkewich, Luke, Avni, \& Wolf, 2000).

In summary, there seems to be evidence that long hours ( $>45 \mathrm{hr} /$ week) are a risk factor for poor health.

\subsection{Reduced hours}

Particularly in the Nordic countries, and mainly in Sweden, there has been an interest in the possible positive health consequences of reduced hours (see chapter 7.1.). Reduced hours are hours below the traditional 40 hours pr week, often at the level of 35 hours or fewer.

Brynja and Bildt from the National Institute for Working Life in Sweden have reviewed 10 published public reports and about 65 other studies 
about health consequences of reduced working hours (Brynja et al., 2005). Based on the present working time interventions, their overall conclusion is that there is no evidence that medical health will improve due to reduced working time. They claim that this may partly be because health in fact did not change due to interventions and partly because of too short follow-up periods. They also conclude that very few studies have explored social or psychological consequences of reduced hours (see chapter 9.2. for a description of an ongoing intervention project on reduced hours).

The conclusion of Brynja and Bildt is in accordance with Åkerstedt (Åkerstedt, 2001), who also, based on a literature review, conclude that there is no scientific evidence that reduced work hours should have any positive effect on health. However, there is clear support for positive social effects which was also supported by the intervention project described in chapter 7.1.. They further conclude that there are large methodological problems with the existing research.

\subsection{Shift work}

Whether shift work is an independent risk factor for health has often been discussed (Härmä, 2006; Bøggild \& Knutsson, 1999). Shift work is associated with social class and it is very difficult to disentangle the effect of shift work from other factors in the work environment and lifestyle associated with shift work (Bøggild, Burr, Tuchsen, \& Jeppesen, 2001). The most probable pathways from shift work to health are 1) changes in lifestyle 2) a mismatch between circadian rhythms, and 3) shift workers' stress due to disturbed social life (Härmä, 2006).

Even though shift work is associated with social class and unhealthy lifestyle, and adequate control not always is performed, Härmä concludes that there is evidence that shift work is an independent risk factor for coronary heart disease, and that there seems to be a joint and multiplicative effect of shift work and adverse lifestyle factors on coronary heart disease (Härmä, 2006). This is also the conclusion in a recent review from the European Heart Network (Theorell et al., 2006), where they also mention that a change from counter clockwise (backward rotating) to clockwise (forward rotating) shifts has been proved (Orth-Gomer, 1983) to decrease the risk of coronary heart disease (Bøggild et al., 1999).

Härmä summarizes that "the evidence suggests that short or disturbed sleep could be a common pathway connecting night work, shift work, extended work hours, and work stress to cardiovascular illness.” (Härmä, 2006).

The most common health-related effect of shift work is disturbed sleep. Åkerstedt has described and discussed the mechanism of sleep 
disturbance in relation to circadian rhythms and the specific impact of aspects on organization of shift work (Åkerstedt, 2003).

In a review of health disorders among shift workers, Knutsson (Knutsson, 2003) concludes that the strongest evidence exists for associations between shift work and peptic ulcer disease, coronary heart disease and compromised pregnancy outcome in terms of miscarriage, low birth weight and preterm birth. There is no evidence with regard to all-cause mortality. With regard to cancer there is no conclusive evidence, but studies pointing at increased risk, particularly for breast cancer. Shift work may also have an impact on diabetes and metabolic variables, but the evidence on this is, according to Knutsson, not conclusive.

Mozurkewich et al. found in a meta-analysis of 6 studies increased risk for adverse pregnancy outcome among shift workers (Mozurkewich et al., 2000).

In the review from STAMI, shift work was found associated with sleep disturbances, digestive problems, increased risk for injury, cardiovascular illness and death and changes in physiological and metabolic measures. They reported mixed evidence for an association with Body Mass Index and mixed evidence with regard to diabetes. Single studies supported associations with electrocardiograph changes, increased Hart Rate Variability and hypertension (Veierstedt et al., 2004).

In a meta-review of 26 reviews from 1994, Harrington summarized the knowledge about shift work and health consequences (Harrington, 1994). He mentioned the disruption of the circadian rhythms as one of the most important physiological problems associated with shift work. Of more specific health issues, he also points to reduced sleep quality as the most common issue. Fatigue is a related and also very common complaint. He also claimed that there is evidence that shift work does increase workers stress ratings and risk for coronary heart disease. The evidence for an association with gastrointestinal disorders is, according to Harrington, not very well documented. Further, he mentioned reduced reaction time at night as well documented, and poorer performance and safety records also associated with night shifts.

Beside the adverse health outcomes, Åkerstedt et al have examined shift work as a predictor of mortality (Åkerstedt, Kecklund, \& Johansson, 2004). In a Swedish sample of 22411 individuals, they found significantly increased risk of mortality for female white-collar shift workers compared to female white-colour day workers. No differences were found among blue-collar workers and among men. These results have not yet been verified in other studies. 


\subsection{Compressed work weeks}

In a resent review (Tucker, 2006), Tucker summarized the current knowledge with regard to health and productivity consequences of different kinds of compressed work weeks. He concluded that there is relatively little evidence to suggest that compressed work weeks negatively affect long-term health, and evidence shows that health outcomes are improved. With regard to sleep he concludes that "the evidence suggests that a welldesigned compressed work week should not lead to chronic sleep deprivation so long as the job is not too demanding." He further stated that there is evidence of heightened levels of fatigue toward the end of 12-hour shifts and after quick returns, and that there is little consistent evidence that compressed work weeks harm job performance and productivity in industrial settings, but that it may impair job performance in some settings, e.g. among nurses. There is little evidence of a link between Compressed Work Weeks and increased accident risk, but extended shifts and quick returns may be associated with increased risk in some situations.

In another review from 1998, Smith et al. (Smith et al., 1998) compared 8-hour and 12-hour shift systems. They concluded that the bulk of the evidence suggests few differences between 8 and 12-hour shifts in the way they affect people, but there may be advantages to 12-hour shifts in terms of lower stress levels, better physical and psychological wellbeing, improved durations and quality of off duty sleep as well as improvements in family relations. On the negative side, the main concerns are fatigue and safety. The authors conclude, however, that 12-hour shifts not automatically induce a significant decrement in safety.

A more resent review has found increased risk of accidents, injuries and acute sleepiness with shift length over 8 hours (Folkard, Lombardi, \& Tucker, 2005).

It is important that the length of shifts allow for enough restitution time particularly in combination with night shifts. 



\section{Examples of interventions in working time arrangements}

Studies reviewed in the previous chapters have explored the adverse effects of long and irregular hours on work-life balance and on measures of general well-being. They have also stressed the importance of employee influence on working hours. In conjunction with the serious health consequences associated with shift work and long hours (see chapter 6), it would be important to know how work hours could be modified or redesigned in order to decrease the adverse effects on health and social life. Unfortunately, there is only few controlled intervention studies in the area (Härmä, 2006).

In this chapter, some examples are given of intervention studies in the area of working time arrangements. Some of them are conducted with control groups and before and after measures, but because controlled intervention studies are sparse, other kinds of evaluation studies, not reported in peer-reviewed journals are also included.

\subsection{Reduced hours}

Although many studies have focused on the effect of long hours and of part-time work on work-life balance and well-being, only few studies have explored the effect of reduced hours with full compensation. While part-time work has some built-in negative side-effects (se chapter 3.1), the same may not be the case if full time employees are compensated for changing to reduced hours. Sweden is one of the few countries, which has implemented trials with reduced hours and full compensation.

An intervention study by Olsson et al. explored the effect of a reduction of hours from 8 to 6 hours per day with full wage compensation. Sixty-four employees within the child and health care sector participated in the intervention and 30 in a control group. After the intervention, employees in the experimental group had significantly improved their attitudes toward working hours and their experience of sufficient time for social activities, particularly time for friends and relaxation. The group with small children benefited most from the intervention. Health was not significantly affected (Olsson, Åkerstedt, Ingre, Holmgren, \& Kecklund, 1999).

Åkerstedt et al. (Åkerstedt, Olsson, Ingre, Holmgren, \& Kecklund, 2001) described the results from an intervention with working hour's reduction in a group of 35 women and 6 men employed in child and eld- 
erly care in Sweden. They had a 9 hours' reduction of working hrs/week to 6 hours per day, and with full compensation. The comparison group consisted of 18 women and 4 men in similar jobs. After a follow-up period of one year, the results showed improvements in the experimental group with regard to: time for social activity, time for friends and family, attitude to work hours, fatigue, sleep and heart/respiratory complaints. The control group did not change.

An on-going large experiment in Sweden further explores the effects of reduced working hours on health and gender equality (se description chapter 9.2).

France started in 1998 a large scale experiment with reduced hours (Costa et al., 2003; Prunier-Poulmarie \& Gatbois, 2001). With effect from January 2000, the working week should be fixed at 35 hours in all companies with minimum 20 employees, and from January 2002 in companies with maximum than 20 employees. The implementation of the law was, however, not without problems, and in 2002, the law was amended again, making it possible for companies who had not yet changed to continue with 39 hours/week. According to Gatbois the result is; 8.5 million employees from large and middle-sized companies and 4.5 million officials are working 35 hours per week. However, 7 million employees from small companies are still working 39 hours/week. The effect of the change in working hours was measured by a survey at the end of 2000, covering 1618 full-time wage earners on reduced hours for minimum in one year and employed at the same company before the change in working hours. The global judgement of the change in working hours was positive. 59\% thought that the reduction of hours had produced an improvement in daily life as a whole, while $13 \%$ found it was impaired and $28 \%$ experienced no overall change. The percentage saying that they got an improvement was higher with higher social level, and the trend was stronger among women than among men. About half of the parents reported that they spend more time with there children, and almost half of the sample spend more time on domestic activities. At the same time, $64 \%$ reported more stress at work and 69\% reported that tasks were performed less carefully at work.

Also other researchers have argued that reduced working hours, e.g. as implemented in France, may lead to intensification of work, hours flexibilization and no clear improvement of well-being at work (Askenazy, 2004).

\subsection{Compressed work weeks}

In order to deal with some of the problems associated with shift and night work, there have been a lot of experiments with different kinds of compressed work weeks within the latest decades. Compressed work weeks have been popular not only because it may result in improved productiv- 
ity for the company but also because it may result in more consecutive days off between shift circles for workers.

Particularly in Sweden, there have been experiments with the so called $3+3$ model, but only few systematic evaluations have been made.

In 2002, a trial with the 3+3 model was started within two health care wards in Linköping in Sweden (Andersson \& Jonsson, 2005). The work scheme was changed to 3 days of work followed by 3 days off in a rolling scheme. The following reduction of hours was compensated in different ways: by slightly longer working days ( 8,5 hrs/day), by 15-20 extra days $\mathrm{pr} /$ year which the employer could dispose of and by trust-hours that could be disposed over by the employee could dispose of an use for competence development, health promotion or other individual purposes. The trial was evaluated with both questionnaires and interviews and through the use of statistics over sickness absence. The evaluation showed positive effects on recovery, self-reported health, and balance between work and private life. Sickness absence decreased in the period, and job satisfaction and experience of possibilities for development increased. The most negative effect reported was more work on holidays.

A very radical experiment with compressed working weeks took place within the child-care sector in Norway. Both private and public full-time child-care institutions applied for dispensation to try a roster with very long working spells followed by long spells off: 4 days and nights of continuous work followed by 7 days off, and after that 3 days and nights of work followed by 7 days off (Enehaug, Sørensen, \& Helte, 2006). The results from the evaluation showed that the main part of the employees (80-90\%) experienced positive changes in family life, leisure time, health, work environment and work tasks due to the new roster. Particularly the effect on work environment and work tasks were rated high. There were no signs of improved self-rated health among the smaller group of employees who responded both to the baseline and to the follow-up questionnaire. The authors conclude that longer follow-up time is needed to be sure if the effects of the schedule on sleep quality and health are consistent over time.

In another Swedish study, the effects of an introduction of double shifts were evaluated (Ekstedt, Kecklund, Dahlgren, \& Åkerstedt, 2001). Due to very long commuting times associated with large construction work, there is a high request for compressed working weeks in many of these projects. An experiment was implemented in a group of 83 construction workers on the construction of a road tunnel system. A shift cycle was introduced with an 8-hour shift followed by two double shifts of 15.5 hours each and 8.5 hours off between the double shifts. After this a free weekend followed by two double shifts and then a week off. The intervention was very thoroughly evaluated with different kinds of measures. The results revealed a very positive attitude toward the long shift among the workers, and no large changes on measures of stress or self- 
reported health. The sleep length was shortened between shifts, and there was an increase in sleepiness and mental fatigue across double shifts. The authors argue that several contextual factors have to be taken into account when explaining the relatively good tolerance towards the schedule.

\subsection{Other changes in shift systems}

As it appeared from the previously mentioned review (Colligan et al., 1990) (se chapter 4), the direction and speed of rotation in shift systems have in many studies been related not only to health but also to social life and well-being. In spite of few outstanding early intervention studies, interventions with systematic evaluation of the effect of changes from one kind of system to another are still relatively sparse.

In a pioneering work as early as in 1983, Kristina Orth-Gomér evaluated the physiological, behavioural and subjective effects of a change from a counter-clockwise to a clockwise rotation schedule in a sample of 45 Swedish policemen. She found significant improvements on a range of physiological measures related to coronary heart disease, on sleep length and quality and on satisfaction with leisure time between shifts and selfreported health. The satisfaction with schedule rotation was, however, not significantly higher in the clockwise rotating group. The author suggests that this may be due to shortened weekends in this group as a result of the prolonged rest periods between shifts (Orth-Gomer, 1983).

A recent Finnish study explored the effect of a very rapidly rotating shift system on sleep, health and well-being (Härmä et al., 2006). An airline company, changed in the Line Maintenance Unit from a backward rotating three-shift system and to a rapidly changing forward rotating system, with morning, evening and night shifts followed by 72 hours off duty. A very thoroughly evaluation was conducted with an intervention group with 273 employees and a control group with 116. Both questionnaires and different kinds of field studies were used. Result showed significant positive changes in the intervention group in favour of the new shift system with regard to: sleep, alertness, and general health, wellbeing at work, social and family life. The improvements on general health were greater for the younger age groups, while the improvements on the rest of the measures were greater for the older age groups.

A German study explored the effect of changes in shift rotas and shortening of working time in 5 different experimental groups, covering 260 employees in the chemical industry (Hornberger \& Knauth, 1995). They changed to three different kinds of shift systems, all characterised by faster shifts, shorter blocks of working days, only 2-4 consecutive night shifts and free evenings in almost every week. By using pre and post measures (no control group), they identified improvements in three out of the five experimental groups: in subjective health and well-being in 
two groups and deterioration in one, reduction in social disturbances in two groups and mixed results regarding leisure time.

A study from Australia evaluated the impact of a change from slowly to rapidly rotating shifts among 72 shift workers at three sewage treatments plants (Smith, Wright, Mackey, Milsop, \& Yates, 1998). They used a participatory approach in the intervention, implying that the employees' were actively involved in choosing the kind of shift system they changed to. Before the intervention, all groups had a slowly rotating 8-hour shift. Two groups chose to change to a rapidly rotating 12 -hour shift roster, while one group first changed to a 8-hour shift roster and after 6 months to at 12-hour shift roster, because the experiences from the other groups were more positive. Workers at all plants reported improvements in quality of home, social and work-life, increased satisfaction with roster design, improved day sleep quality, less tiredness and decrease in physical and psychological circadian malaise. The two groups choosing the 12 hours shift in the first time, reported most improvement. Analyses showed that the effects were associated with how much the employees had supported the particular kind of roster before the implementation, indicating the importance of employee participation in the development and implementation process.

The importance of employee participation in the process of development of shift design is also stressed by Philip Tucker in his review about compressed work weeks (Tucker, 2006) (see chapter 6.4). Also research within the field of worksite health promotion (Crump, Earp, Kozma, \& Hertz-Picciotto, 1996) and stress interventions (Kompier \& Kristensen, 2001) have stressed the importance of employee involvement in the intervention process.

It is important to note, as the study by Orth-Gomér indicated, that the social effects of a change in schedule may sometimes not be in accordance with the health effects. Employees may sometimes prefer to have longer periods of continuous leisure time periods in combination with more compressed work (or counter-clockwise rotation schedules) even though it is contra productive for their health.

\subsection{Increased influence over working hours}

In a Danish intervention project, Pryce et al. (Pryce, Albertsen, \& Nielsen, 2006) explored the effect of an open-rota system that gave the employees increased possibilities for influence over own working schedule. The system was chosen and implemented using a participatory approach, where the employees among different kinds of interventions chose the open-rota system. The system was implemented in a group of four nursing teams, including 86 participants in a psychiatric ward. Changes were compared to simultaneous changes over a 20-month-period in a control 
group with four nursing teams and 91 participants, but without any changes in working time arrangements. Employees in the intervention group reported that they were more satisfied with their work hours, less likely to swap their shift when working within the open-rota system and reported, compared to changes in the control group, significant increases in work-life balance, job satisfaction, social support and community spirit as compared to nurses in the control groups.

Kauffeld et al. (Kauffeld, Jonas, \& Frey, 2004) studied the effect of implementation of a flex-time schedule in a service company in Germany. They compared 18 employees who had been working with a new work-time design in 2.5 year with 15 employees not working with the new work-time design. They did not have baseline measures. Employees in the flex-time group viewed their overall work situations as better than the traditional group. They reported higher demands and decision latitude, work satisfaction, learning opportunities, better cooperation and better communication. In addition they had lower rate of absenteeism, fewer cashier mistakes and lower rate of costumer complaints. No direct measurements of stress or wellbeing were given.

\subsection{Summary on experiments and interventions in working time arrangements}

Although there are relatively few controlled intervention studies in the field, those that are conducted seem to be promising. Positive results of interventions were found with regard to: reduced hours with compensation, compressed working weeks, rapidly rotating shifts and increased influence on work scheduling.

The results from a single experiment reporting results of reduced hours with full compensation were promising. In periods with full employment and need for more workers (as it is the case e.g. in Denmark for the time being), reduced hours, will for political reasons be very difficult to implement. However, it may in many cases be a question of balance, and very long hours may not be as productive as shorter hours, so the same amount of work may be performed at shorter time. Shorter hours may in addition, as suggested from the results, have positive consequences on social life, well-being and health. As the experiences from France tell, it is very important to be aware of possible negative consequences of reduced hours in the form of increased intensity, speed of work and stress. In many jobs influenced by the new organization of working life, particularly in jobs with so called 'trust hours' (see chapter 7), it will also not be possible to make centrally regulations of the working hours.

With regard to the effect of compressed working weeks or shifts, the results from three different studies in different kinds of jobs were positive 
both with regard to the social consequences, the health consequences and the consequences on the work environment. It is, however, important to be aware of possible negative effects on attention, errors, injuries, etc., and on long-term health consequences. The specific job-context and demands to attention etc. needed in the specific job may be highly relevant in relation to the consequences of compressed working weeks or shifts.

The studies exploring changes in shift systems found positive effects of rapidly rotating shifts and of 12-hour shifts compared to 8 hours. These together with the positive effects of 12 hours shifts mentioned in chapter 4 , and the positive effects of compressed working time give support to further exploration of these kinds of changes. As described in chapter 6, other studies have found negative effects of long working spells on fatigue and performance outcomes. Effects on health may be closely linked to the time off between shifts. Is the time used for recovery and recreation, for a second job, or is it associated with increased demands in the household?

Also the studies of increased influence over working time yielded positive results on well-being, work-life balance and work environment. As concluded in chapter 5, increased influenced on working hours, may be a clear advantage in jobs with prior low or limited influence.

\section{Methodological considerations and future perspectives}

There is clearly a need for more well-conducted intervention studies, exploring the effect of different kinds of amendments in working time arrangements. Intervention research is, however, resource demanding, and not easy to conduct in a methodological sensible manner (Kompier et al., 2001). Sound design should be used, at least quasi experimental designs including control groups. Studies should also be supplemented by process evaluations with systematic documentation of the change process and the implementation of the intervention (Semmer, 2006).

Worksite interventions always take place in rapidly changing contexts. Turn-over of staff, change of management or project leaders, merges, downsizing and closing of organisations are common experiences, often making it hard to draw firm conclusions (Olsen, Albertsen, Nielsen, Poulsen, \& Brunnberg, 2007). A thorough evaluation of the implementation process by the use of qualitative as well as quantitative measures is of great value for the interpretation of findings.

Interventions in working time arrangements may have large impact on every-day life of the employees, and it is therefore necessary that the development of interventions take place in close collaboration between work-sites, employees, management and researchers. As shown in some of the studies, and emphasized in the stress intervention literature (Kompier, Geurts, Gruendemann, Vink, \& Smulders, 1998) a participatory approach may also improve the positive effect of an intervention. 
It is likely that there is a publication bias in these kinds of studies, so that more intervention studies showing positive results are published, while negative results or null-findings are not. Because it may have serious consequences for employees if negative results are not published, it is of great importance to obtain design of a good quality so that also nullfindings and negative results can be trusted.

As part of this, it is important to include a wide range of outcome measures such as exploring effects on work-life balance and other social outcomes, well-being, health, absence, work environment and if possible also productivity, injuries, errors and quality of service/ product. As mentioned in the review of Colligan and Rose (Colligan et al., 1990), effects on some outcomes may be positive, while effects on others may simultaneously be negative.

Follow-up time is also crucial in these kinds of studies. Some outcomes may appear immediately after the intervention (particularly on social outcomes) while others (particularly on health) will take much longer periods to show. Long follow-up periods (12 months or more) may in some jobs be difficult to obtain, because turn-over rates are high and/or the speed of major changes in the organizations are common, making it impossible to attribute particular changes to particular intervention. 


\section{New organisations of working life}

Work without boundaries, telework, virtual office etc. are concepts describing trends in the organisation of the new working life.

The organization of working life has changed in many ways within the latest decades, the traditional regulations of time, place and content of work have changed for new and more flexible kinds of regulation. The changes have in some countries and in short been labelled "work without boundaries" or flexible work. It is now very well-defined concepts, but rather broad descriptions of tendencies in the new organization of working life characterised by 1) flexibility in working hours 2) flexibility in working place, and 3) changed organisation of work, with less emphasis on the formal regulation through work descriptions and with more emphasis on personal competences and self-regulation at work (Aronsson, 2005).

With regard to the main topic of this report, the organization of working time, there has been a tendency toward more people employed without any fixed maximum hours. The regulation of work has changed from a focus on hours to a focus on the solution of tasks or fulfilment of projects and goals, regardless of the time use. Also in jobs with a more fixed job content, e.g. service jobs, many employees have gained more influence over own schedules.

Not only has the regulation of the working hours changed, but the regulation in the form of the place where the work is performed has also changed. Mainly due to new technological possibilities, the fixed location of work has changed to a situation where a lot of work can be performed from anywhere with an Internet connection and tele-communication. These possibilities are of course not possible in all jobs, but most prevalent among knowledge workers.

Also the organization of work has changed. Fixed contracts defining the content of work have in many occupations been exchanged with selfregulation, where it is, to a high degree, up to the individual employee to define, plan, carry out and evaluate own work. At the same time personal qualifications, engagement and initiative have been highly requested from the employees.

There is a very rapidly changing world of work behind these tendencies. The stability of organizations, workplaces and employment has decreased. More people are now employed at precarious employments, either voluntarily or involuntarily. The demand on employees is to keep them self-employable (Allvin et al., 2006). 
Jobs can vary in the degree of flexibility. Some people, e.g. selfemployed and professionals have always had a high degree of flexibility in there jobs, while other jobs have less. The tendency seems to be more flexibility in many jobs.

Another way of describing the increased flexibility is by the term of rhythmicity. Researchers have described how the rhythmicity of work and life has changed. Rhythm is a combination of repetition and time, and the institutionalized rhythms have been exchanged for individualized rhythms, which are much harder to defend and maintain than collective rhythms. Work without rhythms is borderless work with unlimited demands (Hvid, 2006).

The consequences of these tendencies of the work environment and of the health and well-being of the employees are not yet known. The research in the field is limited, and particularly the empirical studies are few. Many scholars have, however, identified both potential positive and negative effects.

On the one hand, the new organization of working life has given rise to much more autonomy and influence in work to the employee and at the same time, the job-demands seem to have increased. When the demands are not specified, they can be unlimited. Both the quantity and the quality of work may always be improved, and without specified goals, the possibility of overload is obvious.

With the increased focus on self-regulation and self-management at work in combination with high demands to quality control, deadlines and delivery at time, there is a danger of double bind in the work-situation, a situation where the employees are given a lot of responsibility for the work task, but not the control necessary to fulfil it (Groth \& Rosbjerg, 2006a).

Alvin et al. has described these tendencies in the way that control in work has increased while control over work has decreased. While employees exert a lot of influence on how, when and where the work can be done, they have lost influence and predictability with regard to changes, fluctuations and requests from the market and the context surrounding the work (Allvin et al., 2006).

When work is regulated according to the fulfilment of tasks instead of the length of working hours, it will often have the consequence that management and employees will underestimate the real time costs. The use of invitations to tenders will also increase an underestimation of the time use, because conscious or unconscious underestimation will increase the chances to win the tender (Tynell, 2001).

The personal engagement in work may give rise to high satisfaction when work is successfully performed; on the other hand, it may also be a serious and personal defeat, when the project fails (Tynell, 2002). In a situation with high competition between companies and between employees, and an increasing demand to keep one self-employable, there may be 
a danger of over-commitment to the work, and an unfair competition between time and energy spend at work and time and energy spend in the family. It is likely that the work will come out as the winner.

The specific circumstances and combination of circumstances at work that give rise to positive and negative effects for the employee is still not well documented. There are some few studies, exploring and discussing relevant aspects and dimensions (for an example of an ongoing Nordic project about boundary free work, see chapter 9.3)

\subsection{Trust hours - work based on results and performance}

Studies focusing on the effect of increased individual influence over own working hours and employer flexibility in the form of overwork and shiftwork have already been the focus of previous chapters. The extreme case of full freedom to control own schedule has not been studied so much.

Kecklund et al. (Kecklund et al., 2002) studied the effect of 'trust hours' (work based on results and performance rather than hours) implemented in a trade union. They found as mentioned in chapter 5 in general a positive effect on satisfaction on measures of burnout, stress and sleep. There were, however, a minority on $15 \%$ of employees, who were dissatisfied and wanted regulated working hours back. They experienced more stress and increased workload and insecurity. The group was characterised by higher age, more administrative staff, lower influence at work and experiencing poor group meetings. Parents to small children and ombudsmen were overrepresented in the positive group. They experienced higher satisfaction with the work situation, social life and work-family balance.

\subsection{Teleworking - via telecommunications equipment}

Flexibility in the form of the place for the performance of work has been dealt with in some, but still relatively few studies.

Hill et al. argued that a major impetus for the rapidly increase in employees doing telework, has been expense reduction for the organisations. While the cost of traditional office space has dramatically increased, the cost of portable telecommunications equipment has decreased in the same period. It has among other things been argued that telework could improve productivity and work-life balance (Hill, Miller, Weiner, \& Colihan, 1998). On the one hand, the use of faxes, e-mails, or computers at home for work-related activities may create a work atmosphere at home that is disruptive to family life.

Hill et al. (Hill et al., 1998) explored the consequences of a naturally occurring experiment among IBM employees, of which 157 changed to 
virtual office work, while 89 continued with traditional office work. Employees did not volunteer to leave the traditional office. The consequences were explored with both qualitative and quantitative measures at a single point in time. Both qualitative and quantitative data supported consistently improved productivity and greater flexibility in the timing and location of work for the teleworkers. For work-life balance both favourable and unfavourable consequences were identified in the qualitative analyses and no association was found in the quantitative analyses. Many employees responded that the virtual office blurred the boundary between work and family. Longer working hours, poor teamwork and improved morale were reported for teleworkers in the qualitative analyses, but these results were not supported in the quantitative.

In a later study among 6451 IBM employees, they found that both flex-time and flex-place added positively to better work-family balance. Among those working between $40-50$ hours per week, 28\% of those with both flex-time and flex-place experienced difficulties with work-family balance, compared with $46 \%$ of those with neither flex-time nor flexplace (Hill et al., 2001).

In a naturally occurring experiment, Allvin (Allvin, 2001) studied the implementation of telework at the Swedish energy department in 1997. Among other things, the explored how telework influenced work performance and relations to the organisation. Due to the move of the company to a distant place, the highly skilled managers and professional employees in the department were offered a possibility for telework 3 days a week via IT and telecommunication. They also received compensation for commuting costs and commuting time. Results showed that approximately two thirds of the officers in charge experienced that their work was equally well conducted from home as from office, and equally well within office time as outside office time. Among managers, two thirds experienced that their work was best performed from the office and within office time. There was no experience of change in quality of own work, social relations and loyalty to organisation, but there was an experience of decreased effectiveness for the department as such after introduction of telework. The authors conclude that telework should not be conceived as a deregulation of work and organisation, but as a reregulation, a change toward a new type of regulatory mechanisms better suited to the administration and management of distributed labour.

In her doctoral theses, Hanson further explored the working conditions in the same group of employees from the Swedish Energy department and beside them she also explored a group of freelance journalists. In both groups she found that their work conditions were characterised by contradictions. On the one hand, the freedom was emphasized as a main advantage both with regard to the performance of work and with regard to work-life balance; on the other hand, both groups reported a high workload as well as insufficient time for social interaction and education. The 
freelancers reported a high mental workload due to the demand of constantly having to be initiating and creative at the same time as they should cope with practical, administrative matters and economic insecurity. The deregulation of work created both a distribution and an overlap between work and non-work, resulting in an increased workload due to work becoming both more extensive and widespread (Hanson, 2004).

In another study from Sweden, Hartig et al (2007) explored the effects of telework among 101 full-time governmental employees whose workplace relocated to another city. After the relocation, fifty-eight of the employees performed more than $20 \%$ of their work from home. They found no differences between the teleworking and the non-teleworking groups with regard to the experience of spatial, temporal or mental overlap between work and home. The more perceived overlap, the more likely the respondents were to evaluate it negatively. Teleworkers and nonteleworkers also reported similar effective restoration at home. There was, however, an interaction with gender, so teleworking women reported less, and teleworking men reported more effective restoration than their non-teleworking counterparts (Hartig, Kylin, \& Johansson, 2007).

In the large EU-project, SUSTEL, questionnaire responses from 384 teleworkers with different kinds of telework arrangements from Germany, Italy, The Netherlands, United Kingdom and Denmark were collected together with 30 case studies in large organizations with telework. The results showed that more than $3 / 4$ of the respondents from all countries thought that telework have had a positive effect on their quality of life. A majority also felt that telework had increased the amount of time at home available for non-work activities. In Denmark, Germany, The Netherlands and Italy, larger groups (13\% in Germany to $54 \%$ in Italy) found that telework had decreased the level of conflicts at home, and smaller groups ( 0 in The Netherlands and 16 in Italy) found that telework had increased the level of conflicts. In the UK more people (27\%) felt that telework had increased the level of conflicts, and only 18\% felt that it had decreased. The British respondents reported frequently that this was due to too long working hours. Almost half of the respondents in each country felt more isolated to work-related contacts due to telework. Results also showed, that teleworkers worked many hours, and that they had increased their weekly hours within the last two years (Schmidt, Millard, \& Nielsen, 2003).

\subsection{A new kind of autonomy?}

Another aspect of the new organization of working life is the increased degree of influence not only over working hours but also over content, performance and evaluation of own work. The effects of this increased employee control in work have mainly been seen as positive, but it has 
also been discussed whether there was a limit for the positive effect of control. Grönlund have for example argued that “... the protective effect of control over work may be offset by the high demands in downsized, flexible organisations." and further that "....the transformation of work may change the nature of control" and "...the loosening regulation of work leaves individuals responsible for defining goals, setting priorities and drawing the line for work and non-work” (Grönlund, 2007a). In her study of 379 female and 395 male employees living with a partner and /or children from a representative sample, she explored the effects of influence, and found no tendencies that influence in it self should have negative effects. The results showed that high job demands are associated with longer work hours, more work-family conflicts and lower well-being, while employee control has positive effects, even when demands are high.

\subsection{Precarious work and self-employment}

Precarious work or time limited contracts is another dimension of the new organization of working life. Also in this field, few studies are available.

Evans et al. (Evans, Kunda, \& Barley, 2004) studied technical contractors and explored how they experienced, interpreted and allocated their time and whether they took advantages of the temporal flexibility offered by contract work in the market. They found that contractors perceived themselves to have flexibility, but rather than take advantage of this, the majority worked long hours and rarely scheduled their time flexibly. The authors suggest that the market place more rather than fewer constraints on the workers' time.

There is a high degree of flexibility within the new media sector not only with regard to place and time but also with regard to content and organisation of work for the self-employed.

In a qualitative case-study from the UK, Perrons illuminated the gender-differentiated patterns of ownership and earnings among new media owners and whether flexible working patterns, long hours and home working are compatible with work-life balance. She made 55 interviews with new media owners in the area of Brighton and Hove, said to constitute a 'new media hub' and reflects the varied dimensions of new economy within a relatively small location. Over a third of the interviewed employees identified lack of clear boundaries around project content, uncertainty about the volume of work and inflexible deadlines as major sources of strain. In order to build up their reputation and because of uncertainty of the future, they often put in hours of unpaid work. Few had, however, concern about job security. Mixed support was found for the expectation that ICT could provide new opportunities for women to earn more and have more flexible working practices. Women worked fewer hours, earned less and were more likely to have sole or major responsibil- 
ity for childcare. Half of the sample had serious tensions between work and life, although only $20 \%$ of the respondents in the sample had evenly divided, major or total responsibility of child care. Also experiences with regard to home-work were mixed. About half of the interviewed employees praised the possibility to work from home, and felt that it increased the work-life balance, while others avoided it and felt that work invaded their private life, and forced them to work all the time. She concludes that new media creates new potential opportunities for people to combine interesting paid work with caring responsibilities but that a marked gender imbalance remains (Perrons, 2003).

\subsection{New competences?}

As a consequence of the changes in working life, a demand for development of new competences has grown. In her doctoral thesis, Hanson illuminates and discusses the new competences needed under flexible working conditions. When the working conditions are no longer lucid and well-defined, it requires meta cognitive competences characterised as a self-governing competence, referring to the guiding, supervising function needed to be able to define, structure and discipline own performance. This self-governing competence involves continuous learning and development in the form of higher levels of cognitive complexity, integration and differentiation (Hanson, 2004). Allvin et al. also mentioned the demands for new competences with regard to meta-learning about how to learn and how to adjust quickly to new situations. Also communicative skills and social learning particularly about how to obtain own goals in relation to other people are mentioned by both Hanson and Allvin (Allvin et al., 2006).

\subsection{Summary}

Together the studies presented in this chapter describe both advantages and problems related to the new organisation of working life. As individual dimensions or factors in the work environment both influence over own working time, the possibility of teleworking and influence over content and performance of job can be considered as positive with regard to well-being, stress and work-life balance.

In practice, as the results from the studies illustrated, the flexibility often goes hand in hand with extensive and unpredictable demands, insecurity and long work hours and these dimensions may have deleterious effects on family life and well-being. 
Empirical studies trying to measure the consequences of these new tendencies are sparse, most surveys are lacking far behind with valid and relevant questions illuminating the new tendencies of working life.

Trust hours may for many workers be experienced as positive, while others will perceive the de-regulation of time negatively. It may, particularly if not followed by a high degree of influence over work, lead to more stress, increased workload and insecurity.

Telework may reduce commuting time and give more time for private and family activities and at the same time it may invade the family life with a constant demand of being 'always on' and available. It may increase productivity and give more time for the core work-tasks, and at the same time, it may decrease the feeling of department or team productivity and may reduce the social contact and communication between employees. In situations with unlimited demands, telework may also lead to over-commitment and overwork. The effects of telework are likely to differ for men and women.

Precarious employment and self-employment may potentially give flexibility and more control, but in practice, it may be difficult to enjoy and use the possibility of flexibility, because high competition, uncertainty about the future and demands to build up a reputation forces the self-employed to put in many hours.

As Allvin expresses it in a few words: "The freer the work is, the more difficult it is to be free from work" (Allvin et al., 2006)(own translation). 


\section{Examples of ongoing Nordic projects}

In this chapter, some few examples are given of ongoing Nordic projects in the field of social consequences of long and irregular work hours. The examples are primarily taken from the authors' own research.

\subsection{Work/Life Balance - a research and development program}

Institute hosting the project:

The Finnish Institute of Occupational Health (FIOH)

\section{Project period:}

The "Work/Life balance" research and development program was initiated at the Finnish Institute of Occupational Health in 2004. It is a fiveyear program lasting until 2009.

\section{Aim of the project and main activities}

It aims at social impact through wide-ranging networks with various national and international actors. The program has initiated its own research activity:

- The MONIKKO "Gender equality and diversity in work organisations" project aims to generate new information on age and ageing, gender equality and diversity at work in order to benefit work organisations both in terms of productivity and well-being

- Project on gender segregation in working life: how to reduce negative consequences of horizontal and vertical gender segregation.

- Project on "Combining work and family - a challenge for equality planning" is a research project to estimate the costs related to family leaves and to evaluate the effects of these costs on women's wages and career development, as well as on well-being at work.

- Several EU-projects on gender and health, and a Nordic Project on Social consequences of long and irregular work hours.

- Two Delphi-expert panels: 1) Work/Life balance - challenges and opportunities. 2) Diversity and multiculturalism in Finland. 
Based on research results, new social innovations are developed and introduced in order to improve the balance between the demands of work and family. Family-friendly legislation in Finland, as in other Nordic countries, form a supportive framework for good work-life practices flexible work hours, shorter work days, working from home, and offering professional help for household and childcare duties. Today's rapid changes in working life are constantly creating new demands for the work/life balance.

\section{Sub-project: Delphi expert panel}

The Delphi expert panel, set up as part of the the "Work/Life balance" research and development program at the Finnish Institute of Occupational Health, set out to determine how the roles of work, family and leisure in everyday life are changing, and how the demands of work and family life will be reconciled in the future. The study was carried out by means of the Delphi Method, in which 31 experts contemplated and discussed the future prospects for reconciling work and family life. The study's principal results consisted of differing views on the future reconciliation of work and family life. These are affected by changes occurring in working practices and policies, family life and family policies, as well as in gender and equality issues. Family and leisure time will be more highly valued in the future. However, work takes up a lot of time and encroaches on leisure time. Values are changing, but so are the form and size of families. Traditional gender roles and division of work within the family are also changing. The father's role will grow. The experts were unanimous that solutions supporting the reconciliation of work and family life will be an image factor for companies, and a trump card in the competition about workforce.

\section{Source:}

Got your everyday life together? Finnish
expert views on work, family and leisure
time in 2015. Results from the Delphi
panel. 'People at work' Journal (2007):
31. (in Finnish with English and Swedish
abstracts).

\section{Participants}

Program director: Kaisa Kauppinen, tel. +358 30474 2758,

kaisa.kauppinen@ttl.fi

Program Secretary: Taija Piispanen, tel +358 30474 2717, taija.piispanen@ttl.fi

Collaborating parties: The Finnish Mental Health Association,

The Finnish Family Federation,

National Research and Development Centre for Welfare and Health (Stakes),

The Ministry for Social Affairs and Health,

Ministry of Labour, National and international project partners 


\section{Design and main methods}

The applied research methods vary from questionnaire studies to key person interviews and focus groups with people representing different ranks of their organizations: personnel managers, employee representatives, shop floor workers, etc. The Delphi-expert panel on Diversity and multiculturalism in Finland involved 24 Finnish experts. In the study, diversity referred to the ways in which people are different and at the same time equal, with regard to age, gender, ethnicity, sexual orientation, family situation, disability, religion and beliefs. During 2007, a diversity barometer will be performed as a questionnaire study focused on personnel managers from both the private and the public sector.

\section{Ref to website \\ www.ttl.fi/perhejatyo \\ www.monikko.net \\ http://www.ttl.fi/Internet/English/Informa- tion/Electronic + journals/Tyoterveiset + jo urnal/2006- \\ 01/worklife_balance_a_research_and_de velopment programme.htm}

\section{Publications}

Two special issues of 'People at work' Journal, I and II (2005) edited by Kaisa Kauppinen. The titles of the article include the following:

- "The relationship between job and home demands and resources, and work engagement, burnout, workalcoholism, and marital and life satisfaction" by Jari Hakanen

\footnotetext{
"Knowledge work, paid work at home and family" by Jouko Nätti et al.

"Family-friendly organisational culture as a resource for staff members: questionnaire research in three organisations" by Saija Mauno et al

Special issue of 'Työterveiset -Newsletter of the Finnish Institute of Occupational Health 1/2006': Striking a balance Work, family and everyday life. http://www.ttl.fi/Internet/English/Inform ation/Electronic+journals/Tyoterveiset+journal/2006-01/

“Got your everyday life together?” Finnish expert views on work, family and leisure time in 2015. Results from the Delphi panel. 'People at work' Journal (2007): 31.
}

\subsection{Work hours impact on health}

Institution hosting the project

National Institute for Working Life, Sweden

Project period:

2005-2006

\section{Aim of project including main hypothesis}

The National Institute for Working Life has been commissioned by the Swedish Government to run a trial of reduced working hours. The aim is 
to identify the link between the number of hours worked and the health of employees.

Health hypotheses:

Work Time Reduction (WTR) may affect various aspects of health in different ways:

Subjective health may change before physical health does

- Improved sleep quality may influence other health aspects positively

- More time for physical exercise may influence weight, blood sugar and blood fat positively

Gender hypotheses:

- Women: Less total paid /unpaid workload

- Men: Extra time for leisure activities

- General: easier to combine work and family life

Occupational hypotheses:

- WRT may have different effects for different occupational groups:

- Full time (40) hours may prove too high for some female dominated groups - such as health care

- Occupations with requent emotionally demanding socia contacts may gain WRT may increase the gender segregation of work task

Research questions:

- Are different aspects of health influenced by WTR to various degrees after various time periods?

- Do health effects differ by gender?

- What changes in a work organisation is a result of implementing WTR?

- Does this reorganisation of work differ between men and women?

- Is equality at work influenced?

- Is equality outside of work influenced?

- Is women and men's total workload affected?

- Are effects of WTR different for subgroups of subjects?

Design and main methods

It is a quasi experimental study. The project focuses on a study group including 14 workplaces and a control group of the same size. 400 subjects in each group are followed. Those in the study group will work 75 percent of their normal working time while retaining the same salary (a reduction from 8 to 6 hours). Employees in both groups will then be monitored for changes in working conditions, other living conditions and 
changes in health. Participation in the trial has been restricted to various public sector bodies in different parts of Sweden.

Measurements are taken before, during, at the end and (partly) after the follow-up period. Questionnaires, diaries, physiological measurements and interviews are used.

Participants: names, institutional affiliation and country

Anna Falkenberg, Project leader Carina Bildt, Senior researcher Ida Larsson, Research assistant Peter Barck-Holst, Research assistant All from the National Institute for Working Life, Sweden
Ref. to website, publications and contact person

http://www.reg.se/arbetstid/carina.bildt@h go.se

Funding; who have financed the project

The Swedish Government

\subsection{Boundary-free work - stress, sleep and private life}

Institution hosting the project:

National Research Centre for Working Environment (NRCWE), Denmark.

Project period:

Jan 1, 2006-Dec 31, 2008

Aim of project including main hypothesis:

A lot of people are hired under circumstances where the traditional regulation of work is changed. These jobs we often call "flexible job", "work without limits" or "borderless work". It was previously necessary to deliver your working capacity on a specific place at specific hours. Nowadays more people are hired to fulfil a specific task, independent on how long time it will take or where in the world you will solve it. The regulations that have changed consist of place, time and organization of the work. There is no clear demarcation line when a job is borderless or not. We talk about tendencies, which are more or less common in different jobs.

In borderless work, you have to define, organize and complete the job by yourself. It takes makes great demands on responsibility, selfdevelopment and self-regulation. Borderless work is considered to be very attractive jobs with a lot of influence and god chances for development. But there is a risk that endless demands on qualifications and use of time leads to stress, sleeping problems or imbalance between job and private life.

There may be different causes why people are happy or unhappy with borderless work. The project will examine the causes related to: 
1. The workplace culture, e.g. the degree of trust and reliability, respect and equity at work.

2. The work environment, e.g. the degree of "unpredictability" in tasks and roles, unfinished jobs and conflicts, support from the leadership and colleagues, and the length and placement of the working hours.

3. The situation of the private life, e.g. the social network, the job situation of the partner, economy, self-confidence, and illness or divorce.

\section{Design and main methods}

From the second Danish national psychosocial work environment study, we have selected employees in knowledge work. We examine this group of about 900 persons through a questionnaire and measurements of salivary cortisol. The group is examined twice, with a year between each measurement. In a smaller group, we make an interview to gain information about how they manage to balance work and private life. In another small group we measure the quality of sleep with instruments to place on the wrist. In a $\mathrm{PhD}$ project connected to the project, the organization of the work in selected companies with a high degree of borderless work is examined.

\section{Participants:}

Karen Albertsen, Senior Researcher Anne Helene Garde, Senior Researcher Roger Persson, Senior Researcher Reiner Regulies, Senior researcher Katrine Kjøller Neergaard, Ph.D. student
Ref. to website

http://www.dk/Aktuelforskning/

Arbejdstid.aspx

Contact persons as mentioned above.

\section{Funding}

The project is financed by a grant from The Danish Health and Safety Research Fund

\subsection{Working hours and parents' experience of stress}

Institution hosting the project

The Danish National Institute of Social Research

\section{Project period}

Jan 1, 2005-Dec 31, 2005

Aim of the project including main hypothesis

The main question is:

How do working time arrangements affect women and men's experience of stress in connection with delivering/picking up children, daily shopping and time spent with children? 
The underlying questions are:

- Is there a connection between the number of hour worked and working time flexibility? (The assumption is that if you have working time flexibility you will work more hours). If there is a connection how will this influence the experience of stress in connection with delivering/collecting children, daily shopping and time spent with children?

- Is there a connection between the overlapping of parents' working hours and the individual's experience of stress? (The assumption is that the more overlapping of parents' working hours, the more the individual parent will experience stress in connection with delivering/collecting children, daily shopping and time spent with children?

- If there is a connection will parents total working hours and flexibility in working hours have any influence on the individual's experience of stress?

- Are women experiencing more stress than men independently of number of working hours, working time flexibility and working time overlap? (The assumption is that women in general experience more strain than men).

Design and main methods

Through multivariate analysis of a 1000-person survey from June 2004

Title

How does the arrangement of working hours affect parent's experience of stress in connection with delivering/picking up children, daily shopping and time spent with children?

\section{Participants}

Senior researcher Helle Holt, the Danish National Institute of Social Research, Denmark

Ref. to website

www.sfi.dk

Contact: Helle Holt

\section{Funding}

The Danish National Institute of Social Research has funded the research 


\subsection{Shift work; employees attitudes and expectations}

\section{Institution hosting the project}

The Research Centre for Occupational Health and Working Life in Iceland

Project period

June 30, 2005-June 30, 2007

\section{Aim of project including main hypothesis}

The main question is:

- Is it possible to make the shift work more healthy and attractive for the employees?

The underlying questions are:

- Is shift work more difficult for women than for men? (The assumption is that women are more strained than men because of higher work-family workload).

- Is shift work more difficult for single parents and parents with preschool children than other employees? (The assumption is that it is more difficult for single parents and for parents with young children to work untraditional working hours)

- Does the organisation of work and working hours matter for how easy/difficult he work is for the employees? (The assumption is that regular working hours and shorter (8 hours) shifts are easier for shift workers than irregular hours and longer (12 hours) shifts.

- Do employees influence on the working hours matter for how easy/difficult the work is for the employees? (The assumption is that the work-life balance is easier for shift workers who can to some degree decide which time or days they want to work or do not want to work).

\section{Design and main methods}

The method is both qualitative and quantitative:

- Interviews with 5 focus groups, 18 women and 17 men, shift workers, belonging to different occupational groups in the public and communal sector.

- Analysis of 657-person survey which was distributed to certain working places where shift work is common and who belong to the public and communal sector 


\section{Participants}

Hildur Fjóla Antonsdóttir, assistant

Ólöf Eiríksdóttir, student

Hólmfríður K. Gunnarsdóttir, Senior Researcher

Guðbjörg Linda Rafnsdóttir, Associate

Professor

Herdís Sveinsdóttir, Professor

\section{Contact}

Guðbjörg Linda Rafnsdóttir

\section{Funding}

The project is financed by the partners of the public and communal labour market.

\subsection{The work-life balance: Integrating Family well-being and working life research}

Institution hosting the project

International Research Institute of Stavanger (IRIS)

Project period

A three-year Institute Strategic Program from 2006-2008.

\section{Aim of the project and main activities}

The theme of this project is the interplay between family and working life. Our main aim is to bridge two of IRIS' research fields - family wellbeing (sociology of family) and working life (occupational health) - into a new target area - the study of work-family interaction, which to an increasing degree is the subject of public debate and scholarly research. Our main research questions are: How does work affect the lives and well-being of families? How is the working life influenced by family processes? In this, we include a variety of family forms and occupational groups.

The project is organized around different activities. The research activities are a) publications which are mainly based on existing data from former and ongoing projects on IRIS, b) seminars and work-shops with national and international collaborating partners, c) networking, d) team building, e) participation at international conferences and courses, and f) development of related projects.

The current scientific works in progress are related to four sub-projects:

- Working hours among employees within the on-shore oil industry

- Work-life balance among employees in the health care sector

- Spouses' time-use in a comparative perspective

- The impact of social support on work-life balance and well-being in Norwegian families

\section{Design and main methods}

Depending on the specific research question, the project covers a wide range of research methods. Both questionnaire surveys, semi-structured in in-depth interviews are used. Employees within the different organisa- 
tions studied as well as parents and children in Norwegian families are informants.

\section{Participants}

Project management:

Research director Kjersti Melberg

kjersti.melberg@iris.no

Senior Research Scientist Kari Anne Holte

kari.anne.holte@iris.no

\section{Researchers:}

Research Scientist Brita Gjerstad brita.gjerstad@iris.no

Senior Research Scientist Kåre Hansen

kaare.hansen@iris.no

\section{Collaborating partner:}

Professor Knud Knudsen, University of Stavanger, knud.knudsen@uis.no

Ref. to website, publications and contact person:

www.iris.no

\section{References}

Gjerstad B, Holte KA. Melberg K. Variations of spill-over effects from work to personal life according to family form. Proceedings of the Community, Work and Family II International Conference: CIES-ISCTE 12th-14th April, 2007, Lisbon, Portugal.

Melberg, K. Work-Life Balance and the Importance of Extended Social networks. Proceedings of the Community, Work and Family II International Conference: CIES-ISCTE 12th-14th April, 2007, Lisbon, Portugal.

Melberg, K. 2006. Family well-being between work, care and welfare policies: The case of Norway. Marriage and Family Review, 39, 337-358.

Melberg, K. 2007. Livskvalitet i familien nære relasjoners betydning for „det gode liv“. Sociologisk Forskning, 30-51.

Knudsen, K., Wærness, K. 2007. "National Context and Spouses' Housework in 34 Countries”. forthcoming in European Sociological Review.

\section{Funding:}

The Norwegian Research Council

\subsection{Nordic Study on working hours in nursing}

The project is a subproject of "Occupations of the welfare state: Motivation, qualification and occupational careers " at the Centre for the Study of Professions, Oslo University College.

Institution hosting the project

Centre for the Study of Professions, Oslo University College, Norway

Project period

2006-2009

\section{Aim of project}

The aim of the project is a comparative study of working hours in nursing. In Finland, nurses mainly work full-time while significant proportion of nurses in Norway and Sweden work reduced hours. In Norway and 
Sweden, women's part-time work is usually explained as an adjustment strategy in order to combine family and work. A comparative study will increase our knowledge of the impact of national factors like working time regimes, attitudes to women's full-time work, national support (social and economic) etc. on women's employment patterns. Articles on the relationship between working hours and nurses' work-life balance, professional commitment, working conditions and work ability are carried out.

Data

- The project makes use of the Next-survey, which is financed by the EU and carried out in ten European countries.

- The project is a joint effort between four researchers in Norway, Sweden and Finland.

\section{Participants:}

Bente Abrahamsen, Centre for the Study of Professions at Oslo University College Kari Anne Holte, International Research Institute of Stavanger

Malin Josephson, University of Uppsala Marjukka Laine, Finnish Institute of Occupational Health in Turku
Ref. to website, publications and contact person

http://www.hio.no/content/view/full/1074 http://www.hio.no/content/view/full/10925

Bente.Abrahamsen@hio.no , Kari.Anne.Holte@iris.no Marjukka.Laine@ttl.fi Malin.Josephson@medsci.uu.se

Funding; who have financed the project

The Research Council of Norway and Oslo University College

\subsection{Reciprocity is an asset - a study on flexible working time arrangements}

Institution hosting the project:

University of Turku and University of Jyväskylä, Finland.

Project period:

January 1, 2006-December 31, 2008

Aim of project including main hypothesis:

The Finnish Working Hours Act and the present collective agreements provide vast possibilities to tailorize working time arrangements at workplaces. At their best, workplace-specific working time practices have managed to increase the profitability of enterprises and the well-being of the employees. 
The study charters the possibilities of local agreements and encourages workplaces to use them. It also includes descriptions of the diversified working time models of 26 workplaces. There are no stereotyped solutions, because a successful flexible working time arrangement requires cooperation and the consideration of local starting-points of one's own.

One of the most interesting examples is a so-called four-shift working time arrangement which was in use in Fazer leipomot Oululainen in Lahti. Four-shift system is destined to aged employees (over 50-year old). The idea with the four-shift working time system is that aged employees are working three weeks followed by one week off. Employees in days off week (so-called fourth week) constitute the "reservoir of labour". In particular, during the peak periods, the employer can call them back to work.

Employees in Fazer leipomot Oululainen have been quite satisfied with the four-shift arrangement, because they can have one week off every month. The employer admits that the system is more expensive than the conventional three-shift work, but the work motivation has notably increased, the number of days of illness has decreased, and the system makes it possible for the employees to work until the age of retirement.

The system is based on trust, and it is a very good example of locallevel social capital in cooperation and negotiation relations. In the foodstuff industry, the flexibility cannot be reached by the extension of working day, because employees simply cannot work more than eight hours per day.

\section{Participants:}

The main researchers are:

Heikki Uhmavaara from the University of Turku

Pertti Jokivuori from the University of Jyväskylä

Ref. to website, publications and contact person

Pertti Jokivuori

SoCa Project coordinator
Agora Center

PL 35, 40014 Jyväskylän yliopisto

pertti.jokivuori@jyu.fi

www.agora.jyu.fi/soca

Funding; who have financed the project

The study is based on an income policy agreement for the years 2001-2002, signed by the social partners and financed by the programme "Well-being at work” 


\section{Summary from Seminar on long and irregular working hours at the National Institute of Occupational Health (NIOH), Denmark}

Thursday 2nd June, 2005

As part of a strategic effort, four experienced researchers were invited to the Danish National Institute of Occupational Health (now: National research Centre for the Working Environment) to give state-of-the-art presentations about the social and psycho physiological consequences of long and irregular working hours. The seminar was arranged by senior researchers Karen Albertsen and Anne Helene Garde. A governing thought behind the seminar was to adopt a cross-disciplinary approach and to create a favourable atmosphere for discussion.

Professor Tage Søndergaard Kristensen, National Institute of Occupational Health, Denmark, undertook dual tasks as he was not only an invited speaker but also the chairman of the seminar. Prof. Kristensen started the seminar session with a presentation entitled: "Working time, demands at work and developments in fatigue, sleep and heart disease". After his presentation, he continued as a firm but engaging chairman.

Dr Nicole Jansen, Department of Epidemiology, Maastricht University, The Netherlands, was next in line and continued by giving a talk on the topic "Work-family Conflict and Fatigue: The role of Working Time Arrangements".

Professor Ulf Lundberg, Department of Psychology and Centre for Health Equity Studies (CHESS), Sweden, began the afternoon session by giving a presentation entitled "Stress and Workload: Health Promoting and Health Damaging Effects”.

Professor Torbjörn Åkerstedt, Institute of Psychosocial Medicine, Karolinska Institutet, Sweden, was last in line when he gave his talk about: "Health and long/irregular/flexible work hours".

Each presentation lasted 40 minutes and was followed by 25 minutes for discussion, facilitated by a panel of researchers from the NIOH in The Nordic Countries: Carina Bildt, Sweden; Karen Albertsen, Denmark, Kaisa Kauppinen, Finland and Kristinn Tómasson, Island.

Despite the many good questions from the debating panel and the audience the following summary will only refer to the presentations. 


\section{1. "Working time, demands at work and developments in fatigue, sleep and heart disease"}

\section{New trends in job demands}

Tage Søndergaard Kristensen outlined the main developments with regard to measurement of demands at work and as part of this, working hours. He emphasized that two dimensions of work demands should be separated: intensity (pace) and extensity (hours). The basic issue is the situation where there is a (miss) match between the amount of work and the time available to do it. For many years there has been a development towards shorter working hours in Europe; now these trends seem to be replaced by new trends: A marked intensification of work, longer working hours for many groups, irregular working hours, unclear and fuzzy working hours, and increasing working hours for women. In work without boundaries, the distinctions between working time and free time disappears, the distinction between workplace and home disappears and the personality of the employees becomes an area of interest for the company. When this development contributes to vanishing of traditional life forms, conflicts between work and family life escalates. In parallel with these trends, statistics show marked increases in symptoms of fatigue, sleep trouble and distress within the last decade, and resent research has documented significantly increased risk for Acute Myocardial Infarction for people working long hours and for people sleeping few hours. This complex of symptoms associated with sleeping problems and distress can be described by the concept "The New Fatigue", characterised by the simultaneous appearance of tiredness and sleeping problems. Long working hours, shift work, high work pace, high emotional demands, conflicts and bullying and mismatch between work and family demands can all contribute to the development of these symptoms; which appear in turn to be associated with cardiovascular disease.

\section{Demands at work and work-family conflicts}

A citation from a working mother characterised the essence of workfamily conflicts:” Every day I leave my job too early - only to discover, that I get home to my family too late". Studies from Great Britain have shown that parents, together with managers, is one of the groups suffering most from too little sleep. The consequences are numerous; sleep deprived persons become irritable and shout, argue with their partner, feel sleepy at work, make mistakes at work and experience are more often involved in car accidents of near-by-accidents. According to analyses in Danish material, it is single parents and couples with children below 6 years who suffer most from lack of energy to the family. There are high associations between the experience of lack of energy to the family and quantitative demands at work, and between work-family conflicts and decreased mental health and vitality. 
Tage Kristensen summarized his speech with the discouraging conclusion that the demands at work seem to be increasing are becoming more diffuse and fuzzy, fatigue and sleep deficit/problems as well as familywork-conflicts seem to increase; but nobody

seems to know what to do about it.

\section{2. "Work-family Conflict and Fatigue: The role of Working Time Arrangements"}

\section{Shift-workers with high levels of fatigue}

Nicole Jansen presented results from her own research about fatigue and work-family conflict in relation to different types of working hour systems. The Maastricht Cohort Study is a prospective cohort study with a heterogeneous population at baseline covering 12140 employees from 45 different companies \& organizations. The cohort was followed over 3-year with frequent questionnaire measurements ( 3 / year). She outlined the reciprocal effects between working time arrangements, work-family conflict and fatigue. Central to her theory was the concepts of "Need for recovery" and "prolonged fatigue". Need for recovery describes the short-term effects of a day of work and measured by items as: "Finding it hard to relax at the end of a working day" or "Often being too tired to start other activities after work". Prolonged fatigue describes a symptom picture with severe fatigue, reduced concentration, reduced motivation and reduced activity. Significantly more employees working in three and five shifts had a high need for recovery and prolonged fatigue compared with day workers. These employees were in turn more likely to leave shift work. Backward rotating shift had more deleterious effects that forward rotating shifts in addition. Nicole Jansen documented that shift work predicted increased risk of infections as common cold, flu-like illness and gastroenteritis.

Gender differences in work environmental predictors of work-family conflicts

Nicole Jansen defined work-family conflict as "a form of inter-role conflict in which the role pressures from the work and family domains are mutually incompatible in some respect. Word-family conflicts contain two main aspects: Perception of insufficient energy and insufficient time to successfully perform work and family roles. For example: frequently having to cancel family appointments because of overtime work or having little energy at work because of high demands at home”. Eleven percent of the men and 9 percent of the women in the sample were characterised as having work-family conflicts. The analyses revealed large gender differences in factors increasing or reducing the likelihood of workfamily conflicts. The likelihood was elevated for men with high psychological, physical or emotional job demands and for men experiencing 
conflicts with co-workers or supervisors. It was reduced for men having high decision latitude at work, or high social support from co-workers or supervisors. For women, only physical demands and long commuting time predicted work-family conflicts. Men with full responsibility for housekeeping and men, who cared for chronically ill family members at home had also higher likelihood of work-family conflict, while women who had dependent children at home had higher likelihood, and women who had domestic help had lower likelihood of work-family conflicts. Work-family conflicts were at the same time antecedents of outcomes as elevated need for recovery, prolonged fatigue, sickness absence, leaving shift work and changing work hours.

\section{Working time can be amended}

Nicole Jansen ended her speech by summarizing possible preventable measures with regard to working hours: limitation of overtime hours, compensation of overtime work, control over working hours, predictability of working hours, flexible working hours and ability to adjust working hours. She pointed out some specific national characteristics in the Netherlands with regard to child care facilities and policies in favour of parttime work as a means to combine work and family life adequately. This last point actualizes a need for cross-national studies.

\section{3. "Stress and Workload: Health Promoting and Health Damaging Effects"}

\section{Health consequences of stress}

Ulf Lundberg continued after lunch with informative statistics, outlining a steep increase in long-term sick leave among Swedish women (particularly) and men, due to musculoskeletal disorders, depression, burnout syndromes, chronic fatigue and sleeping problems. He outlined the physiological responses to acute and chronic stress. Where acute stress results in adequate and positive health effects as: improved immune function decreased pain sensitivity and improved memory function; sustained or chronic stress has exactly the opposite effects: impaired immune function, increased pain sensitivity and impaired memory function. He showed examples of excretion of epinephrine, nor epinephrine and cortisol in response to different work- and home settings. Results showed higher levels at work than at home, and higher levels among blue-collar workers. The health problems associated with elevated levels of catecholamine were described as: blood clotting, increasing the risk of atherosclerosis, hypertension, myocardial infarction and stroke. The health problems associated with elevated cortisol levels as: abdominal fat, elevated free fatty acids, impaired immune function, insulin resistance and cognitive impairment. He documented further associations between 
stress and common colds, stress and impaired wound healing and stress and development of AIDS among HIV-patients.

Why are women more sick but live longer than men?

Ulf Lundberg posed the question: "Why are women more sick but live longer than men?", and he gave some possible explanations: Men have poorer lifestyles than women with regard to smoking, alcohol and eating habits. Men exhibit more risky behaviour; they are exposed to more accidents and more risky work conditions. Men are more successful with their suicide attempts, and more men die of alcohol-related diseases. Up to the menopause, women are protected against cardiovascular diseases by estrogens. Why are women more sick than men, then? Different explanations can be found in biological differences and differences in jobs and work environment.

\section{Total workload for men and women}

Ulf Lundberg has studied the total workload of men and women measured as time spent per week on paid and unpaid work. In a study of 1000 men and 1000 women, all highly educated and in full-time employment and matched for occupation, age and family situation, he found the total weekly workload among women in all age-groups up to 50 , to be 5-8 hours higher than for men. He also found a much steeper association between number of children and weekly workload for women than for men. The total workload has increased for both men and women over the last 10 years, but the total difference between full-time employed male and female white-collar workers has not changed in this Swedish material. Hours of paid work have increased for both men and women. Household work has increased among men and decreased among women, while the largest increase observed in child care activities among women, leaving the question, why child care activities take up so much more time now than only ten years ago.

\section{Rest and recovery for men and women}

Ulf Lundberg also discussed whether women had fewer opportunities to rest and recover after work than men. He referred to the famous study by Frankenhaeuser and Lundberg from 1989 that documented increase in nor-epinephrine levels after end of work among women and decrease among men. The study was replicated in 1999 among male and female managers, and with the same results. He also documented that a high physiological stress level at work among women is associated with a high level in the evening at home, while a high level at work among men was unrelated to the home level. 


\section{Muscle tension}

Musculoskeletal problems are the most commonly reported work-related complains, and they are more prevalent among women than men. Lundberg illustrated how muscle tension is highly associated with stress, and how muscle tension is elevated in patients with pain both during work and during breaks. He concluded that 1) "the same low threshold motor-units seem to be active both during physical effort and during stress-induced muscle tension" and that 2) "Mental stress may keep low threshold motor units active in the absence of biomechanical demands, for example during breaks at work and after work and thus, prevent rest and repair of muscle fibres".

A key message was that it is important to obtain a balance between activity with mobilisation of energy (e.g. in terms of secretion of epinephrine, nor-epinephrine and cortisol) on the one hand, and on the other rest and recovery (e.g. in terms of secretion of growth hormones, estrogens and testosterone).

Lundberg ended his talk by emphasizing that "In modern society, lack of time for rest and recuperation seems more important for a poor health than intensive force or stress during work.”

\section{4“Health and long/irregular/flexible work hour”}

\section{Increase in sleeping problems}

Torbjörn Åkerstedt started by presenting data that identified Sweden and Finland as the two leading countries in Europe with regard to Jobimpaired sleeping problems. Denmark was as low as number 11 out of 15 countries. In the last five years, there has been a significant increase in sleeping problems in Sweden, especially in the youngest age groups. Women report more sleeping problems than men in all age groups. The primary reason for the increase in sleeping problems can be found in stress related to school or work. Sleepiness at work can have serious consequences, e.g. accidents. In addition, Åkerstedt showed documentation of how very short sleeping periods, or micro-sleep (lasting only a few seconds) among train drivers working during the night resulted in missed signals. On long drives, as many as $25 \%$ of the train drivers had episodes of micro-sleep.

It is not only a question of sleep or no sleep but also a question of quality of sleep. People suffering from burnout have e.g. a much more fragmentised sleep with more minor awakenings and fewer episodes of deep sleep. Stress can be understood as the anticipation of bad things. It is not what you have already done that is stressful, it is the coming tasks. Stress in the form of too high demands increases bedtime arousal both physiologically and psychologically which in turn leads to increased 
sleep fragmentation, resulting in more fatigue and sleepiness, making the demands even more difficult to fulfil.

It is important to distinguish at least four different forms of fatigue/sleepiness:

1) Sleepiness as a drive toward sleep 2) Physical fatigue 3) Mental fatigue, e.g. impaired memory function and 4) Emotional fatigue, e.g. lack of or reduced emotional reaction. Disturbed sleep follows conditions as depression and burnout and predicts myocardial infarction, diabetes and mortality. A range of different physiological consequences further follows disturbed sleep. The optimum duration of sleep is in general seven hours a day. Mortality is increased for those sleeping both more and less than seven hours.

\section{Irregular or flexible working hours}

Åkerstedt pointed out that irregular and flexible working hours should be distinguished. He introduced variability and flexibility based on work done in the SALTSA project. Variable working hours refer to working hours being variable from day to day, week to week or month to month. Flexibility means that the working hours can be influenced. He offered a draft definition of flexibility: Flexible Working Hours involve a continuous choice on behalf of employers, employees, or both, regarding the amount and temporal distribution of working hours". So flexibility can be seen from the employee or from the employer's point of view, and it is import to distinguish between the two. While individual flexibility is general in a positive thing, variability is bad. A fixed number of work hours that you can deviate from seem to be the optimal arrangement seen from the employee's point of view. Variability was positively associated with stress, fatigue, sleeping problems, allergies, anxiety, irritability, back pain, headache and pains in the stomach. Flexibility showed an inverse relationship, thus exhibited negative associations to all of the problems stated above. The most stressful situation is those, where variability is high and flexibility low. With regard to self-selected part-time work, there is no clear health data, but there are documented positive social effects. The same is true for trust hours, meaning that you are employed to do a specific task, but has no specified working time.

\section{Long working hours}

With regard to long work hours it is also crucial to be clear about definitions. Does it mean overtime in opposition to part-time work? Does it mean long shifts, long sequence of shifts or short rest between shifts? It is also crucial to be aware that overtime is associated with other factors such as being male, higher work demands, higher decision latitude and lower physical demands at work.

Åkerstedt made a brief state-of-the-art review over the research about long working hours and health. He summarized the findings from the 
review by van der Hulst (2003), who have found scientific documentation for associations between long hours, and mortality, cardiovascular disease, diabetes, disability retirement, subjective mental and physical health, fatigue, blood pressure and blood glucose. The directions of associations were by no means straightforward. The inconclusive result is probably due to the many problems that arises in field research where the possibilities for experimental control often are small or non-existent. Consequently it is almost impossible to control for all other relevant factors. A kerstedt documented in own data an increased risk of mortality among blue-collar workers working overtime, and a decreased risk of mortality among white-collar workers working overtime. He also documented that the degree of volunteering and pleasure associated with overtime was crucial for the effect of overtime on early retirement, with overtime being protective for those who liked it or had chosen it themselves. He further documented a heavily increased risk of mental fatigue among female supervisors working more than $55 \mathrm{~h} /$ week, and a more moderate increase among female supervisors working between 49 an 54 hours.

Where do we go from here?

Even if Åkerstedt presented results from a highly successful intervention study among physicians, where changes in working hours/week and rest periods had resulted in significant decrease in serious medical errors, in medication and in diagnosis (Lockley et al 2004), he concluded that much research is questionable, and that there is a great need for high quality studies. There are no clear health/mortality effects of long hours unless overtime is very high ( $>10 \mathrm{~h} /$ week). Results are often confounded from stress, voluntariness, influence over work hours and family situation. Variability seems to be bad for the health and good for the individual flexibility, but too little data is available. Anything that limits sleep yields fatigue (short daily breaks, long extension of work hours). 


\section{Reference List}

European Social Statistics. Labour force survey results 2002. (2003). Luxemburg: European commission.

Quality of life in Europe - First results of a new pan-European survey (2005). European Foundation for the Improvement of living and Working Conditions. Chance for balance - et fælles ansvar. Hovedrapport fra Familie- og arbejdslivskommissionen (2007). København: Familie- og Arbejdslivskommissionen. Ahlberg, J., Kononen, M., Rantala, M., Sarna, S., Lindholm, H., Nissinen, M. et al. (2003a). Self-reported stress among multiprofessional media personnel. Occup Med, 53, 403-405.

Ahlberg, K., Ahlberg, J., Kononen, M., Partinen, M., Lindholm, H., \& Savolainen, A. (2003b). Reported bruxism and stress experience in media personnel with or without irregular shift work. Acta Odontol Scand, 61, 315-318.

Åkerstedt, T. (2001). Arbetstider, hälsa ock säkerhet - sammenfatning av aktuell forskning (Rep. No. 299). Stocholm: Karolinska Institutet.

Åkerstedt, T. (2003). Shift work and disturbed sleep/wakefulness. Occup Med, 53, 89-94.

Åkerstedt, T., Kecklund, G., \& Johansson, S. E. (2004). Shift work and mortality. Chronobiol Int, 21, 1055-1061.

Åkerstedt, T., Knutsson, A., Westerholm, P., Theorell, T., Alfredsson, L., \& Kecklund, G. (2004). Mental fatigue, work and sleep. J Psychosom Res, 57, 427-433.

Åkerstedt, T., Olsson, B., Ingre, M., Holmgren, M., \& Kecklund, G. (2001). A 6-hour working day-effects on health and well-being. J Hum Ergol, 30, 197-202.

Ala-Mursula, L., Vahtera, J., Kouvonen, A., Vaananen, A., Linna, A., Pentti, J. et al. (2006). Long hours in paid and domestic work and subsequent sickness absence: does control over daily working hours matter? Occup Environ Med, 63, 608-616.

Ala-Mursula, L., Vahtera, J., Pentti, J., \& Kivimaki, M. (2004). Effect of employee worktime control on health: a prospective cohort study. Occup Environ Med, 61, 254-261.
Albertsen, K., Kristensen, T. S., \& Pejtersen, J. H. (2007). Lange og skæve arbejdstider - Kan øget indflydelse på arbejdstidens placering forbedre arbejde-privatlivsbalancen? Tidsskrift for arbejdsliv, 9, 61-80.

Allvin, M. (2001). Distansarbete - Ett instrument för frihet eller controll? (Rep. No. 10). Stockholm: Arbetslivsinstitutet.

Allvin, M., Aronsson, G., Hagström, T., Johansson, G., \& Lundberg, U. (2006). Gränslöst arbete - socialpsykologiska perspektiv på det nya arbetslivet. (1 ed.) Malmö: Liber.

Andersson, H. \& Jonsson, L. (2005). Utvärdering av användning av arbetstidsmodellen 3-3 på akutmottagningen och LAH (Rep. No. 34). Stockholm: Arbetslivsinstitutet.

Antonsdóttir, H. F., Rafnsdóttir, G. L., Sveinsdóttir, H., \& Gunnarsdóttir, H. K. (2006). Á vaktinni með sveigjanlegum stöðugleika. Rannsóknastofa í vinnuvernd. (Rep. No. 2006:1). Reykjavik: Ritröð Rannsóknastofu í vinnuvernd [Research Centre for Occupational Health and Working Life].

Anxo, D., Fagan, C., Smith, M., Letablier, M. T., \& Perraudin, C. (2007). Part-time work in European companies. Establishment survey on working time 2004-2005 Dublin: European foundation for the improvenment of living and working conditions.

Aronsson, G. (2005). Gränslöst arbete eller arbetets nya gränser? tvär/snitt humanistisk ock samhällsvetenskabelig forskning, 2, 2-5.

Artazcoz, L., Artieda, L., Borrell, C., Cortés, I., Benach, J., \& Garcia, V. (2004). Combining job and family demands and being healthy. What are the differences between men and women? European Journal of Public Health, 14, 48.

Askenazy, P. (2004). Shorter work time, hours flexibility amd labour force intencification. Eastern Economic Journal, 30, 603-614.

Baltes, B. B. \& Heydens-Gahir, H. A. (2003). Reduction of work-family conflict through the use of selection, optimization, and compensation behaviors. 
Journal of Applied Psychology, 88, 1005-1018.

Barnett, R. C. (1998). Toward a review and reconceptualization of the work/family literature. Genetic, Social, and General Psychology Monographs, 124, 125-182.

Barnett, R. C. \& Gareis, K. C. (2000). Reduced-hours employment - The relationship between difficulty of trade-offs and quality of life. Work and Occupations, 27, 168-187.

Barnett, R. C. \& Gareis, K. C. (2002). Full-time and reduced-hours work schedules and marital qualiy - A study of female physicans with young children. Work and Occupations, 29, 364-379.

Barnett, R. C. \& Shen, Y.-C. (1997). Gender, High- and low-schedulecontrol housework tasks, and psychological distress - A study of dual earner couples. Journal of Family Issues, 18, 403-428.

Barnett, R. C., Gareis, K. C., \& Brennan, R. (1999). Fit as a mediator of the relationship between work hours and burnout. Journal of Occupational Health Psychology, 4, 307-317.

Barton, J., Aldridge, J., \& Smith, P. (1998). The emotional impact of shift work on the children of shift workers. Scand J Work Environ Health, 24 Suppl 3, 146-150.

Batt, R. \& Valcour, P. M. (2003). Human resources practices as predictors of work-family outcomes and employee turnover. Industrial Relations, 42, 189220.

Beckers, D. G., van der, L. D., Smulders, P. G., Kompier, M. A., van Veldhoven, M. J., \& Van Yperen, N. W. (2004). Working overtime hours: relations with fatigue, work motivation, and the quality of work. J Occup Environ Med, 46, 1282-1289.

Berg, P., Kalleberg, A. L., \& Appelbaum, E. (2003). Balancing work and family: The role of high-commitment environments. Industrial Relations, 42, 168-188.

Bildt, C. \& Michelsen, H. (2002). Gender differences in the effects from working conditions on mental health: a 4-year follow-up. Int Arch Occup Environ Health, 75, 252-258.

Bildt, C. \& Nordh, M. W. (2004). Utvärdering av heltidsbeslutet $i$ Bollnäs kommun (Rep. No. 2004:24). Arbetslivsinstitutet.

Blair - Loy, M. (2003). Competing devotions: career and family among women executives. Cambridge, Mass.: Harvard University Press.

Bøggild, H., Burr, H., Tuchsen, F., \& Jeppesen, H. J. (2001). Work environment of Danish shift and day workers. Scand.J Work Environ Health, 27, 97-105.

Bøggild, H. \& Knutsson, A. (1999). Shift work, risk factors and cardiovascular disease. Scand $J$ Work Environ Health, 25, 85-99.

Brough, P., O’Driscoll, M. P., \& Kalliath, T. J. (2005). The ability of 'family friendly' organizational resources to predict work-family conflict and job and family satisfaction. Stress and Health, 21, 223-234.

Brynja, O. \& Bildt, C. (2005). Arbetstidsförkortning och hälsa- En literaturgenomgång av befintlig forskning (Rep. No. 11).

Carlson, D. S. \& Perrewé, P. L. (1999). The role of social support in the stresser-strain relationship: An examination of work-family conflict. Journal of Management, 25, 513-540.

Caruso, C. C., Hitckhock, E. M., Dick, R. B., Russo, J. M., \& Schmit, J. M. (2004). Overtime and extended work shifts: Recent findings on illnesses, injuries and health behaviors (Rep. No. 2004-143). U.S. Department of health and human services, center for disease control and prevention, National Institute for Safety and Health (NIOSH).

Clark, S. C. (2001). Work cultures and work/family balance. Journal of Vocational Behavior, 58, 348-365.

Clissold, G., Smith, P., Accutt, B., \& Di Milia, L. (2002). A study of female nurses combining partner and parent roles with working a continuous threeshift roster: the impact on sleep, fatigue and stress. Contemp Nurse, 12, 294-302.

Colligan, M. J. \& Rosa, R. R. (1990). Shiftwork effects on social and family life. Occupational Medicine, 5, 315-322.

Costa, G., Åkerstedt, T., Nachreiner, F., Frings-Dresen, M., Folkard, S., Gadbois, C. et al. (2003). SALTSA As time goes by - Flexible work hours, health and well-being (Rep. No. 8:2003). The 
National Institute for Working Life and The Swedish Trade Unions in Cooperation.

Costa, G., Sartori, S., \& Akerstedt, T. (2006). Influence of flexibility and variability of working hours on health and well-being. Chronobiol.Int, 23, $1125-1137$.

Crompton, R. \& Lyonette, C. (2006). Work-Life 'Balance' in Europe. ACTA SOCIOLOGICA, 49, 379-393.

Crump, C. E., Earp, J. A., Kozma, C. M., \& Hertz-Picciotto, I. (1996). Effect of organization-level variables on different employee participation in 10 federal worksite health promotion programs. Health Educ Q, 23, 204-223.

Duxbury, L., Higgins, C., \& Lee, C. (1994). Work-family conflict. A comparison by gender, family type, and preceived control. Journal of Family Issues, 15, 449-466.

Eiriksdóttir, Ó., Rafnsdóttir, G. L., Sveinsdóttir, H., \& Gunnarsdóttir, H. K. (2006). Á vaktinni. Viðhorf fólks og væentingar. (Rep. No. 1). Ritröð Rannsóknastofu í vinnuvernd.

Ekstedt, M., Kecklund, G., Dahlgren, A., \& Åkerstedt, T. (2001). Kan dubbelskift vara en acceptabel arbetstidslösning? Effekt på återhämtning, stress och hälsa. Stockholm: Institutet för psykosocial medicin (IPM), Töres Theorell.

Elloy, D. F. \& Smith, C. R. (2003). Patterns of stress, work-family conflict, role conflict, role ambiguity and overload among dual-career and single career couples: An Austrian study. Cross Cultural Management, 10, 55-66.

Enehaug, H., Sørensen, B. Aa., \& Helte, A. (2006). Sociale, arbeidsmiljø- og helsemessige effekter av komprimert arbeidstid. Evaluering av en 3-7, 4-7 turnusordning i private barnevernsinstitusjoner. Oslo: Arbeidsforskningsinstittutet.

Evans, J. A., Kunda, G., \& Barley, S. R. (2004). Beach time, bridge time, and billable hours: The temporal structure of technical contracting. Administrative Science Quarterly, 49, 1-38.

Ezoe, S. \& Morimoto, K. (1994). Behavioral lifestyle and mental health status of Japanese factory workers. Prev Med, 23, 98-105.

Fagan, C. (2003). Working-time preferences and work-life balance in EU some policy considerations for enhanc- ing the quality of life Dublin: European Foundation for the Improvement of Living and Working Conditions.

Fenwick, R. \& Tausig, M. (2001). Scheduling stress - Family end health outcomes of shift work and schedule control. American Behavioral Scientist, 44, 1179-1198.

Feveile, H., Jensen, C., \& Burr, H. (2002). Risk factors for neck-shoulder and wrist-hand symptoms in a 5-year follow-up study of 3,990 employees in Denmark. Int Arch Occup Environ Health, 75, 243-251.

Folkard, S. (2003). The impact of age and the flexibility of work hours on outcome measures. In SALTSA - As time goes by - Flexible work hours, health and well-being (pp. 110-126). The National Institute of Working Life and The Swedish Trade Unions in Co-operation.

Folkard, S., Lombardi, D. A., \& Tucker, P. T. (2005). Shiftwork: safety, sleepiness and sleep. Ind Health, 43, 20-23.

Forssell, J. \& Jonsson, L. (2005). Deltidsarbetslöshet ock deltidsarbete i Europa - Förklaringsmodeller ock statistik (Rep. No. 2005:30). Arbetslivsinstitutet.

Fox, M. L. \& Dwyer, D. J. (1999). An investigation of the effects of time and involvement in the relationship between stressors and work-family conflict. $J$ Occup Health Psychol, 4, 164-174.

Fridriksdóttir, H. (2004). Раð parf einhvern veginn að púsla pessu saman. Rannsókna á vinnustreitu og sampettingu fjölskyldulífs og atvinnu Reykjavík: Háskóli Íslands.: M.A. ritgerð í félagsfræði.

Fu, C. K. \& Shaffer, M. A. (2001). The tug of work and family - Direct and indirect domain-specific determinants of work-family conflict. Personnel Review, 30, 502-522.

Galambos, N. L. \& Walters, J. B. (1992). Work hours, schedule inflexibility, and stress in dual earner spouses. Canadian Journal of Behavioural Science, 24, 290-302.

Geurts, S. \& Demerouti, E. (2003). Work/non-work interface: A review of theories and findings. In M.J.Schabracq, J. A. Winnubst, \& C. L. Cooper (Eds.), The handbook of work and health psychology (pp. 279-312). John Wiley \& Sond Ltd. 
Geurts, S., Rutte, C., \& Peeters, M. (1999). Antecedents and consequences of work-home interference among medical residents. Soc Sci Med, 48, 1135-1148.

Geurts, S. A. \& Sonnentag, S. (2006). Recovery as an explanatory mechanism in the relation between acute stress reactions and chronic health impairment. Scand J Work Environ Health, 32, 482-492.

Grönlund, A. (2004). Flexibilitet eller friktion? Om inflytande över arbetstiden ock konflikten mellem arbete ock familj. Sociologisk Forskning, 1, 35-54.

Grönlund, A. (2007a). Employee control in the era of flexibility - a stress buffer or a stress amplifier? European Societies, 9, 409-428.

Grönlund, A. (2007b). More control, less conflict? Job demand-control, gender and work-family conflict. Gender, Work \& Organization, 14, 476.

Grosswald, B. (2004). The effect of shift work on family satisfaction. Families in Society: The Journal of Contemporary Social Services I, 85, 413-423.

Groth, S. \& Rosbjerg, R. (2006a). Selvledelse - medicin eller vira? In T.Dalsgaard (Ed.), Stress - et vilkår i det moderne arbejdsliv? (pp. 174-198). Jurist- og Økonomiforbundets Forlag.

Groth, S. \& Rosbjerg, R. (2006b). Stressens fysiologiske og psykologiske konsekvenser. In T.Dalsgaard (Ed.), Stress - et vilkår i det moderne arbejdsliv? (pp. 9-25). Jurist- og Økonomiforbundets Forlag.

Grzywacz, J. G. \& Marks, N. F. (2000). Reconceptualizing the work-family interface: an ecological perspective on the correlates of positive and negative spillover between work and family. $J$ Occup Health Psychol, 5, 111-126.

Gunnarsdóttir, H. K., Rafnsdóttir, G. L., Helgadóttir, B., \& Tomasson, K. (2003). Psychosocial risk factors for musculoskeletal disorders among personnel in geriatric care. American Journal of Industrial Medicine, 44, 679-684.

Hanson, M. (2004). Det flexibla arbetes villkor - Om självförvaltandets kompetens. Stockholm: Pedagogiska Institutionen Stockholms Universitet.

Harada, H., Suwazono, Y., Sakata, K., Okubo, Y., Oishi, M., Uetani, M. et al.
(2005). Three-shift system increases job-related stress in Japanese workers. $J$ Occup Health, 47, 397-404.

Härmä, M. (2006). Workhours in relation to work stress, recovery and health. Scand J Work Environ Health, 32, 502-514.

Härmä, M., Hakala, T., Kandolin, I., Sallinen, M., Virkkala, J., Bonnefond, A. et al. (2006). A controlled intervention study on the effects of a vary rapidly forward rotating shift system on sleep-wakefulness and well-being among young and elderly shift workers. International Journal of Psychophysiology, 59, 70-79.

Harrington, J. M. (1994). Shift work and health - a critical review of the literature on working hours. Ann Acad Med Singapore., 23, 699-705.

Hartig, T., Kylin, C., \& Johansson, G. (2007). The telework tradeoff: Stress Mitigation vs. constrained restoration. Applied Psychology: An International Review, 56, 231-253.

Hattery, A. J. (2001). Tag-Team parenting: Costs and benefits of utilizing nonoverlapping shift work in families with small children. Families in Society: The Journal of Contemporary Social Services, 82, 419-427.

Heymann, S. J. \& Earle, A. (2001). The impact of parental working conditions on school-age children: the case of evening work. Community, Work \& Family, 4, 2001.

Higgins, C., Duxbury, L., \& Johnson, K. L. (2000). Part-time work for women: Does i really help balance work and family? Human Resource Management, 39, 17-32.

Hill, E. J., Hawkins, A. J., Ferris, M., \& Weitzman, M. (2001). Finding an extra day a week: The positive influence of perceived job flexibility on work and family life balance. Family Relations, 50, 49-58.

Hill, E. J., Märtinson, V., \& Ferris, M. (2004). New-concept part-time employment as a work-family adaptive strategy for women professionals with small children. Family Relations, 53, 282-292.

Hill, E. J., Miller, B. C., Weiner, S. P., \& Colihan, J. (1998). Influences of the virtual office on aspects of work and work/life balance. Personnel Psychology, 51, 667-683. 
Hochschild, A. (1989). The second shift: Working Parents and the revolution at home. New York: Viking Penguin.

Hochschild, A. (1995). The culture of politics: Traditional, postmodern, cold modern and warm modern ideals of care. Social Politics: International studies of gender, state and society., 2, 331-346.

Hochschild, A. (1997). The Time Bind. When Work becomes Home and Home becomes Work. New York: Metropolitan Books.

Højrup, T. (1989). Det glemte folk. København: Institut for Europæisk Folkelivsforskning. Statens Byggeforskningsinstitut.

Hornberger, S. \& Knauth, P. (1995). Effects of various types of change in shift schedules: a controlled longitudinal study. Work \& Stress, 9, 124-133.

Hughes, D. L. \& Galinsky, E. (1994). Gender, job and family conditions, and phychological symptoms. Psychology of Women Quaterly, 18, 251-270.

Hvid, H. (2006). Arbejde og bæredygtigthed. København: Frydenlund.

Jacobs, J. A. \& Gerson, K. (2001). Overworked individuals or overworked families. Work and Occupations, 28, 40-63.

Jacobs, J. A. \& Gerson, K. (2004). The Time Divide. Harvard University Press.

Jaffe, M. P., Smolensky, M. H., \& Wun, C. C. (1996). Sleep quality and physical and social well-being in North American petrochemical shift workers. South.Med J, 89, 305-312.

Jansen, N. W. H. (2003). Working time arrangements, work-family conflict, and fatique. University Maastricht.

Jansen, N. W. H., Kant, I., Kristensen, T. S., \& Nijhuis, F. J. (2003). Antecedents and consequences of work-family conflict: A prospective cohort study. Journal of Occupational and Environmental Medicine, 45, 479-491.

Jansen, N. W. H., Kant, I. J., Nijhuis, F. J. N., Swaen, G. M. H., \& Kristensen, T. S. (2004). Impact of worktime arrangements on work-home interference among Dutch employees. Scand J Work Environ Health, 30, 139-148.

Janssen, D. \& Nachreiner, F. (2004). Health and psychosocial effects of flexible working hours. Rev Saude Publica, 38 Suppl, 11-18.
Kandolin, I. (1993). Burnout of female and male nurses in shiftwork. Ergonomics., 36, 141-147.

Kandolin, I., Härmä, M., \& Toivanen, M. (2001). Flexible working hours and well-being in Finland. Journal of Human Ergology, 30, 35-40.

Karasek, R. \& Theorell, T. (1990). Healthy work. Stress, productivity, and the reconstruction of working life. Basic Books.

Kauffeld, S., Jonas, E., \& Frey, D. (2004). Effects of a flexiblework-time design on employee-and companyrelated aims. European Journal of Work and Organizational Psychology, 13, 79-100.

Kauppinen, K., Kumpulainen, R., \& Houtman, I. (2003). Gender issues in safety and health at work. Luxembourg: European Agency for Safety and Health at Work.

Kauppinen, K. and Toivanen, M. (2006). Balancing work, family and leisure time - a life-long process. Työtetveiset.Newsletter of the Finnish Institute of Occupational Health, 6-7.

Kecklund, G., Dahlgren, A., \& Åkerstedt, T. (2002). Undersökning av förtroendearbetstid: Vad betyder inflytende över arbetstiden för stress, hälse ock välmående (Rep. No. 305). Institutet för Psykosocial Medicin (IPM), Avdelingen for Stressforskning, Karolinska Institutet, Stockholm, Sverige.

Kinnunen, U. \& Mauno, S. (1998). Antecedents and outcomes of work-family conflict among employed women and men in Finland. Human Relations, 51, 157-177.

Knutsson, A. (2003). Health disorders of shift workers. Occupational Medicine, 53, 103-108.

Knutsson, A. (2004). Methodological aspects of shift-work research. Chronobiol Int, 21, 1037-1047.

Kompier, M. \& Kristensen, T. S. (2001). Organizational work stress interventions in a theoretical, methodological and practical context. In J.Dunham (Ed.), (pp. 164-190). London and Philadelphia: Whurr Publishers.

Kompier, M. A. J., Geurts, S. A. E., Gruendemann, R. W. M., Vink, P., \& Smulders, P. G. W. (1998). Cases in stress prevention: The success of a participative and stepwise approach. Stress Medicine, 14, 155-168. 
Kring, C. (2005). Arbejdsliv og familieliv - Get a balance. Institut for Produktion of Ledelse. Danmarks Tekniske Universitet.

Kristensen, T. S., Smith-Hansen, L., \& Jansen, N. (2005). A systematic approach to the assessment of the psychological work environment and the associations with family work conflict. In Bianchi S.M., Casper L.M, \& King R.B. (Eds.), Work, family, health and well-being. (pp. 433-450). Mahwah, NJ: Lawrence Erlbaum Associates.

Kummerling, A. \& Lehndorff, S. (2007). Extented and unusual working hours in European companies. Establishment survey on working time 2004-2005. Dublin: European foundation for the improvement of living and working conditions.

Lazarus, R. S. (1991). Emotion \& Adaptation. New York: Oxford University Press.

Lundberg, U. \& Frankenhaeuser, M. (1999). Stress and workload of men and women in high-ranking positions. J Occup Health Psychol, 4, 142-151.

Lundberg, U., Mårdberg, B., \& Frankenhaeuser, M. (1994). The total workload of male and female white collar workers as related to age, occupational level, and number of children. Scandinavian Journal of Psychology, 35, 315-327.

Major, V. S., Klein, K. J., \& Ehrhart, M. G. (2002). Work time, work interference with family, and psychological distress. Journal of Applied Psychology, 87, 427-436.

Marchand, A., Demers, A., \& Durand, P. (2005). Does work really cause distress? The contribution of occupational structure and work organization to the experience of psychological distress. Soc Sci Med, 61, 1-14.

Matthews, S. \& Power, C. (2002). Socioeconomic gradients in psychological distress: a focus on women, social roles and work-home characteristics. Soc Sci Med, 54, 799-810.

Melkas, T. (2005). Gender Equality Barometer 2004. Helsinki: Ministry of social affairs and heath.

Menaghan, E. G. \& Parcel, T. L. (1991). Determining children's home environments: The impact of maternal characteristics and current occupational and family conditions. Journal of Marriage and the Family, 53, 417-431.
Moen, P. \& Yu, Y. (2000). Effective work/life strategies: Working couples, work conditions, gender, and life quality. Social Problems, 47, 291-326.

Mozurkewich, E. L., Luke, B., Avni, M., \& Wolf, F. M. (2000). Working conditions and adverse pregnancy outcome: a meta-analysis. Obstet Gynecol, 95, 623-635.

Mulinari, P. (2004). Flexibilitetens gänser- berättelser från golvet om ofrivillig deltid, solidaritet och flexibili-

tet.Working paper från HELA-projektet 2004:4 (Rep. No. 2004:12). Stockholm: Arbetslivsinstitutet.

Myrdal, A. \& Klein, V. (1957). Kvinnans två roller. Stockholm: Tidens Förlag.

Neményi, E., Herczog, M., Kravalik, Z., Jones, M., Bekarian, L., \& Huggins, R. (2006). Employment in social care in Europe European Foundation for the Improvement of Living and Working Conditions.

Ng, T. W. H., Sorensen, K. L., \& Feldman, D. C. (2007). Dimensions, antecedents, and consequences of workaholism: a conceptual integration and extension. Journal of Organizational Behavior, 28, 111-136.

Nicol, A. M. \& Botterill, J. S. (2004). On-call work and health: a review. Environ Health, 3, 15.

Olsen, O., Albertsen, K., Nielsen, M. L., Poulsen, K. B., \& Brunnberg, H.Olsen, O., Albertsen, K., Nielsen, M. L., Poulsen, K. B., \& Brunnberg, H. (2007). Workplace restructurings in intervention studies - a challenge for design and analyses.

Ref Type: Unpublished Work

Olsson, B., Åkerstedt, T., Ingre, M., Holmgren, M., \& Kecklund, G. (1999). Kortare arbetsdag, hälsa ock välbefinnande (Rep. No. 281). Stockholm: Statens Institut för Psykosocial Miljömedicin.

Orth-Gomer, K. (1983). Intervention on coronary risk factors by adapting a shift work schedule to biologic rhythmicity. Psychosomatic Medicine, 45, 407-415.

Parcel, T. L. \& Menaghan, E. G. (1990). Maternal working conditions and children's verbal facility: Studying the intergenerational transmission of inequality from mothers to young children. Social Psychology Quarterly, 53, 132-147. 
Parcel, T. L. \& Menaghan, E. G. (1993). Family social capital and children's behavior problems. Social Phychology Quarterly, 56, 120-135.

Parent-Thirion, A., Macías, E. F., Hurley, J., \& Vermeylen, G. (2007). Forth European working conditions survey. Dublin: European foundation for the improvement of living and working conditions.

Perrons, D. (2003). The new economy and the work-life balance: Conceptual explorations and a case study of new media. Gender Work and Organization, 10, 65-93.

Piekkola, H. \& Ruuskanen, O.-P. (2006). Work and time use across life cycle Mothers and agening workers (Rep. No. 73). Ministry of Social Affairs and Health, Finland.

Portela, L. F., Rotenberg, L., \& Waissmann, W. (2004). Self-reported health and sleep complaints among nursing personnel working under $12 \mathrm{~h}$ night and day shifts. Chronobiol.Int, 21, 859-870.

Presser, H. B. (2000). Nonstandard work schedules and marital instability. Journal of Marriage and the Family, 62, 93-110.

Prunier-Poulmarie, S. \& Gatbois, C. (2001). The French 35-hour workweek: A wide-ranging social change. Journal of Human Ergology, 30, 41-46.

Pryce, J., Albertsen, K., \& Nielsen, K. M. (2006). Evaluation of an open-rota system in a Danish psychiatric hospital: a mechanism for improving job satisfaction and work-life balance. $J$ Nurs Manag, 14, 282-288.

Rasmussen, P. (2005). Når arbejdet tager magten. København: Reitzels Forlag.

Ray, R. \& Schmitt, J. (2007). No-vacation nation Washington D.C.: center for Economic and Policy research.

Riedmann, A., Bielenski, H., Szczurowska, T., \& Wagner, A. (2006). Working time and work-life balance in European companies. Establishment survey on working time 2004-2005 European Foundation for the Improvement of living and Working Conditions. Rones, A. \& Matthiesen, S. B. (2006). I klem eller balanse. Om arbeid, stress og familieliv. Bergen: Fagbokforlaget. Sallinen, M., Kinnunen, U., \& Ronka, A. (2004). Adolescents' experiences of parental employment and parenting: connections to adolescents’ well-being. J Adolesc., 27, 221-237.

Schmidt, L., Millard, J., \& Nielsen, J. (2003). Report on SUSTEL fieldwork Linking theoretical framework, empirical findings and sustainability (Rep. No. 11). Danish Techonological Institute - Centre for Competence and IT/buisness analysis.

Semmer, N. K. (2006). Job stress interventions and the organization of work. Scand J Work Environ Health, 32, 515527.

Shields, M. (1999). Long working hours and health. Health Rep, 11, 33-48.

Shields, M. (2002). Shift work and health. Health Rep, 13, 11-33.

Skipper, J. K., Jr., Jung, F. D., \& Coffey, L. C. (1990). Nurses and shiftwork: effects on physical health and mental depression. J Adv Nurs, 15, 835-842.

Smith, L. \& Folkard, S. (1993). The perceptions and feelings of shiftworkers' partners. Ergonomics, 36, 299-305.

Smith, L., Folkard, S., Tucker, P., \& Macdonald, I. (1998). Work shift duration: a review comparing eight hour and 12 hour shift systems. Occup Environ Med, 55, 217-229.

Smith, P. A., Wright, B. M., Mackey, R. W., Milsop, H. W., \& Yates, S. C. (1998). Change from slowly rotating 8hour shifts to rapidly rotating 8-hour and 12-hour shifts using participative shift roster design. Scand J Work Environ Health, 24 Suppl 3, 55-61.

Spector, P. E., Cooper, C. L., Poelmans, S., Allen, T. D., O’Driscoll, M., Sanches, J. I. et al. (2004). A cross-national comparative study of work-family stressors, working hours, and wellbeing: China and Latin America versus the Anglo world. Personnel Psychology, 57, 119-142.

Strazdins, L., Korda, R. J., Lim, L. L., Broom, D. H., \& D'Souza, R. M. (2004). Around-the-clock: parent work schedules and children's well-being in a 24-h economy. Soc Sci Med, 59, 1517-1527.

Tausig, M. \& Fenwick, R. (2001). Unbinding time: Alternate work schedules and work-life balance. Journal of Family and Economical Issues, 22, 101-119.

Theorell, E. T., Kristensen, T. S., Kornitzer, M., Marmot, M., Orth-Gomér, K., \& Steptoe, A. (2006). Stress and 
cardiovascular disease The European Heart Network.

Thomas, L. T. \& Ganster, D. C. (1995). Impact of family-supportive work variables on work-family conflict and strain: A control perspective. Journal of Applied Psychology, 80, 6-15.

Tucker, P. (2006). Compressed working weeks (Rep. No. 12). Geneva: International Labour Office.

Tynell, J. (2001). Da medarbejderne blev en ressource. Roskilde Universitetscenter.

Tynell, J. (2002). „Det er mig egen skyld“ - nyliberale styringsrationaler inden for Human Resource Management. Tidsskrift for arbejdsliv, 4, 7-24.

Väänänen, A., Kevin, M. V., Ala-

Mursula, L., Pentti, J., Kivimäki, M., \& Vahtera, J. (2004). The double burden of and negative spillover between paid and domestic work: associations with health among men and women. Women Health, 40, 1-18.

van Amelsvoort, L. G., Jansen, N. W. H., Swaen, G. M., van den Brandt, P. A., \& Kant, I. (2004). Direction of rotation among three-shift workers in relation to psychological health and work-family conflict. Scandinavian Journal of Work Environment and Health, 30, 149-156. van der Hulst, M. (2003). Long work hours and health. Scandinavian Journal of Work, Environment \& Health, 29, 171-188.

van der Hulst, M. \& Geurts, S. (2001). Associations between overtime and psychological health in high and low reward jobs. Work \& Stress, 15, 227-240.

van Rijswijk, K., Bekker, M. H., Rutte, C. G., \& Croon, M. A. (2004). The relationships among part-time work, workfamily interference, and well-being. $J$ Occup Health Psychol, 9, 286-295.

Veierstedt, B. \& Boix, F. (2004). Arbeidsforhold av betydning for helse. Oslo: Statens Arbeidsmiljøinstitutt (STAMI).

Voydanoff, P. (2004). The effect of work demands and ressources on work-tofamily conflict and facilitation. Journal of Marriage and Family, 66, 398-412.

White, L. \& Keith, B. (1990). The effect of shift work on the quality and stability of marital relations. Journal of Marriage and the Family, 52, 453-462. 


\section{Kort sammendrag}

\section{Baggrund:}

Organiseringen af vores arbejdsliv har ændret sig radikalt i løbet af de seneste årtier. Den globale 24-timers økonomi har i væsentlig grad påvirket de måder arbejdslivet er organiseret på. De nye organisationsformer har bl.a. betydet mere fleksible og mere varierende arbejdstider.

Formålet med denne rapport er 1) at sammenfatte den internationale, videnskabelige viden med hensyn til sociale konsekvenser af lange og uregelmæssige arbejdstider og ansattes indflydelse på arbejdstiden og 2) at beskrive konteksten i de forskellige Nordiske lande med hensyn til arbejdsmarked, organisering af arbejdstiden og velbefindende, samt at give nogle eksempler på Nordiske forskningsprojekter med fokus på sociale konsekvenser af organiseringen af arbejdstiden.

\section{Metode:}

Litteratur med fokus på sociale konsekvenser af arbejdstidens organisering på velbefindende, stress og arbejde-privatlivsbalance blev søgt i de store databaser, som PSYC-info og Pub Med, og blev suppleret med øvrig relevant litteratur. Resultater fra mere end 85 undersøgelser blev inkluderet i litteraturgennemgangen. Tilgængelig EU statistik blev tillige anvendt ved beskrivelsen af den Nordiske kontekst.

\section{Resultater:}

Sammenlignet med gennemsnittet i Europa, er der i de Nordiske lande en høj beskæftigelsesrate for kvinder, et moderat antal arbejdstimer, høj arbejdsintensitet og større indflydelse på arbejdstempo og skemalægning. Der er også flere ansatte, som oplever stress, søvnproblemer og irritation, men samtidig er der flere som er tilfredse med balance mellem arbejde og privatliv.

Resultaterne fra litteraturgennemgangen viste stærk evidens for, at lange arbejdstider er associeret med dårlig balance mellem arbejde og privatliv og med lavt psykisk velbefindende for kvinder. I populationer af mænd var resultaterne mindre entydige, mens det i populationen af blandet køn var tydeligt, at overarbejde var associeret med dårlig arbejde-privatlivsbalance. Der var dog ikke evidens for at overarbejde som sådan var associeret med dårligt psykisk velbefindende i de blandede populationer.

Der var stærk evidens for, at forskellige former for uregelmæssige arbejdstider og arbejde på skæve tidspunkter havde en negativ indflydelse på balancen mellem arbejde og privatliv, og nogen evidens for, at det havde en negativ indflydelse på børnenes trivsel og på den ægteskabelige 
tilfredshed. Ansattes indflydelse på egen arbejdstid var ret konsistent associeret med bedre arbejde-privatlivs balance og bedre psykisk velbefindende.

Selvom der blev fundet relativt få kontrollerede interventionsundersøgelser på området, viste de, der var, positive resultater. Interventioner som omfattede reduceret timetal med lønkompensation, komprimerede arbejdsuger, hurtigt roterende skift og øget indflydelse på skemalægning viste alle gavnlige effekter på det sociale liv.

Som en del af den nye organisering af arbejdslivet, er øget indflydelse på arbejdstiden, on-line hjemmearbejde og indflydelse på indhold og udførelse af arbejdet blevet anset for positive faktorer i forhold til stress, trivsel og balance mellem arbejde og privatliv. Resultaterne fra undersøgelserne illustrerer imidlertid også, at fleksibiliteten ofte var associeret med mere ekstensive og mere uforudsigelige krav, med mindre sikkerhed i ansættelsen og med længere arbejdstider; alt sammen forhold som kan have en negativ indflydelse på familiens trivsel.

\section{Konklusion:}

De sociale konsekvenser af lange og uregelmæssige arbejdstider, deltidsarbejde og indflydelse på egen arbejdstid er relativt veldokumenteret i den videnskabelige litteratur. Der mangler imidlertid flere gode interventionsundersøgelser og undersøgelser, som fokuserer på de sociale konsekvenser af lange og uregelmæssige arbejdstider med hensyn til børns trivsel og den ægteskabelige tilfredshed og stabilitet. 


\section{Short summary}

\section{Background:}

The organization of our working life has undergone radical changes within the last few decades. The global 24-hour-economy has significantly influenced the way working life has been organized. The new forms of organization have made a pressure toward more flexible and more variable working time arrangements.

Aim:

The purposes of the report is 1) to summarize the international scientific knowledge with regard to social consequences of long and irregular working hours and employee influence over working hours and 2) to describe the context of the labor market in the different Nordic countries and to describe and give examples of Nordic research projects focusing on the social consequences of the organization of working hours.

\section{Method:}

Literature focusing on the social consequences of the organization of working hours on psychological well-being, stress and work-life balance was searched in large databases such as PSYC-info and Pub Med, and was supplemented with other relevant literature. Results from more than 85 studies were included in the review. Available EU statistics were also utilized in the description of the Nordic countries.

\section{Results:}

Compared to the European average, the Nordic countries have high employment rates for women, an average number of working hours, high intensity at work, and more influence on speed and schedule. However, more people experience stress, sleeping problems and irritability, but, at the same time, more people enjoy a better work-life balance.

The results from the literature review strongly supported that a greater number of working hours were associated with a lower level of work-life balance and with decreased psychological well-being among women. In male samples, the results were less conclusive, while in gender mixed samples it was strongly supported that overtime work was associated with lower levels of work-life balance. However, there was no evidence to show that overtime work as such was associated with reduced well-being in the gender mixed samples.

There was strong evidence that different kinds of non-standard working hours had a negative influence on work-life balance, and some evi- 
dence that it had a negative influence on children's well-being and on marital satisfaction. Employee control over work schedule was rather consistently associated with better work-life balance and with improved psychological well-being.

Although there were relatively few controlled intervention studies in the field, those that were found, gave promising results. Interventions that included reduced hours with wage compensation, compressed working weeks, rapidly rotating shifts and increased influence on work schedules all showed positive effects on social life indicators.

As part of the new organisation of working life, control over working time, tele-working and influence over content and performance of job were considered to be positive with regard to well-being, stress and worklife balance. However, the results from the studies also illustrated that the flexibility was often associated with more extensive and more unpredictable demands, with less security and longer working hours, which may have negative effects on family well-being.

\section{Conclusion:}

The social consequences of long and irregular working hours, part time work and influence over working time schedule are relatively well documented in scientific literature. There is, however, a lack of intervention studies and studies focusing on the social consequences of long and nonstandard working hours regarding children's development and well-being as well as marital satisfaction.

Insert Word files with tables in landscape orientation in A4 format 
Appendix Table 1+2 
Table 1 Studies of working hour arrangements, work-life balance, stress and wellbeing

\begin{tabular}{|c|c|c|c|c|c|c|c|}
\hline Reference & Country & $\begin{array}{l}\text { Purpose, design and } \\
\text { statistics }\end{array}$ & Sample & Outcome measures & Other measures & $\begin{array}{l}\text { Measures of working } \\
\text { time arrangements }\end{array}$ & Findings \\
\hline $\begin{array}{l}\text { Ahlberg et al. } \\
\text { (2003a) and } \\
\text { Ahlberg et al. } \\
\text { (2003b) }\end{array}$ & Finland & $\begin{array}{l}\text { Explored whether } \\
\text { irregular shift work } \\
\text { etc. was associ- } \\
\text { ated with bruxism } \\
\text { and stress } \\
\text { Cross- sectional } \\
\text { analyses }\end{array}$ & $\begin{array}{l}750 \text { employees at the } \\
\text { Finnish } \\
\text { Broadcasting Com- } \\
\text { pany with irregular } \\
\text { shift work) and } 750 \\
\text { randomly selected } \\
\text { controls with regular } \\
\text { 8-hour daytime work }\end{array}$ & $\begin{array}{l}\text { Self-reported bruxism } \\
\text { (frequency of tooth grinding) } \\
\text { Experienced stress }\end{array}$ & $\begin{array}{l}\text { Weekly working hours } \\
\text { Age } \\
\text { Gender } \\
\text { Health-care use } \\
\text { Dissatisfaction with } \\
\text { current work shift } \\
\text { schedule }\end{array}$ & Irregular shift work & $\begin{array}{l}\text { Those with irregular shifts were more often dissatisfied with } \\
\text { their } \\
\text { - work shift schedule. Irregular shift work was signifi- } \\
\text { - cantly associated with more frequent } \\
\text { stress, but not with self-reported bruxism. Workers } \\
\text { dissatisfied } \\
\text { - with their current schedule reported both bruxism and } \\
\text { stress more often than those who felt satisfied. }\end{array}$ \\
\hline $\begin{array}{l}\text { Ala-Mursula } \\
\text { et al. (2004) }\end{array}$ & Finland & $\begin{array}{l}\text { Investigated the } \\
\text { health effects of } \\
\text { employee work } \\
\text { time control } \\
\text { Prospective cohort } \\
\text { study linking } \\
\text { questionnaire data } \\
\text { from } 1997 \text { and } \\
2000 \text { with sickness } \\
\text { absence records } \\
1997 \text { and } 2000\end{array}$ & $\begin{array}{l}4218 \text { permanent full } \\
\text { time municipal em- } \\
\text { ployees, } 903 \text { men and } \\
3315 \text { women) }\end{array}$ & $\begin{array}{l}\text { Psychological distress (12 } \\
\text { items of GHQ) } \\
\text { Self-rated health (single } \\
\text { item) } \\
\text { Sickness absences (medi- } \\
\text { cally certified ( }>3 \text { days) }\end{array}$ & $\begin{array}{l}\text { Smoking } \\
\text { Alcohol consumption } \\
\text { BMI } \\
\text { Sedentary lifestyle } \\
\text { Occupational status } \\
\text { Marital status } \\
\text { Dependent children }\end{array}$ & $\begin{array}{l}\text { Work time control } \\
\text { ( } 6 \text { items): control } \\
\text { over beginning and } \\
\text { end of day, breaks, } \\
\text { scheduling of } \\
\text { shifts, vacation, } \\
\text { unpaid leave }\end{array}$ & $\begin{array}{l}\text { Women: } \\
\text { - Low level of work time control prospectively related to } \\
\text { higher odds for psychological distress, poor self-rated } \\
\text { health and medically certified sickness absence. The } \\
\text { health effects were most evident among women with } \\
\text { families. } \\
\text { Men: } \\
\text { - Low level of work time control predicted sickness } \\
\text { absences among those with dependent children and } \\
\text { those with manual occupations. It was not associated } \\
\text { with self-rated health or distress. }\end{array}$ \\
\hline $\begin{array}{l}\text { Albertsen et } \\
\text { al. (2007) }\end{array}$ & Denmark & $\begin{array}{l}\text { Explore the effect } \\
\text { of long and non- } \\
\text { standard hours and } \\
\text { influence over } \\
\text { working hours on } \\
\text { work-life balance } \\
\text { Cross-sectional } \\
\text { analyses using } \\
\text { multiple regression }\end{array}$ & $\begin{array}{l}3517 \text { employees from } \\
\text { a representative } \\
\text { sample }\end{array}$ & WFC (5 items) & $\begin{array}{l}\text { Type of family } \\
\text { Work without bounda- } \\
\text { ries } \\
\text { Quantitative demands } \\
\text { Influence } \\
\text { Role conflicts } \\
\text { Social support from } \\
\text { management } \\
\text { Social support form } \\
\text { colleagues } \\
\text { Trust } \\
\text { Justice }\end{array}$ & $\begin{array}{l}\text { Working hours } \\
\text { Irregular hours } \\
\text { Influence on } \\
\text { working hours }\end{array}$ & $\begin{array}{l}\text { Longer working hours were associated with more conflicts. } \\
\text { Part-time work with fewer conflicts. Work at non-standard } \\
\text { hours was associated with more conflicts and influence on } \\
\text { working hours was associated with fewer conflicts. } \\
\text { Influence did not moderate the effects of long and non- } \\
\text { standard hours on WFC. } \\
\text { After control for working hours, women experienced more } \\
\text { conflicts than men. }\end{array}$ \\
\hline Allvin (2001) & Sweden & $\begin{array}{l}\text { To explore how } \\
\text { telework was } \\
\text { implemented and } \\
\text { how it influences } \\
\text { work performance } \\
\text { and relation to } \\
\text { organisation } \\
\text { Analyses of or- } \\
\text { ganisations and } \\
\text { questionnaire }\end{array}$ & $\begin{array}{l}107 \text { highly skilled } \\
\text { managers and profes- } \\
\text { sional employees at } \\
\text { the Swedish energy } \\
\text { department (app. } \\
55 \% \text { women) }\end{array}$ & - & - & $\begin{array}{l}\text { Due to a distant } \\
\text { move of the com- } \\
\text { pany, employees } \\
\text { were offered a } \\
\text { possibility for } \\
\text { telework } 3 \text { days a } \\
\text { week via IT and } \\
\text { telecommunication } \\
\text { plus compensation } \\
\text { for commuting } \\
\text { costs and commut- } \\
\text { ing time. }\end{array}$ & $\begin{array}{l}\text { Officers in charge: } \\
\text { - App. } 70 \% \text { experienced that their work was equally well } \\
\text { conducted from home as from office, and equally well } \\
\text { in or outside office time. } \\
\text { Managers: } \\
\text { - App. } 65 \% \text { experienced that their work was best per- } \\
\quad \text { formed from the office and within office time. } \\
\text { All: No experience of change in quality of own work, social } \\
\text { relations and loyalty to organisation. Experience of de- } \\
\text { creased effectivity for the department as such. }\end{array}$ \\
\hline
\end{tabular}




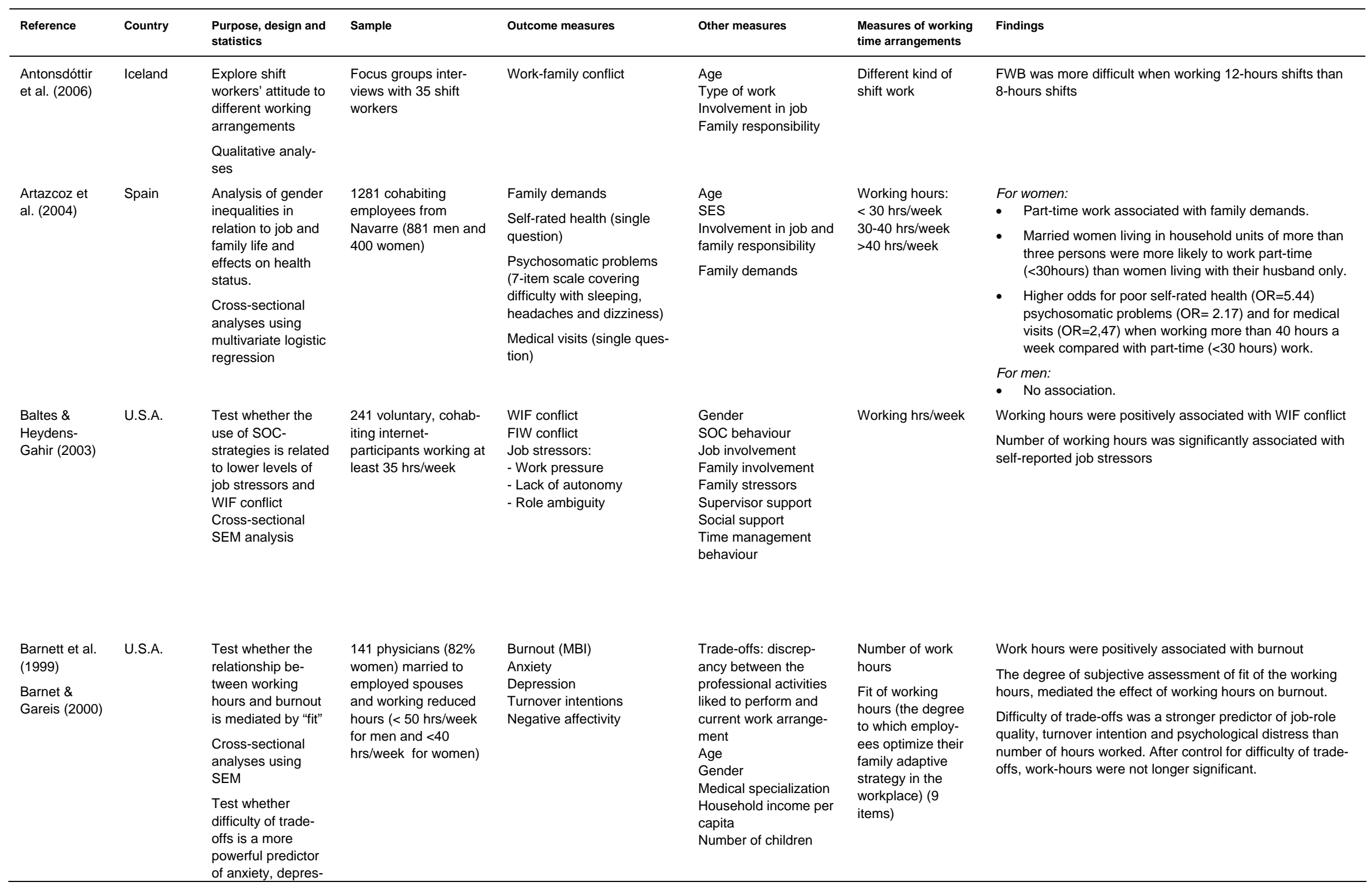




\begin{tabular}{|c|c|c|c|c|c|c|c|}
\hline Reference & Country & $\begin{array}{l}\text { Purpose, design and } \\
\text { statistics }\end{array}$ & Sample & Outcome measures & Other measures & $\begin{array}{l}\text { Measures of working } \\
\text { time arrangements }\end{array}$ & Findings \\
\hline & & $\begin{array}{l}\text { sion, job-role } \\
\text { quality and turn- } \\
\text { over intentions } \\
\text { than working hours }\end{array}$ & & & & & \\
\hline $\begin{array}{l}\text { Barnett \& } \\
\text { Shen (1997) }\end{array}$ & U.S.A. & $\begin{array}{l}\text { Estimate the } \\
\text { association be- } \\
\text { tween time spent } \\
\text { on housework } \\
\text { tasks and psycho- } \\
\text { logical distress }\end{array}$ & $\begin{array}{l}265 \text { employed dual- } \\
\text { earner couples }\end{array}$ & $\begin{array}{l}\text { Psychological distress: } \\
\text { anxiety (14 items), depres- } \\
\text { sion (10 items) }\end{array}$ & $\begin{array}{l}\text { Gender } \\
\text { Gender role ideology } \\
\text { Number of children } \\
\text { Preschool children } \\
\text { Number of hrs/week in } \\
\text { paid employment } \\
\text { Marital quality } \\
\text { Number of hours spent } \\
\text { in market work }\end{array}$ & $\begin{array}{l}\text { Absolute and } \\
\text { proportional time } \\
\text { spent in low- and } \\
\text { high schedule } \\
\text { control housework } \\
\text { tasks (11 items). }\end{array}$ & $\begin{array}{l}\text { Time spent in low-schedule control household tasks (but not } \\
\text { total time or high-control) was related to psychological } \\
\text { distress after adjustment. }\end{array}$ \\
\hline $\begin{array}{l}\text { Barnett \& } \\
\text { Gareis (2002) }\end{array}$ & U.S.A. & $\begin{array}{l}\text { Tested whether the } \\
\text { relationship be- } \\
\text { tween work hours } \\
\text { and marital-role } \\
\text { quality would be } \\
\text { mediated by the } \\
\text { proportion of low- } \\
\text { schedule control } \\
\text { household tasks }\end{array}$ & $\begin{array}{l}98 \text { married full-time } \\
\text { and reduced hours } \\
\text { female physicians with } \\
\text { children }\end{array}$ & Marital quality & $\begin{array}{l}\text { WFI } \\
\text { Satisfaction with } \\
\text { division of childcare } \\
\text { Husbands work hours } \\
\text { Household income } \\
\text { Negative affectivity }\end{array}$ & $\begin{array}{l}\text { Work Schedule } \\
\text { Division low-control } \\
\text { household tasks }\end{array}$ & $\begin{array}{l}\text { Long working hours were associated with higher MRQ. The } \\
\text { relationship was mediated by the proportion of low- } \\
\text { schedule-control household tasks they performed relative to } \\
\text { their husbands. }\end{array}$ \\
\hline $\begin{array}{l}\text { Barton et al. } \\
\text { (1998) }\end{array}$ & U.K. & $\begin{array}{l}\text { To compare the } \\
\text { emotional state of } \\
\text { children of shift and } \\
\text { day working fathers }\end{array}$ & $\begin{array}{l}1908-11 \text { years old } \\
\text { children. } 91 \text { from shift } \\
\text { working homes and } \\
99 \text { from day working. } \\
\text { Drawn from } 2 \text { primary } \\
\text { schools within a } \\
\text { predominantly shift } \\
\text { working region }\end{array}$ & $\begin{array}{l}\text { Global self-worth and } \\
\text { perceived competences in } 5 \\
\text { domains } \\
\text { (The Harter Self-Perception } \\
\text { questionnaire) } \\
\text { Depression } \\
\text { (Children's Depression } \\
\text { Inventory) }\end{array}$ & $\begin{array}{l}\text { OBS: No measures of } \\
\text { parental occupation } \\
\text { and socioeconomic } \\
\text { class, but the sample } \\
\text { were drawn from a } \\
\text { socioeconomic homo- } \\
\text { geneous area. }\end{array}$ & $\begin{array}{l}\text { Shift working } \\
\text { fathers } \\
\text { Day working } \\
\text { fathers }\end{array}$ & $\begin{array}{l}\text { Daughters of shift working fathers reported poorer self- } \\
\text { perceived school-performance and greater discrepancies } \\
\text { between perceived and ideal level of competence, more } \\
\text { depressive symptomatology and lower level of self-esteem. } \\
\text { No such effects were found for the sons of shift-working } \\
\text { fathers. }\end{array}$ \\
\hline $\begin{array}{l}\text { Batt \& Val- } \\
\text { cour (2003) }\end{array}$ & U.S.A. & $\begin{array}{l}\text { Explores the } \\
\text { relationship be- } \\
\text { tween policy and } \\
\text { WFC etc. } \\
\text { Cross- sectional } \\
\text { analyses using } \\
\text { multivariate linear } \\
\text { regression }\end{array}$ & $\begin{array}{l}557 \text { primarily profes- } \\
\text { sional and managerial } \\
\text { employees in dual } \\
\text { earner couples }\end{array}$ & $\begin{array}{l}\text { W- }>\text { F conflict (two items) } \\
\text { Perception of control over } \\
\text { work time ( } 8 \text { items) } \\
\text { Intention to quit job (5 } \\
\text { items) }\end{array}$ & $\begin{array}{l}\text { - Supervisor } \\
\text { supportiveness of WFI } \\
\text { - Access to flexible } \\
\text { schedule policy } \\
\text { - Dependent care } \\
\text { policies (index) } \\
\text { Salary } \\
\text { Job security } \\
\text { Career } \\
\text { Decision authority } \\
\text { ( } 3 \text { items) } \\
\text { Coordination } \\
\text { ( } 3 \text { items) } \\
\text { Flexible technology } \\
\text { use }\end{array}$ & $\begin{array}{l}\text { Work hours/week } \\
\text { Access to flexible } \\
\text { schedule policy }\end{array}$ & $\begin{array}{l}\text { Among women: } \\
\text { Positive association between hr/week and W->F conflicts } \\
\text { - Among men: } \\
\text { No association between hrs/week and W->F conflict } \\
\text { - No association between flexible scheduling policy and } \\
\text { work-family conflict or perception of control over man- } \\
\text { aging work and family demands. } \\
\text { - Among women: Supervisor supportiveness of WFI was } \\
\text { associated with lower levels of work-family conflict and } \\
\text { turn-over intentions } \\
\text { Among men: } \\
\text { - Flexible policy was associated with lower level of turn- } \\
\text { over intentions }\end{array}$ \\
\hline
\end{tabular}




\begin{tabular}{|c|c|c|c|c|c|c|c|}
\hline Reference & Country & $\begin{array}{l}\text { Purpose, design and } \\
\text { statistics }\end{array}$ & Sample & Outcome measures & Other measures & $\begin{array}{l}\text { Measures of working } \\
\text { time arrangements }\end{array}$ & Findings \\
\hline $\begin{array}{l}\text { Beckers et al. } \\
\text { (2004) }\end{array}$ & $\begin{array}{l}\text { The } \\
\text { Nether- } \\
\text { lands }\end{array}$ & $\begin{array}{l}\text { Study the relation- } \\
\text { ship between } \\
\text { overtime and } \\
\text { mental fatigue } \\
\text { Cross-sectional } \\
\text { analyses using } \\
\text { MANCOVA }\end{array}$ & $\begin{array}{l}1807 \text { full-time em- } \\
\text { ployees ( } 77 \% \\
\text { males, } 23 \% \text { females) }\end{array}$ & Fatigue (5 items) & $\begin{array}{l}\text { (6 items) } \\
\text { Demographic var. } \\
\text { Age } \\
\text { Gender } \\
\text { Salary level } \\
\text { Job demands } \\
\text { Job variety } \\
\text { Decision latitude } \\
\text { Work motivation }\end{array}$ & $\begin{array}{l}\text { Overtime hr/week } \\
\text { (mean 3.52) }\end{array}$ & $\begin{array}{l}\text { - No general association between overtime and mental } \\
\text { fatigue. } \\
\text { - Fatigued and non- motivated workers reported worse } \\
\text { psychosocial work environment regardless of number } \\
\text { of overtime hours. } \\
\text { - Overtime workers were in general employees with jobs } \\
\text { characterised by high decision latitude, high job variety } \\
\text { and high job demands, and they had high work motiva- } \\
\text { tion. }\end{array}$ \\
\hline $\begin{array}{l}\text { Berg et al. } \\
(2003)\end{array}$ & U.S.A. & $\begin{array}{l}\text { Examines the } \\
\text { effect of high- } \\
\text { performance work } \\
\text { practice and work } \\
\text { environment on } \\
\text { WLB support from } \\
\text { company } \\
\text { Cross-sectional } \\
\text { analyses using } \\
\text { multivariate or- } \\
\text { dered logit analy- } \\
\text { ses }\end{array}$ & $\begin{array}{l}4374 \text { employees from } \\
\text { three manufacturing } \\
\text { industries ( } 37 \% \\
\text { females) }\end{array}$ & $\begin{array}{l}\text { Workers perception of } \\
\text { company help to balance } \\
\text { work and family life (single } \\
\text { question) }\end{array}$ & $\begin{array}{l}\text { Family status } \\
\text { High-performance } \\
\text { work practice } \\
\text { Job demands: } \\
\text {-Involuntary overwork } \\
\text { - intrinsic rewards } \\
\text { scale } \\
\text {-Job stressors } \\
\text {-Conflict with co- } \\
\text { workers } \\
\text { Formal and informal } \\
\text { supports } \\
\text { High-commitment } \\
\text { environment }\end{array}$ & $\begin{array}{l}\text { Work hrs/week } \\
\text { Involuntary over- } \\
\text { time }\end{array}$ & $\begin{array}{l}\text { Work hr/week and involuntary overtime correlated nega- } \\
\text { tively with workers perception of company help to balance } \\
\text { work and family life after adjustment for all other variables }\end{array}$ \\
\hline $\begin{array}{l}\text { Bildt \& } \\
\text { Michelsen } \\
\text { (2002) }\end{array}$ & Sweden & $\begin{array}{l}\text { Examine how } \\
\text { working conditions } \\
\text { in } 1993 \text { influenced } \\
\text { the occurrence of } \\
\text { poor mental health } \\
\text { in } 1997 . \\
\text { Prospective study, } \\
\text { Univariate and } \\
\text { multivariate analy- } \\
\text { ses with Cox } \\
\text { regression }\end{array}$ & $\begin{array}{l}222 \text { women and } 198 \\
\text { men participating in } \\
1993 \text { and 1997, } \\
\text { representative for } \\
\text { Stockholm, but not for } \\
\text { Sweden. }\end{array}$ & $\begin{array}{l}\text { Sub-clinical depression } \\
\text { (based on two sub-scales } \\
\text { from the Swedish version of } \\
\text { the Nottingham life-quality } \\
\text { questionnaire) } \\
\text { Psychological well-being } \\
\text { (12 item version of GHQ) } \\
\text { Alcohol consumption }\end{array}$ & $\begin{array}{l}\text { Occupational factors: } \\
\text { Job strain } \\
\text { Social support } \\
\text { Occupational pride } \\
\text { Development possibili- } \\
\text { ties } \\
\text { Physical workload } \\
\text { Non-occupational } \\
\text { factors: } \\
\text { Marital status } \\
\text { Social contacts } \\
\text { Demanding life events } \\
\text { Smoking habits } \\
\text { Physical activity } \\
\text { Perceived load outside } \\
\text { work } \\
\text { Quality of social } \\
\text { contacts (by interview) } \\
\text { Coping strategies (by } \\
\text { interview) }\end{array}$ & $\begin{array}{l}\text { Areas of working } \\
\text { hours: } \\
\text { Overtime work } \\
\text { Shift work }\end{array}$ & $\begin{array}{l}\text { For women: } \\
\text { - Sub-clinical depression was predicted by: shift work, } \\
\text { job strain and poor quality of social contacts. } \\
\text { - Low psychological well-being was not predicted by } \\
\text { occupational variables. } \\
\text { - Alcohol consumption was predicted by low occupa- } \\
\text { tional pride and no education } \\
\text { Overtime work was not predictive for any of the outcomes. } \\
\text { For men: } \\
\text { - Sub-clinical depression was predicted by low occupa- } \\
\text { tional pride and in univariate analyses also by shift } \\
\text { work. } \\
\text { Overtime work was not predictive. }\end{array}$ \\
\hline
\end{tabular}




\begin{tabular}{|c|c|c|c|c|c|c|c|}
\hline Reference & Country & $\begin{array}{l}\text { Purpose, design and } \\
\text { statistics }\end{array}$ & Sample & Outcome measures & Other measures & $\begin{array}{l}\text { Measures of working } \\
\text { time arrangements }\end{array}$ & Findings \\
\hline $\begin{array}{l}\text { Brough et al. } \\
\text { (2005) }\end{array}$ & $\begin{array}{l}\text { New } \\
\text { Zealand }\end{array}$ & $\begin{array}{l}\text { Examines the } \\
\text { relationship be- } \\
\text { tween use of } \\
\text { organizational } \\
\text { "family friendly" } \\
\text { resources and } \\
\text { WFC and job-and } \\
\text { family satisfaction } \\
\text { Follow-up study } \\
\text { using SEM analy- } \\
\text { ses }\end{array}$ & $\begin{array}{l}398 \text { employed men } \\
\text { and women from } 23 \\
\text { large organisations } \\
\text { covering a diversity of } \\
\text { industries }\end{array}$ & $\begin{array}{l}\text { WFI ( } 5 \text { items) } \\
\text { FWI ( } 5 \text { items) } \\
\text { Family satisfaction } \\
\text { Job satisfaction }\end{array}$ & $\begin{array}{l}\text { Gender } \\
\text { Partner } \\
\text { Dependants } \\
\text { Partner employed } \\
\text { Work resources } \\
\text { Family resources }\end{array}$ & $\begin{array}{l}\text { Work hrs/week } \\
\text { Family friendly } \\
\text { resources (e.g. } \\
\text { flexible working } \\
\text { hours, assistance } \\
\text { with child } \\
\text { care/elder care and } \\
\text { job sharing) }\end{array}$ & $\begin{array}{l}\text { Long working hours were predictive of increased level of } \\
\text { WFC and dissatisfaction with job and family. } \\
\text { Organisational family friendly resources predicted family } \\
\text { satisfaction }\end{array}$ \\
\hline Clark (2001) & U.S.A. & $\begin{array}{l}\text { Examined the } \\
\text { relationship be- } \\
\text { tween three as- } \\
\text { pects of work } \\
\text { culture: flexibility of } \\
\text { working hours, } \\
\text { flexibility of work } \\
\text { and supportive } \\
\text { supervision }\end{array}$ & $\begin{array}{l}179 \text { employed indi- } \\
\text { viduals (Hr/week } \\
\text { average } 44 \text { hours) }\end{array}$ & $\begin{array}{l}\text { Family functioning } \\
\text { Home satisfaction } \\
\text { Work satisfaction } \\
\text { Employee citizenship } \\
\text { Role conflict }\end{array}$ & $\begin{array}{l}\text { Age } \\
\text { Education } \\
\text { Gender } \\
\text { Income } \\
\text { Organisational size } \\
\text { Dual career } \\
\text { Hrs/week } \\
\text { Number of dependents }\end{array}$ & $\begin{array}{l}\text { Temporal flexibility } \\
\text { (5 items about } \\
\text { flexibility to set } \\
\text { ones own working } \\
\text { hours) } \\
\text { Operational flexibil- } \\
\text { ity ( } 5 \text { items about } \\
\text { flexibility to alter } \\
\text { one's work) } \\
\text { Supportive super- } \\
\text { vision ( } 3 \text { items) }\end{array}$ & $\begin{array}{l}\text { Temporal flexibility was not associated with work and } \\
\text { personal outcomes. } \\
\text { Operational flexibility was associated with increased work } \\
\text { satisfaction, increased family well-being and decreased role } \\
\text { conflicts. } \\
\text { Supportive supervision was associate with employee } \\
\text { citizenship }\end{array}$ \\
\hline $\begin{array}{l}\text { Clissold et al. } \\
\text { (2002) }\end{array}$ & Australia & $\begin{array}{l}\text { Explored the effect } \\
\text { of shift work on } \\
\text { sleep, fatigue and } \\
\text { stress }\end{array}$ & Female nurses & $\begin{array}{l}\text { Sleep } \\
\text { Chronic fatigue } \\
\text { Stress }\end{array}$ & $\begin{array}{l}\text { Singles } \\
\text { Partner } \\
\text { Partner with children }\end{array}$ & $\begin{array}{l}\text { Continuous 3-shift } \\
\text { roster }\end{array}$ & $\begin{array}{l}\text { The average sleep duration per 24-hours was almost one } \\
\text { hour less for nurses who combine shift work, partner and } \\
\text { parent roles. } \\
\text { Results showed interaction between work and family roles } \\
\text { resulting in chronic fatigue. } \\
\text { Interview data found shift work associated with reduced } \\
\text { opportunities for participation in social and leisure activities } \\
\text { by all three of the groups studied. }\end{array}$ \\
\hline $\begin{array}{l}\text { Costa et al. } \\
(2006)\end{array}$ & Italy & $\begin{array}{l}\text { Examine the effect } \\
\text { of flexibility (indi- } \\
\text { vidual discretions } \\
\text { and autonomy) and } \\
\text { variability (com- } \\
\text { pany control and } \\
\text { decision) } \\
\text { Cross-sectional } \\
\text { analyses using } \\
\text { multiple logistic } \\
\text { regression }\end{array}$ & $\begin{array}{l}21505 \text { workers from } \\
\text { the Third European } \\
\text { Survey of Working } \\
\text { Conditions }(2000), \\
\text { gender mixed sample, } \\
\text { both employed and } \\
\text { self-employed }\end{array}$ & $\begin{array}{l}\text { Nineteen health disorders } \\
\text { Four psychosocial condi- } \\
\text { tions: } \\
\text {-hr fit to social and family } \\
\text { commitment } \\
\text { - able to do the same job } \\
\text { when } 60 \\
\text {-health and safety at risk } \\
\text {-job satisfaction }\end{array}$ & $\begin{array}{l}\text { Age } \\
\text { Gender } \\
\text { Marital status } \\
\text { No of Children } \\
\text { Occupation } \\
\text { Shift work } \\
\text { Night work } \\
\text { Mode of employment } \\
\text { Time pressure } \\
\text { Mental and physical } \\
\text { workload } \\
\text { Participation in work } \\
\text { organization }\end{array}$ & $\begin{array}{l}\text { Shift work } \\
\text { Night Work } \\
\text { Variability: Same } \\
\text { no of hrs each } \\
\text { day? Each week? } \\
\text { Same start and } \\
\text { finishing point? } \\
\text { Flexibility: } \\
\text { Breaks when } \\
\text { whished? Holidays } \\
\text { when wanted? } \\
\text { Influence on } \\
\text { working hours? }\end{array}$ & $\begin{array}{l}\text { Flexibility was associated positively with work satisfaction; } \\
\text { family and social commitment, ability to do same job when } \\
60 \text { and negatively to trauma, overall fatigue, irritability, and } \\
\text { headache. } \\
\text { Variability was negatively associated with family and } \\
\text { social commitments, stress, hearth disease, anxiety, stom- } \\
\text { achache, irritability, sleep problems } \\
\text { Shift work was associated with stomach ache and skin } \\
\text { problems, sleep, digestive and cardiovascular troubles, } \\
\text { Night work was negatively associated with family and social } \\
\text { commitment and perceived health and safety risk and } \\
\text { positively with sleeping problems and heart disease } \\
\text { Time pressure was associated with stress, headaches, } \\
\text { muscular pain and allergies }\end{array}$ \\
\hline
\end{tabular}




\begin{tabular}{|c|c|c|c|c|c|c|c|}
\hline Reference & Country & $\begin{array}{l}\text { Purpose, design and } \\
\text { statistics }\end{array}$ & Sample & Outcome measures & Other measures & $\begin{array}{l}\text { Measures of working } \\
\text { time arrangements }\end{array}$ & Findings \\
\hline $\begin{array}{l}\text { Crompton \& } \\
\text { Lyonette } \\
\text { (2006) }\end{array}$ & U.K. & $\begin{array}{l}\text { Examine national } \\
\text { variations in re- } \\
\text { ported levels of } \\
\text { work-life conflict } \\
\text { Cross-sectional } \\
\text { analyses }\end{array}$ & $\begin{array}{l}2363 \text { full-time em- } \\
\text { ployees from Britain, } \\
\text { Finland, France, } \\
\text { Norway and Portugal. } \\
\text { Drawn from the family } \\
2002 \text { module of the } \\
\text { Int. Soc Survey Prog. } \\
\text { (ISSP) }\end{array}$ & Work-life conflict (4 items) & $\begin{array}{l}\text { Age } \\
\text { Proff./managerial class } \\
\text { Intermediate class } \\
\text { Being female } \\
\text { Child in household }\end{array}$ & $\begin{array}{l}\text { Weekly working } \\
\text { hours } \\
\text { Division of domes- } \\
\text { tic labor }\end{array}$ & $\begin{array}{l}\text { WLC was in all countries associated with working hours, } \\
\text { highest association in France (0.31) followed by Norway, } \\
\text { Britain, Finland and Portugal (0.12). } \\
\text { Division of domestic labor differed, with the most equal } \\
\text { share in Norway, followed by Finland, Britain, France and } \\
\text { Portugal. France had, regardless of good child care facili- } \\
\text { ties, a high level of WLC. A traditional division of the do- } \\
\text { mestic labour was a significant predictor of work-life conflict } \\
\text { in France. }\end{array}$ \\
\hline $\begin{array}{l}\text { Eiriksdottir et } \\
\text { al. (2006) }\end{array}$ & Iceland & $\begin{array}{l}\text { Analyse shift } \\
\text { workers attitude to } \\
\text { different working } \\
\text { arrangements }\end{array}$ & $\begin{array}{l}820 \text { shift-workers } \\
\text { Questionnaire }\end{array}$ & $\begin{array}{l}\text { Work-family/leisure time } \\
\text { conflict } \\
\text { Sleep difficulty }\end{array}$ & $\begin{array}{l}\text { Age } \\
\text { Type of work } \\
\text { Involvement in job and } \\
\text { family responsibility }\end{array}$ & $\begin{array}{l}\text { Different kind of } \\
\text { shift work }\end{array}$ & $\begin{array}{l}\text { Shift work was associated with poor work-life balance } \\
\text { FWB was most difficult for single parents } \\
\text { Shift workers had some difficulties with sleep }\end{array}$ \\
\hline $\begin{array}{l}\text { Elloy \& Smith } \\
\text { (2003) }\end{array}$ & U.S.A. & $\begin{array}{l}\text { Studied stress, } \\
\text { WFC and overload } \\
\text { among dual-career } \\
\text { and single career } \\
\text { couples } \\
\text { Cross-sectional } \\
\text { analyses using } \\
\text { multivariate covari- } \\
\text { ance }\end{array}$ & $\begin{array}{l}178 \text { lawyers and } \\
\text { accountants, } 62 \text { in } \\
\text { dual-career couples } \\
\text { and } 59 \text { in single. } \\
\text { Response rate: } 26.3 \%\end{array}$ & $\begin{array}{l}\text { WFC (8item) } \\
\text { Family conflict } \\
\text { Stress } \\
\text { Overload ( } 8 \text { item) } \\
\text { Role conflict and ambiguity }\end{array}$ & Sex & $\begin{array}{l}\text { Dual Career } \\
\text { couples/ single } \\
\text { career couples }\end{array}$ & $\begin{array}{l}\text { Dual career couples experienced higher levels of stress, } \\
\text { overload, role-conflicts, role-ambiguity and family conflicts, } \\
\text { but not significant higher levels of WFC }\end{array}$ \\
\hline $\begin{array}{l}\text { Ezoe \& } \\
\text { Morimoto } \\
\text { (1994) }\end{array}$ & Japan & $\begin{array}{l}\text { Correlate behav- } \\
\text { ioral lifestyles with } \\
\text { major components } \\
\text { of mental health } \\
\text { Cross-sectional } \\
\text { analyses using } \\
\text { multiple logistic } \\
\text { regression analy- } \\
\text { ses }\end{array}$ & $\begin{array}{l}2132 \text { male and } 668 \\
\text { female workers } \\
\text { employed at a camera } \\
\text { manufacturing com- } \\
\text { pany }\end{array}$ & $\begin{array}{l}\text { General Health (28 item } \\
\text { GHQ scale) } \\
\text { Subscales: } \\
\text { Somatic symptoms, anxiety } \\
\text { and insomnia, social dys- } \\
\text { function }\end{array}$ & $\begin{array}{l}\text { Age } \\
\text { Marital status } \\
\text { Physical health status }\end{array}$ & $\begin{array}{l}\text { Smoking } \\
\text { Consuming alcohol } \\
\text { Eating breakfast } \\
\text { Sleeping hours } \\
\text { Working hours } \\
\text { Physical exercise } \\
\text { Nutritional balance } \\
\text { Mental stress }\end{array}$ & $\begin{array}{l}\text { Among males: } \\
\text { - Shorter length of working hours was associated with } \\
\text { higher social dysfunction } \\
\text { - Working hrs/day were associated with somatic symp- } \\
\text { toms, with } 9 \text { hr/day as optimum and more or less as } \\
\text { worse. } \\
\text { - Working hours was negatively associated with smoking } \\
\text { and negatively associated with hours of sleep. } \\
\text { Among females } \\
\text { - Shorter length of working hours was associated with } \\
\text { lower social dysfunction and lower psychological dis- } \\
\text { tress. }\end{array}$ \\
\hline $\begin{array}{l}\text { Fenwick \& } \\
\text { Tausig } \\
\text { (2001) } \\
\text { Tausig \& } \\
\text { Fenwick } \\
\text { (2001) }\end{array}$ & U.S.A. & $\begin{array}{l}\text { Examine whether } \\
\text { alternate work } \\
\text { schedules affects } \\
\text { perceived work-life } \\
\text { imbalance and } \\
\text { effects of shift work } \\
\text { and schedule } \\
\text { control on family } \\
\text { and health. } \\
\text { Cross-sectional }\end{array}$ & $\begin{array}{l}2958 \text { employees from } \\
\text { a representative } \\
\text { sample of } 3381 \\
\text { employees in The } \\
1992 \text { National Study } \\
\text { on the Changing } \\
\text { Workforce }\end{array}$ & $\begin{array}{l}\text { WLB }(2 \text { items) } \\
\text { Distress ( } 6 \text { items) } \\
\text { Dissatisfaction (single item } \\
\text { Burnout ( } 5 \text { items) } \\
\text { Lack of work-home balance } \\
\text { (single item) } \\
\text { Work-home conflict (single } \\
\text { item) } \\
\text { Days sick } \\
\text { Poor general health }\end{array}$ & $\begin{array}{l}\text { Gender } \\
\text { Race } \\
\text { Education } \\
\text { Current school atten- } \\
\text { dance } \\
\text { Family status (6 } \\
\text { dummy variables) } \\
\text { Occupation } \\
\text { Union member }\end{array}$ & $\begin{array}{l}\text { Full-time: } \\
\text { - M-F Day shift } \\
\text { - Non-Day shift } \\
\text { - Non-M-F shift } \\
\text { - Rotating shift } \\
\text { Part-time } \\
\text { Perceived sched- } \\
\text { ule control (single } \\
\text { question) } \\
\text { Availability of }\end{array}$ & $\begin{array}{l}\text { Number of working hrs/week was associated with poorer } \\
\text { work-life balance and more conflicts between work and } \\
\text { home and with burnout and distress. } \\
\text { Part-time was associated with worse work-life balance } \\
\text { when work hours were controlled. (The negative associa- } \\
\text { tion with part-time work was suppressed until control for the } \\
\text { difference in hours worked between full and part-time } \\
\text { employees was performed). } \\
\text { Workers with high schedule control reported better work-life } \\
\text { balance, less burnout, distress and dissatisfaction, better }\end{array}$ \\
\hline
\end{tabular}




\begin{tabular}{|c|c|c|c|c|c|c|c|}
\hline Reference & Country & $\begin{array}{l}\text { Purpose, design and } \\
\text { statistics }\end{array}$ & Sample & Outcome measures & Other measures & $\begin{array}{l}\text { Measures of working } \\
\text { time arrangements }\end{array}$ & Findings \\
\hline & & $\begin{array}{l}\text { analyses using } \\
\text { linear regression }\end{array}$ & & Minor health problems & & $\begin{array}{l}\text { flexible schedule } \\
\text { options ( } 4 \text { items) } \\
\text { Working hrs/week }\end{array}$ & $\begin{array}{l}\text { general health and less minor physical health problems. } \\
\text { There was no evidence that schedule control mediated } \\
\text { other associations. } \\
\text { There was no association between work-life balance and } \\
\text { availability of flexible schedule options. } \\
\text { Workers with regular } M \text { - } F \text { day shift reported less work-home } \\
\text { imbalance and less work-home conflict and less dissatisfac- } \\
\text { tion and more minor physical problems compared to overall } \\
\text { mean } \\
\text { Workers with non } M-F \text { shift reported more work-home } \\
\text { imbalance and conflicts and higher levels of burnout com- } \\
\text { pared to overall mean } \\
\text { Non-day workers and workers on rotating shifts did not } \\
\text { report more psychological distress than overall mean }\end{array}$ \\
\hline $\begin{array}{l}\text { Folkard } \\
(2003)\end{array}$ & U.K. & $\begin{array}{l}\text { Examines the } \\
\text { impact of meas- } \\
\text { ures of flexibility on } \\
\text { different outcomes } \\
\text { Cross-sectional } \\
\text { analyses using } \\
\text { ANOVA }\end{array}$ & $\begin{array}{l}2093 \text { British aircraft } \\
\text { maintenance engi- } \\
\text { neers, predominantly } \\
\text { males. The main part } \\
\text { working in shifts }\end{array}$ & $\begin{array}{l}\text { Interference of work sched- } \\
\text { ule with various leisure and } \\
\text { non-leisure activities } \\
\text { Health } \\
\text { Perceived risk }\end{array}$ & Age & $\begin{array}{l}\text { Days notice of } \\
\text { schedule } \\
\text { Control over } \\
\text { specific shifts } \\
\text { Control over } \\
\text { specific start and } \\
\text { finishing time }\end{array}$ & $\begin{array}{l}\text { The more control experienced on any of the three measures } \\
\text { of flexibility, the lower was the level of interference of } \\
\text { schedule with leisure time. } \\
\text { Health was better and perceived risk lower the more control } \\
\text { over shifts and over starting and finishing times. Notice of } \\
\text { schedule did not have any impact on these outcomes. }\end{array}$ \\
\hline $\begin{array}{l}\text { Fox \& Dwyer } \\
\text { (1999) }\end{array}$ & U.S.A. & $\begin{array}{l}\text { Examines whether } \\
\text { time and involve- } \\
\text { ment spent in work } \\
\text { and family would } \\
\text { moderate the } \\
\text { stressor-strain } \\
\text { relationship } \\
\text { Cross-sectional } \\
\text { analyses using } \\
\text { multiple regression }\end{array}$ & $\begin{array}{l}113 \text { registered nurses } \\
\text { (all female) }\end{array}$ & $\begin{array}{l}\text { Work-family conflict ( } 1 \text { item) } \\
\text { Family-work conflict }(1 \text { item })\end{array}$ & $\begin{array}{ll}\text { Work stressors: } \\
\text { - } & \text { Quantitative } \\
& \text { workload (7 items) } \\
\text { - } & \text { Workload variabil- } \\
& \text { ity } \\
\text { - } & \text { Stressful events } \\
\text { - } & \text { (45 items) } \\
\text { Supervisor sup- } & \text { port (12 items) } \\
\text { - } & \text { Family stressors } \\
& (7 \text { items) }\end{array}$ & $\begin{array}{l}\text { Work time and } \\
\text { involvement: } \\
\text { Job involvement: (7 } \\
\text { items) } \\
\text { Actual time in- } \\
\text { volvement (4 } \\
\text { items) } \\
\text { Family time and } \\
\text { involvement: } \\
\text { Actual time in- } \\
\text { volvement in family } \\
\text { (4 items) }\end{array}$ & $\begin{array}{l}\text { Time and involvement influenced the stressor-interdomain } \\
\text { conflict relationship: } \\
\text { High work time were associated with high WFC when there } \\
\text { was low support from supervisor, while high work time was } \\
\text { associated with low WFC when there was high support from } \\
\text { supervisor. } \\
\text { High work time were associated with high WFC when there } \\
\text { was marital conflicts, while high work time was associated } \\
\text { with lower WFC when there was no marital conflicts. }\end{array}$ \\
\hline $\begin{array}{l}\text { Fridriksdóttir } \\
\text { et al. (2004) }\end{array}$ & Iceland & $\begin{array}{l}\text { Work and family } \\
\text { arrangements } \\
\text { among bank } \\
\text { personnel } \\
\text { Cross -sectional } \\
\text { study analysed by } \\
\text { odds ratio and } \\
\text { factor analysis }\end{array}$ & $\begin{array}{l}1475 \text { personnel in the } \\
\text { bank branches. } \\
\text { Thereof } 86 \% \text { women } \\
\text { and } 14 \% \text { men } \\
\text { Questionnaire and } \\
\text { interviews (with nine } \\
\text { persons) }\end{array}$ & $\begin{array}{l}\text { Work/ family conflict } \\
\text { Stress } \\
\text { ( } 5 \text { items in each scale) }\end{array}$ & $\begin{array}{l}\text { Gender } \\
\text { Age } \\
\text { Social support } \\
\text { Autonomy } \\
\text { (5 items in most } \\
\text { scales) }\end{array}$ & $\begin{array}{l}\text { Paid work hours pr. } \\
\text { week }\end{array}$ & $\begin{array}{l}\text { Increased stress and more problems with the work-life } \\
\text { balance for women and men among the employees when } \\
\text { working more than } 40 \mathrm{hrs} / \text { week. } \\
\text { Association between supervisor's supportiveness and a } \\
\text { better work-life balance among women and men. }\end{array}$ \\
\hline $\begin{array}{l}\text { Fu \& Shaffer } \\
(2001)\end{array}$ & $\begin{array}{l}\text { Hong } \\
\text { Kong }\end{array}$ & $\begin{array}{l}\text { Examines the } \\
\text { influence of family } \\
\text { and work-specific } \\
\text { determinants (incl. }\end{array}$ & $\begin{array}{l}267 \text { employees from a } \\
\text { University in Hong } \\
\text { Kong. Response rate } \\
33 \% \text {. }\end{array}$ & $\begin{array}{l}\text { FIW (3 item) } \\
\text { WIF (3 item) }\end{array}$ & $\begin{array}{l}\text { Marital status } \\
\text { Working status of } \\
\text { spouse } \\
\text { Presence of children }\end{array}$ & $\begin{array}{l}\text { Hours spent on } \\
\text { household work } \\
\text { Hours spent on } \\
\text { paid work }\end{array}$ & $\begin{array}{l}\text { Hours spent on paid work were associated with higher WIF, } \\
\text { and hours spent on household work were associated with } \\
\text { higher FIW. }\end{array}$ \\
\hline
\end{tabular}




\begin{tabular}{|c|c|c|c|c|c|c|c|}
\hline Reference & Country & $\begin{array}{l}\text { Purpose, design and } \\
\text { statistics }\end{array}$ & Sample & Outcome measures & Other measures & $\begin{array}{l}\text { Measures of working } \\
\text { time arrangements }\end{array}$ & Findings \\
\hline & & $\begin{array}{l}\text { Work hours) ion } \\
\text { WIF and FIW }\end{array}$ & & & $\begin{array}{l}\text { Gender } \\
\text { Domestic support } \\
\text { Work: } \\
\text { Role autonomy } \\
\text { Role ambiguity } \\
\text { Role conflict } \\
\text { Social support }\end{array}$ & & \\
\hline $\begin{array}{l}\text { Galambos \& } \\
\text { Walters } \\
\text { (1992) }\end{array}$ & Canada & $\begin{array}{l}\text { Explore dual- } \\
\text { earner couples } \\
\text { work schedule as } \\
\text { predictor of stress } \\
\text { in both partners } \\
\text { Cross sectional } \\
\text { analyses using } \\
\text { multiple regression }\end{array}$ & $\begin{array}{l}96 \text { dual-career cou- } \\
\text { ples }\end{array}$ & $\begin{array}{l}\text { Job-Family Role Strain (16 } \\
\text { items scale) } \\
\text { Depression } \\
\text { Anxiety }\end{array}$ & SES & $\begin{array}{l}\text { Wives number of } \\
\text { work hours (aver- } \\
\text { age } 31 \text { hrs/week) } \\
\text { Husbands' number } \\
\text { of work hours } \\
\text { (average } 42 \\
\text { hrs/week) } \\
\text { Wives Schedule } \\
\text { inflexibility } \\
\text { Husbands sched- } \\
\text { ule inflexibility }\end{array}$ & $\begin{array}{l}\text { Husbands' work hours were associated with husbands' } \\
\text { Role Strain } \\
\text { Wives work hours were associated with wives role strain } \\
\text { Wives schedule inflexibility was associated with wives role } \\
\text { strain } \\
\text { Wives' work hours were associated with depression and } \\
\text { anxiety among there husbands } \\
\text { Husbands work hours were unrelated to the wellbeing of the } \\
\text { wives. } \\
\text { Husbands schedule inflexibility was associated with hus- } \\
\text { bands Role Strain but was unrelated to the wellbeing of the } \\
\text { wives. }\end{array}$ \\
\hline $\begin{array}{l}\text { Geurts et al. } \\
\text { (1999) }\end{array}$ & $\begin{array}{l}\text { The } \\
\text { Nether- } \\
\text { lands }\end{array}$ & $\begin{array}{l}\text { Studied WHI as } \\
\text { mediator of the } \\
\text { relationship be- } \\
\text { tween work and } \\
\text { home characteris- } \\
\text { tics and psycho- } \\
\text { logical health } \\
\text { Cross-sectional } \\
\text { regression analy- } \\
\text { ses }\end{array}$ & $\begin{array}{l}166 \text { medical residents } \\
\text { of an academic } \\
\text { hospital }\end{array}$ & $\begin{array}{l}\text { Negative WHI (5 item scale } \\
\text { by Kopelman 1983) }\end{array}$ & $\begin{array}{l}\text { Quantitative workload } \\
\text { (11 items) } \\
\text { Lack of job autonomy } \\
\text { (8 items) } \\
\text { Dependency of supe- } \\
\text { rior (6 items) } \\
\text { Dual career } \\
\text { Parental status } \\
\text { Evaluation of child } \\
\text { care arrangements } \\
\text { Social support } \\
\text { Gender }\end{array}$ & $\begin{array}{l}\text { Evaluation of Work } \\
\text { time schedule }(9 \\
\text { item scales from } \\
\text { Jansen } 1997, \\
\text { evaluating various } \\
\text { aspects of work } \\
\text { time schedule } \\
\text { interference with } \\
\text { leisure time and } \\
\text { sleep). } \\
\text { Spouse working } \\
\text { over time fre- } \\
\text { quently }\end{array}$ & $\begin{array}{l}\text { Negative WHI was increased the more negative residents } \\
\text { evaluated their work time schedule (a } 9 \text { item scale evaluat- } \\
\text { ing various aspects of work time schedule interference with } \\
\text { leisure time and sleep). } \\
\text { Negative WHI was increased when employees had a } \\
\text { spouse who worked overtime frequently and the more } \\
\text { negative residents evaluated their work time schedule }\end{array}$ \\
\hline $\begin{array}{l}\text { Grönlund } \\
\text { (2007a, } \\
\text { 2007b) }\end{array}$ & Sweden & $\begin{array}{l}\text { Studied the effect } \\
\text { of job control on } \\
\text { WFC, psychologi- } \\
\text { cal wellbeing and } \\
\text { long working hours. } \\
\text { Cross-sectional } \\
\text { logistic regression } \\
\text { analyses }\end{array}$ & $\begin{array}{l}379 \text { female and } 395 \\
\text { male employees living } \\
\text { with partner and /or } \\
\text { children from a repre- } \\
\text { sentative sample as } \\
\text { part of the European } \\
\text { Social Survey }\end{array}$ & $\begin{array}{l}\text { WFC ( } 4 \text { item scale) } \\
\text { Psychological wellbeing (5 } \\
\text { item scale) } \\
\text { Long work hours (usually } \\
\text { more than } 40 \text { hours/week) }\end{array}$ & $\begin{array}{l}\text { Job control ( } 3 \text { items) } \\
\text { Job demands ( } 2 \text { items) } \\
\text { Social class } \\
\text { Gender } \\
\text { Number of children }\end{array}$ & $\begin{array}{l}\text { Work hours (1-39/ } \\
40 / 41 \text { or more) }\end{array}$ & $\begin{array}{l}\text { WFC was associated with long hours, but much more of the } \\
\text { variation was explained by job demands. High job control } \\
\text { also contributed. } \\
\text { Psychological well-being was associated with longer hours } \\
\text { among women, but not men. Psychological wellbeing was } \\
\text { negatively associated with shorter hours among men. } \\
\text { Psychological wellbeing was highly associated with job } \\
\text { control; moderatelyto high job demands and negatively to } \\
\text { WFC. } \\
\text { Long hours were associated with high job demands, but not } \\
\text { with high control. }\end{array}$ \\
\hline $\begin{array}{l}\text { Grönlund } \\
(2004)\end{array}$ & Sweden & $\begin{array}{l}\text { To study the effect } \\
\text { of flexible working }\end{array}$ & $\begin{array}{l}1836 \text { employees } \\
\text { within industry, fi- }\end{array}$ & $\begin{array}{l}\text { WFC (single item) } \\
\text { Social life-conflicts (single }\end{array}$ & $\begin{array}{l}\text { Social class } \\
\text { Number and age of }\end{array}$ & $\begin{array}{l}\text { Work hours } \\
\text { Company flexibility }\end{array}$ & $\begin{array}{l}\text { Working hours and non- day work was associated with } \\
\text { more WFC and more social life and hobby conflicts. }\end{array}$ \\
\hline
\end{tabular}




\begin{tabular}{|c|c|c|c|c|c|c|c|}
\hline Reference & Country & $\begin{array}{l}\text { Purpose, design and } \\
\text { statistics }\end{array}$ & Sample & Outcome measures & Other measures & $\begin{array}{l}\text { Measures of working } \\
\text { time arrangements }\end{array}$ & Findings \\
\hline & & $\begin{array}{l}\text { time on WFC, } \\
\text { social life and } \\
\text { hobbies. } \\
\text { Cross-sectional } \\
\text { linear regression } \\
\text { analyses }\end{array}$ & $\begin{array}{l}\text { nance and health care } \\
\text { from a representative } \\
\text { sample }\end{array}$ & $\begin{array}{l}\text { item) } \\
\text { Hobby-conflict (single item) }\end{array}$ & $\begin{array}{l}\text { children } \\
\text { Gender } \\
\text { Job-group }\end{array}$ & $\begin{array}{l}\text { (single item) } \\
\text { Employee flexibility } \\
(6 \text { items) } \\
\text { Non-day work }\end{array}$ & $\begin{array}{l}\text { Employee flexibility was not associated with less WFC, but } \\
\text { it was associated with less social life- and less hobby } \\
\text { conflicts. } \\
\text { However, moderate degrees of flexibility was associated } \\
\text { with less WFC, while total flexibility was associated with } \\
\text { more WFC until control for social class and company } \\
\text { flexibility, meaning that higher WFCC for those with total } \\
\text { flexibility could be explained by higher social class and } \\
\text { more company flexibility. } \\
\text { Family combinations: } \\
\text { - Man in full-time, women in part-time (compared to both } \\
\text { in full time or man in part-time) associated with less } \\
\text { WFC for women, but not for men. } \\
\text { - Man in non-day work and both in non-day work associ } \\
\text { ated with more WFC for men but not for women. } \\
\text { - Man in flextime and both in flextime was associated } \\
\text { with more WFC for men, but not for women }\end{array}$ \\
\hline $\begin{array}{l}\text { Grosswald } \\
(2004)\end{array}$ & U.S.A. & $\begin{array}{l}\text { To study shift work } \\
\text { on family relation- } \\
\text { ships. } \\
\text { Cross-sectional } \\
\text { analyses using } \\
\text { multivariate logistic } \\
\text { regression }\end{array}$ & $\begin{array}{l}\text { Sample: } 2429 \text { em- } \\
\text { ployees not living } \\
\text { alone, taken from a } \\
\text { representative sample } \\
\text { of } 3552 \text { employees }\end{array}$ & $\begin{array}{l}\text { Family satisfaction (single } \\
\text { question) }\end{array}$ & $\begin{array}{l}\text { Shift work } \\
\text { Autonomy } \\
\text { Culture } \\
\text { Education } \\
\text { Occupation } \\
\text { No. of children<6 } \\
\text { Marital status } \\
\text { Age } \\
\text { Household income } \\
\text { Race/ethnicity }\end{array}$ & $\begin{array}{l}\text { Number of work } \\
\text { hrs/week } \\
\text { Prefer to work } \\
\text { fewer hours } \\
\text { Evening and night } \\
\text { shifts compared to } \\
\text { day workers }\end{array}$ & $\begin{array}{l}\text { No association between number of hrs/week and family } \\
\text { satisfaction } \\
\text { Preference of fewer work hours was associated with lower } \\
\text { family satisfaction } \\
\text { Family satisfaction was lower for employees working eve- } \\
\text { ning and night shifts, also after adjustment for gender, } \\
\text { education and income. OR } 0.7 \text { after adjustment. } \\
\text { Working flexible shifts with no set hours were not associ- } \\
\text { ated with decreased family satisfaction. }\end{array}$ \\
\hline $\begin{array}{l}\text { Grzywacz \& } \\
\text { Marks (2000) }\end{array}$ & U.S.A. & $\begin{array}{l}\text { To develop a } \\
\text { expanded concep- } \\
\text { tualization of work- } \\
\text { family interface and } \\
\text { identify correlates } \\
\text { Cross-sectional } \\
\text { Multivariate ordi- } \\
\text { nary least squares } \\
\text { estimates }\end{array}$ & $\begin{array}{l}1986 \text { employees ( } 948 \\
\text { women and } 1038 \\
\text { men) from a National } \\
\text { survey }\end{array}$ & $\begin{array}{l}\text { Negative spillover W-> F } \\
\text { Positive spillover W-> F } \\
\text { Negative spillover F->W } \\
\text { Positive spillover F->W } \\
\text { (Scales constructed with 3-4 } \\
\text { items) }\end{array}$ & $\begin{array}{l}\text { Family factors (6 } \\
\text { measures) } \\
\text { Work factors: } \\
\text { - Decision latitude } \\
\text { - Pressure at work } \\
\text { - Support at work } \\
\text { Individual char.: } \\
\text { - Age } \\
\text { - Race/ethnicity } \\
\text { - Education } \\
\text { - Earnings } \\
\text { - Neuroticism } \\
\text { - Extraversion }\end{array}$ & $\begin{array}{l}1-19 \mathrm{hrs} / \text { week } \\
20-35 \mathrm{hrs} / \text { week } \\
45 \text { or more } \\
\text { hrs/week }\end{array}$ & $\begin{array}{l}\text { For both men and women: } \\
\text { - } 45 \text { or more hrs/week associated with more negative } \\
\text { spillover W->F } \\
\text { For women: } \\
\text { - Working part-time } 1-19 \mathrm{hrs} / \text { week was associated With } \\
\quad \text { less negative spillover W->F and F-> W }\end{array}$ \\
\hline $\begin{array}{l}\text { Hanson } \\
\text { (2004) }\end{array}$ & Sweden & $\begin{array}{l}\text { Explore what } \\
\text { characterizes the } \\
\text { work conditions in } \\
\text { flexible forms of } \\
\text { work and how the }\end{array}$ & $\begin{array}{l}377 \text { freelance journal- } \\
\text { ists, } 48 \% \text { men } \\
\text { Questionnaire data on } \\
377, \text { e-mail interviews } \\
\text { with } 35\end{array}$ & & & & $\begin{array}{l}\text { Freedom was on the one hand emphasized as a main } \\
\text { advantage both with regard to the performance of work and } \\
\text { with regard to work-life balance; on the other hand, it was } \\
\text { related to high workload as well as insufficient time for } \\
\text { social interaction and education. }\end{array}$ \\
\hline
\end{tabular}




\begin{tabular}{|c|c|c|c|c|c|c|c|}
\hline Reference & Country & $\begin{array}{l}\text { Purpose, design and } \\
\text { statistics }\end{array}$ & Sample & Outcome measures & Other measures & $\begin{array}{l}\text { Measures of working } \\
\text { time arrangements }\end{array}$ & Findings \\
\hline & & $\begin{array}{l}\text { individual handles } \\
\text { the flexible work } \\
\text { settings in the form } \\
\text { of competence }\end{array}$ & & & & & $\begin{array}{l}\text { The deregulation of work created both a distribution and an } \\
\text { overlap between work and non-work, resulting in an in- } \\
\text { creased workload due to work becoming both more exten- } \\
\text { sive and widespread }\end{array}$ \\
\hline $\begin{array}{l}\text { Hattery } \\
(2001)\end{array}$ & U.S.A. & $\begin{array}{l}\text { Understand the } \\
\text { costs and benefits } \\
\text { of utilizing nonover- } \\
\text { lapping shift work } \\
\text { as a strategy for } \\
\text { WLB } \\
\text { Qualitative study } \\
\text { using semi- } \\
\text { structured inter- } \\
\text { views }\end{array}$ & $\begin{array}{l}30 \text { mothers selected } \\
\text { from a random sample }\end{array}$ & - & - & $\begin{array}{l}\text { Nonoverlapping } \\
\text { shifts: both parents } \\
\text { work outside home, } \\
\text { but at different } \\
\text { nonoverlapping } \\
\text { shifts. }\end{array}$ & $\begin{array}{l}\text { Positive factors mentioned: } \\
\text { - Saving on child care costs } \\
\text { - Provision of all child care by parents } \\
\text { Negative factors mentioned: } \\
\text { - Difficulties with scheduling } \\
\text { - Sleep deprivation } \\
\text { - Lack of marital couple time } \\
\text { Effect of "solo parenting" }\end{array}$ \\
\hline $\begin{array}{l}\text { Heymann \& } \\
\text { Earle (2001) }\end{array}$ & U.S.A. & $\begin{array}{l}\text { Effects of parental } \\
\text { evening work on } \\
\text { home environment } \\
\text { among children }\end{array}$ & $\begin{array}{l}1133 \text { school children } \\
\text { ( } 5-10 \text { years) }\end{array}$ & $\begin{array}{l}\text { Home Observation Meas- } \\
\text { urement of the Environment } \\
\text { (HOME) - measure of } \\
\text { cognitive stimulation and } \\
\text { emotional support provided } \\
\text { by a child's family }\end{array}$ & $\begin{array}{l}\text { Total number of hours } \\
\text { worked } \\
\text { Parental education } \\
\text { Poverty } \\
\text { Number of children } \\
\text { Race } \\
\text { Child's gender }\end{array}$ & $\begin{array}{l}\text { Parents evening } \\
\text { work ( } 7.30 \text { PM- } \\
9.30)\end{array}$ & $\begin{array}{l}\text { Having one or more parents work in the evening had a } \\
\text { negative effect on the HOME score (10\% decline). Effect for } \\
\text { mothers working evenings was } 11 \% \text { and for fathers } 8 \% \text {. } \\
\text { Effects among poor families were } 16 \% \text { and among non- } \\
\text { poor } 9 \% \text {. }\end{array}$ \\
\hline $\begin{array}{l}\text { Higgins et al. } \\
(2000)\end{array}$ & Canada & $\begin{array}{l}\text { Explore effects of } \\
\text { part-time work } \\
\text { among career and } \\
\text { non-career women } \\
\text { Analysed cross- } \\
\text { sectional by } 2 \times 2 \\
\text { MANOVA and } \\
\text { interview data (with } \\
15 \text { career and } 30 \\
\text { earner part-time } \\
\text { mothers) }\end{array}$ & $\begin{array}{l}712 \text { mothers in part- } \\
\text { time earner positions } \\
\text { and } 117 \text { career } \\
\text { positions were com- } \\
\text { pared to } 4371 \text { full-time } \\
\text { working mothers in } \\
\text { earner positions and } \\
1521 \text { in career posi- } \\
\text { tions }\end{array}$ & $\begin{array}{l}\text { Role overload } \\
W->F \text { Interference } \\
\text { F->W interference } \\
\text { Individual time management } \\
\text { Family time management } \\
\text { Perceived stress } \\
\text { Depressed mood } \\
\text { Life satisfaction }\end{array}$ & $\begin{array}{l}\text { (Age } \\
\text { Children } \\
\text { Age of children } \\
\text { Work hr/week } \\
\text { Education } \\
\text { Income } \\
\text { Family income) }\end{array}$ & $\begin{array}{l}\text { Part-time vs. full } \\
\text { time } \\
\text { Career vs. earner }\end{array}$ & $\begin{array}{l}\text { Among earning mothers: } \\
\text { Part-time work was associated with lower role overload and } \\
\text { lower F->W Interference, lower W-> F interference, better } \\
\text { Time management for family and individual and higher life } \\
\text { satisfaction, compared to full-time. It was unrelated to stress } \\
\text { Among career mothers: } \\
\text { No less role overload or F->W conflicts among part-time } \\
\text { working mothers, slightly better Time management for } \\
\text { family, and better time management for individual and lower } \\
\text { W - }>\text { F interference compared to full-time. Part-time was } \\
\text { related to higher life-satisfaction but not to stress. } \\
\text { Life-satisfaction was lower among earners and depressed } \\
\text { mood was higher among earners than among career } \\
\text { mothers. }\end{array}$ \\
\hline $\begin{array}{l}\text { Hill et al. } \\
\text { (2001) }\end{array}$ & U.S.A. & $\begin{array}{l}\text { Influence of job } \\
\text { flexibility on WFB. } \\
\text { Cross-sectional } \\
\text { Multiple regression } \\
\text { analysis }\end{array}$ & 6451 IBM employees & WFB (scale of five items) & $\begin{array}{l}\text { Demographics (gen- } \\
\text { der, marital status, } \\
\text { preschool children, } \\
\text { occupational level) } \\
\text {-Unpaid domestic } \\
\text { labour } \\
\text {-Working hrs/week } \\
\text { incl. commuting time }\end{array}$ & $\begin{array}{l}\text { Working hrs/week } \\
\text { incl. commuting } \\
\text { time } \\
\text { Perceived flexibility } \\
\text { (5 items) } \\
\text { Flex-time } \\
\text { Flex-place (possi- } \\
\text { bility to work from } \\
\text { different places) }\end{array}$ & $\begin{array}{l}\text { Working hours (incl. commuting time) were negatively } \\
\text { associated with WLB } \\
\text { Strong positive association between perceived flexibility and } \\
\text { work-family balance. Both flex-time and flex-place added } \\
\text { positively to better work-family balance. } \\
\text { Among those working between } 40-50 \text { hours per week: } \\
28 \% \text { of those with both flex-time and flex-place experienced } \\
\text { difficulties with work-family balance, compared with } 46 \% \text { of } \\
\text { those with neither flex-time nor flex-place. }\end{array}$ \\
\hline
\end{tabular}




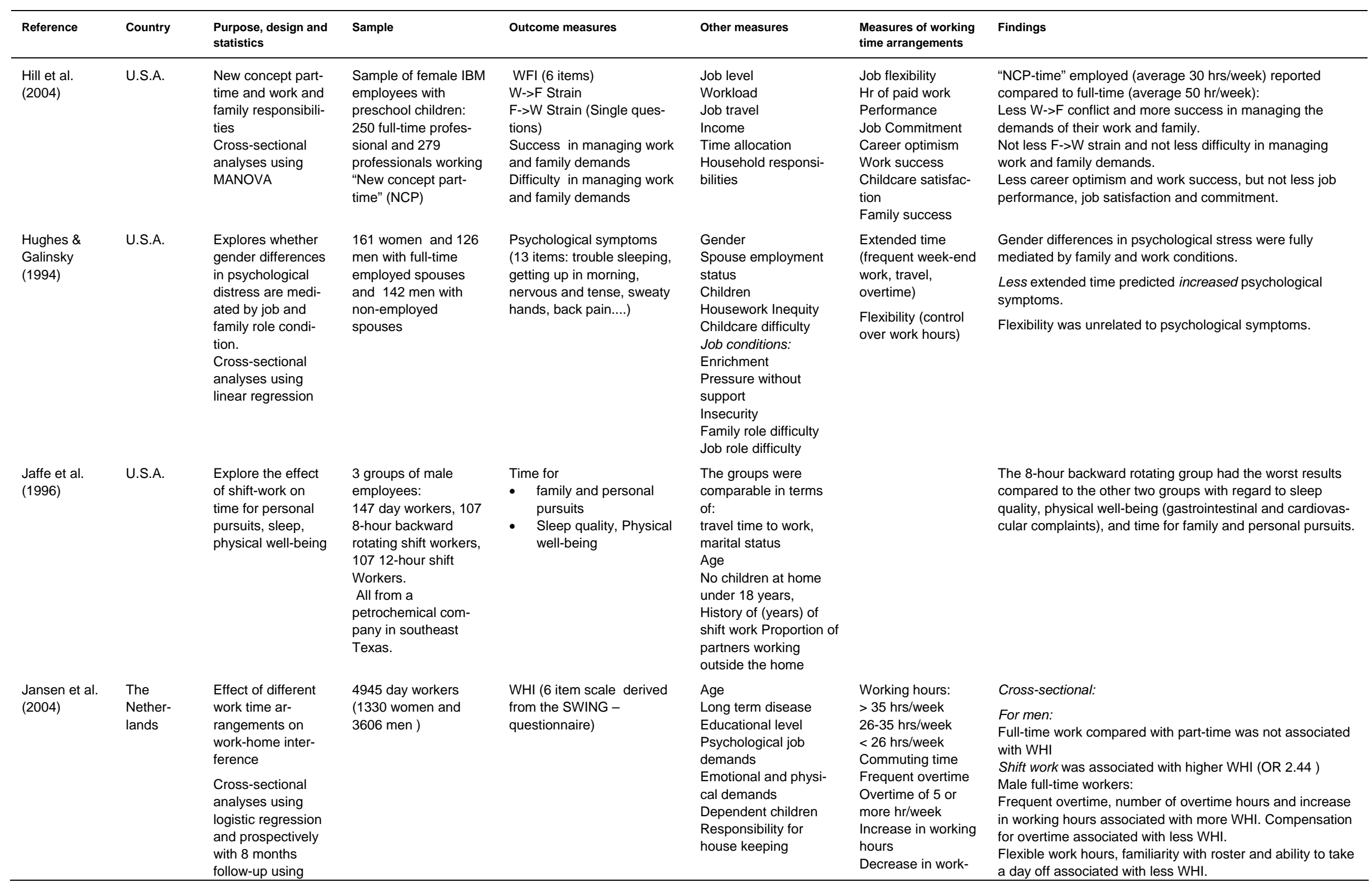




\begin{tabular}{|c|c|c|c|c|c|c|c|}
\hline Reference & Country & $\begin{array}{l}\text { Purpose, design and } \\
\text { statistics }\end{array}$ & Sample & Outcome measures & Other measures & $\begin{array}{l}\text { Measures of working } \\
\text { time arrangements }\end{array}$ & Findings \\
\hline & & linear regression & & & & $\begin{array}{l}\text { ing hours } \\
\text { Compensation for } \\
\text { overtime } \\
\text { Shift work } \\
\text { Flexible work hours } \\
\text { Work roster known } \\
1 \text { month in ad- } \\
\text { vance } \\
\text { Able to take a day } \\
\text { off when wanted }\end{array}$ & 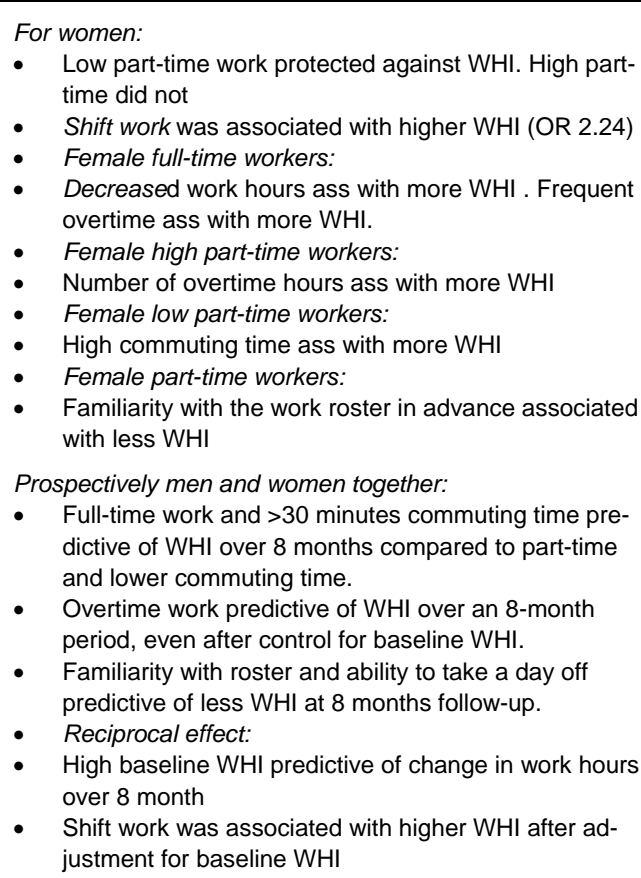 \\
\hline $\begin{array}{l}\text { Jansen et al. } \\
\text { (2003) }\end{array}$ & $\begin{array}{l}\text { The } \\
\text { Nether- } \\
\text { lands }\end{array}$ & $\begin{array}{l}\text { Risk factors for the } \\
\text { onset of WFC and } \\
\text { consequences. } \\
\text { Prospective analy- } \\
\text { ses with } 6 \text { follow- } \\
\text { up measures over } \\
2 \text { years, using } \\
\text { multivariate Cox } \\
\text { regression analy- } \\
\text { ses }\end{array}$ & $\begin{array}{l}\text { At } 1 \text { year follow-up: } \\
5785 \text { employed men } \\
\text { and } 1098 \text { employed } \\
\text { women with a mini- } \\
\text { mum of } 26 \text { hrs/week }\end{array}$ & $\begin{array}{l}\text { WFC measured by a single } \\
\text { question ("Are you able to } \\
\text { adequately combine work } \\
\text { and family life?") } \\
\text { Need for recovery from } \\
\text { work } \\
\text { Fatigue }\end{array}$ & $\begin{array}{l}\text { Gender } \\
\text { Age } \\
\text { Educational level } \\
\text { Long tern disease } \\
\text { Work Characteristics: } \\
\text { Psychological job } \\
\text { demands } \\
\text { Decision latitude } \\
\text { Social support } \\
\text { Emotional demands } \\
\text { Physical demands } \\
\text { Conflicts with co- } \\
\text { worker or supervisor } \\
\text { Job insecurity } \\
\text { Private situation: } \\
\text { Family status } \\
\text { Demands at home } \\
\text { Support at home } \\
\text { Presence of life events }\end{array}$ & $\begin{array}{l}\text { Working hr/week } \\
\text { Flexible working } \\
\text { hours } \\
\text { Overtime work } \\
\text { Work schedules } \\
\text { (day or shift) } \\
\text { Commuting time }\end{array}$ & $\begin{array}{l}\text { At 1-year follow-up for women: } \\
\text { WFC was predicted by more than } 30 \text { minutes commuting } \\
\text { time and by overtime work. RR for WFC was as high for } \\
\text { female shift workers as for male, but not significant. Flexi- } \\
\text { ble work hours were not predictive. } \\
\text { At 1-year follow-up for men: } \\
\text { WFC was predicted by a range of work characteristics. } \\
\text { Commuting times were not predictive and overtime work } \\
\text { and flexible work hours were not predictive, but shift work } \\
\text { was.. }\end{array}$ \\
\hline
\end{tabular}




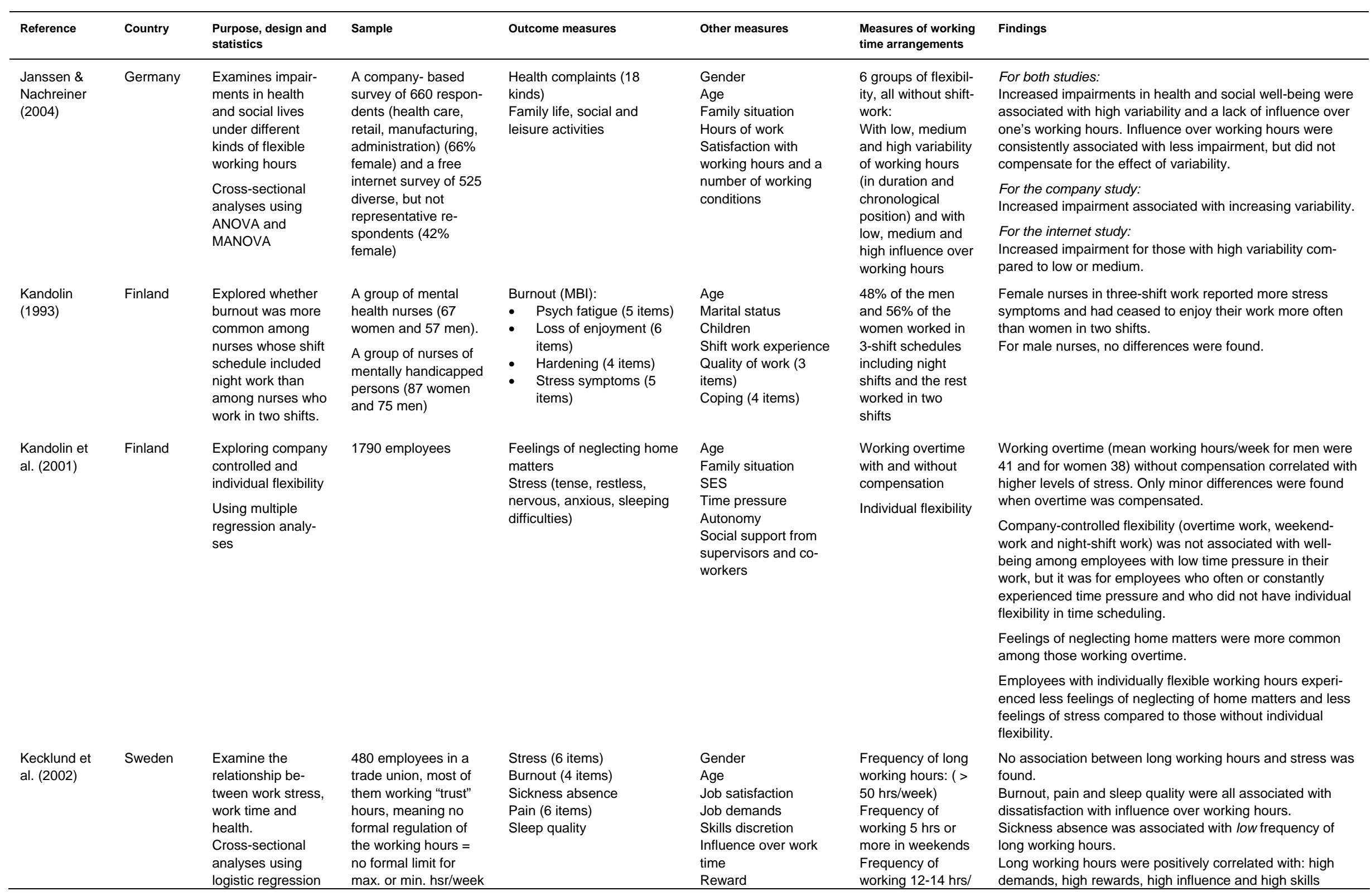




\begin{tabular}{|c|c|c|c|c|c|c|c|}
\hline Reference & Country & $\begin{array}{l}\text { Purpose, design and } \\
\text { statistics }\end{array}$ & Sample & Outcome measures & Other measures & $\begin{array}{l}\text { Measures of working } \\
\text { time arrangements }\end{array}$ & Findings \\
\hline & & & & & $\begin{array}{l}\text { Social support from } \\
\text { colleagues and man- } \\
\text { agement } \\
\text { Adequate breaks } \\
\text { Working hours }\end{array}$ & $\begin{array}{l}\text { day } \\
\text { Frequency of } \\
\text { working }<7,5 \\
\text { hrs/day. } \\
\text { Influence over } \\
\text { working time }\end{array}$ & $\begin{array}{l}\text { discretion } \\
\text { Employees with trust hours were more satisfied with work- } \\
\text { ing time and reported advantages for social life. } \\
\text { Influence over work hours was positively associated with } \\
\text { measures of burnout, pain and sleep. } \\
\text { Influence over work hours did not explain as much of the } \\
\text { variance as dissatisfaction with work, high demands and } \\
\text { low rewards. }\end{array}$ \\
\hline \multirow[t]{2}{*}{$\begin{array}{l}\text { Kinnunen \& } \\
\text { Mauno } \\
(1998)\end{array}$} & \multirow[t]{2}{*}{ Finland } & \multirow{2}{*}{$\begin{array}{l}\text { Examine the } \\
\text { prevalence, ante- } \\
\text { cedents and } \\
\text { consequences of } \\
\text { work-family conflict } \\
\text { Cross-sectional } \\
\text { analyses, using } \\
\text { multiple linear } \\
\text { regression }\end{array}$} & \multirow{2}{*}{$\begin{array}{l}501 \text { employees from } \\
\text { three areas: public } \\
\text { sector, manufacturing } \\
\text { for export and home } \\
\text { market }\end{array}$} & \multirow[t]{2}{*}{$\begin{array}{l}W->F \text { conflict } \\
F->W \text { conflict }\end{array}$} & \multirow{2}{*}{$\begin{array}{l}\text { Number of children } \\
\text { Age of youngest child } \\
\text { Spouses employment } \\
\text { status } \\
\text { Job insecurity } \\
\text { Leadership relations } \\
\text { Influence at work }\end{array}$} & $\begin{array}{l}\text { Working full time or } \\
\text { part-time (under or } \\
\text { over } 35 \text { hrs/week) }\end{array}$ & $\begin{array}{l}\text { Among Women: } \\
\quad \mathrm{W}->\mathrm{F} \text { conflict was associated with full-time job (and } \\
\text { leadership relations, no. of children and job insecurity. }\end{array}$ \\
\hline & & & & & & Non-day shift & $\begin{array}{l}\text { Among Men: } \\
\text { - } \quad \mathrm{F}>\mathrm{W} \text { conflict was not associated with working time, but } \\
\quad \text { with number of children and job insecurity. } \\
\text { - } \mathrm{W}->\mathrm{F} \text { conflict was associated with education and } \\
\text { number of children living at home }\end{array}$ \\
\hline \multirow[t]{5}{*}{$\begin{array}{l}\text { Lundberg \& } \\
\text { Franken- } \\
\text { haeuser } \\
\text { (1999) }\end{array}$} & \multirow[t]{5}{*}{ Sweden } & $\begin{array}{l}\text { Examine psycho- } \\
\text { logical and physio- } \\
\text { logical stress } \\
\text { responses among } \\
\text { managers }\end{array}$ & \multirow[t]{5}{*}{$\begin{array}{l}21 \text { female and } 21 \\
\text { male managers and } \\
\text { professional special- } \\
\text { ists in high-ranking } \\
\text { positions from an } \\
\text { insurance company }\end{array}$} & \multirow{5}{*}{$\begin{array}{l}\text { Questionnaire: } \\
\text { Everyday stress } \\
\text { Psychosomatic symptoms } \\
\text { Other health- related vari- } \\
\text { ables } \\
\text { Self-reports (log-books): } \\
\text { 1. Pressed for time and } \\
\text { demands, 2. Tense, tired } \\
\text { irritated 3. Alert, concen- } \\
\text { trated 4. being out of control } \\
\text { Psycho physiological tests: } \\
\text { Ephedrine } \\
\text { Nor epinephrine } \\
\text { Cortisol } \\
\text { Systolic and diastolic blood } \\
\text { pressures } \\
\text { Heart rate }\end{array}$} & \multirow[t]{5}{*}{$\begin{array}{l}\text { Work situation } \\
\text { Leadership styles }\end{array}$} & \multirow[t]{5}{*}{$\begin{array}{l}\text { Total workload } \\
\text { (sum of paid and } \\
\text { unpaid work) }\end{array}$} & \multirow[t]{2}{*}{$\begin{array}{l}\text { There was no difference between men and women on time } \\
\text { spent on paid work ( } 49.1 \text { hrs/week for women and } 49.8 \text { for } \\
\text { men). Women spent twice as much time on unpaid home } \\
\text { and household work ( } 16.2 \text { for women and } 8 \text { for men). } \\
\text { Women carried main responsibility for almost all duties at } \\
\text { home. }\end{array}$} \\
\hline & & \multirow{2}{*}{$\begin{array}{l}\text { Questionnaire and } \\
\text { semi- structured } \\
\text { interviews. }\end{array}$} & & & & & \\
\hline & & & & & & & $\begin{array}{l}\text { Women perceived more stress than men from home and } \\
\text { household work }\end{array}$ \\
\hline & & $\begin{array}{l}\text { Measures from } 7 \\
\text { time points from a } \\
\text { day at work and a } \\
\text { day at home }\end{array}$ & & & & & $\begin{array}{l}\text { In women but not in men epinephrine and nor epinephrine } \\
\text { was significantly elevated after work }\end{array}$ \\
\hline & & $\begin{array}{l}\text { Analyses of vari- } \\
\text { ance }\end{array}$ & & & & & \\
\hline \multirow[t]{2}{*}{$\begin{array}{l}\text { Lundberg et } \\
\text { al. (1994) }\end{array}$} & \multirow[t]{2}{*}{ Sweden } & \multirow{2}{*}{$\begin{array}{l}\text { Compare workload } \\
\text { and stress level of } \\
\text { full-time employed } \\
\text { men and women at } \\
\text { same educational } \\
\text { and occupational } \\
\text { level }\end{array}$} & \multirow{2}{*}{$\begin{array}{l}501 \text { men and } 679 \\
\text { women from four } \\
\text { occupational areas in } \\
\text { white collar sectors: } \\
\text { technology and } \\
\text { natural science, } \\
\text { education, health } \\
\text { care, administrative } \\
\text { work }\end{array}$} & \multirow{2}{*}{$\begin{array}{l}\text { Perceived total work-load } \\
\text { Stress from paid work } \\
\text { Conflicting demands }\end{array}$} & $\begin{array}{l}\text { Perceived autonomy at } \\
\text { work }\end{array}$ & \multirow{2}{*}{$\begin{array}{l}\text { Total workload } \\
\text { (sum of paid and } \\
\text { unpaid work) }\end{array}$} & \multirow{2}{*}{$\begin{array}{l}\text { Women reported higher levels of work overload, stress and } \\
\text { conflict than men. This increased with the number of chil- } \\
\text { dren at home. }\end{array}$} \\
\hline & & & & & $\begin{array}{l}\text { Control over house- } \\
\text { hold work }\end{array}$ & & \\
\hline $\begin{array}{l}\text { Major et al. } \\
(2002)\end{array}$ & Canada & $\begin{array}{l}\text { Examine the } \\
\text { effects of work time }\end{array}$ & $\begin{array}{l}513 \text { employees in a } \\
\text { Fortune } 500 \text { Company }\end{array}$ & $\begin{array}{l}\text { WIF (6 item scale from } \\
\text { Netemeyer et al.) }\end{array}$ & $\begin{array}{l}\text { Career identity sali- } \\
\text { ence }\end{array}$ & $\begin{array}{l}\text { Schedule flexibility } \\
(21 \text { items) }\end{array}$ & $\begin{array}{l}\text { Work time was positively related to WIF. } \\
\text { Work time was indirectly related to psychological distress }\end{array}$ \\
\hline
\end{tabular}




\begin{tabular}{|c|c|c|c|c|c|c|c|}
\hline Reference & Country & $\begin{array}{l}\text { Purpose, design and } \\
\text { statistics }\end{array}$ & Sample & Outcome measures & Other measures & $\begin{array}{l}\text { Measures of working } \\
\text { time arrangements }\end{array}$ & Findings \\
\hline & & $\begin{array}{l}\text { on WFC and WFC } \\
\text { on psychological } \\
\text { distress } \\
\text { Cross-sectional } \\
\text { analyses using } \\
\text { multiple regression } \\
\text { analyses and SEM }\end{array}$ & (62,1 \% male) & $\begin{array}{l}\text { Depression ( } 20 \text { item scale) } \\
\text { Somatic complaints ( } 12 \\
\text { items) }\end{array}$ & $\begin{array}{l}\text { Work-role overload } \\
\text { Org. Rewards and org. } \\
\text { Expectations for time } \\
\text { spent on work } \\
\text { Perceived financial } \\
\text { needs } \\
\text { Parental demands (no } \\
\text { of children) }\end{array}$ & $\begin{array}{l}\text { Work time com- } \\
\text { puted on answers } \\
\text { from three ques- } \\
\text { tions about aver- } \\
\text { age hrs/week, hrs } \\
\text { worked yesterday } \\
\text { and second job. }\end{array}$ & $\begin{array}{l}\text { through WIF } \\
\text { Several work and family characteristics were significantly } \\
\text { related to work time } \\
\text { Non job responsibilities were not related to WIF } \\
\text { Interactions between work time and non job responsibility } \\
\text { were not significant = no moderation effects } \\
\text { Schedule flexibility was negatively related to WIF } \\
\text { Interactions between schedule flexibility and work time were } \\
\text { not significant = no moderation effects }\end{array}$ \\
\hline $\begin{array}{l}\text { Marchand et } \\
\text { al. (2005) }\end{array}$ & Canada & $\begin{array}{l}\text { Examine the } \\
\text { contribution of } \\
\text { occupation and } \\
\text { work organisation } \\
\text { on psychological } \\
\text { distress } \\
\text { Cross-sectional } \\
\text { analyses using } \\
\text { Multi-level hierar- } \\
\text { chical regression }\end{array}$ & $\begin{array}{l}9501 \text { workers ( } 43.5 \% \\
\text { female) from } 419 \\
\text { occupations in Que- } \\
\text { bec }\end{array}$ & $\begin{array}{l}\text { Psychological distress (PSI } \\
14 \text { item) }\end{array}$ & 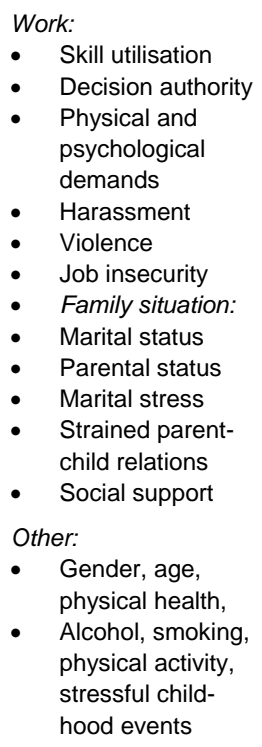 & $\begin{array}{l}\text { Working hrs in } \\
\text { main and second } \\
\text { job } \\
\text { Work schedule } \\
\text { irregularity (single } \\
\text { item with frequency } \\
\text { response catego- } \\
\text { ries) }\end{array}$ & $\begin{array}{l}\text { Position in the occupational structure and workplace con- } \\
\text { straints-resources explain a small part of the variation in } \\
\text { individual psychological distress beyond the part explained } \\
\text { by family situation, social support and personal characteris- } \\
\text { tics. } \\
\text { Irregular schedule was in the multivariate model associated } \\
\text { with psychological distress, while working hours were not. }\end{array}$ \\
\hline $\begin{array}{l}\text { Mattheus \& } \\
\text { Power (2002) }\end{array}$ & Great U.K. & $\begin{array}{l}\text { Assesses the } \\
\text { contribution of } \\
\text { work-home factors } \\
\text { on socio-economic } \\
\text { differences in } \\
\text { psychological } \\
\text { distress among } \\
\text { women } \\
\text { Cross-sectional } \\
\text { analyses using } \\
\text { univariate logistic } \\
\text { regression }\end{array}$ & $\begin{array}{l}4960 \text { women at age } \\
33, \text { taken from a birth } \\
\text { cohort study }\end{array}$ & $\begin{array}{l}\text { Psychological distress } \\
\text { (Malaise Inventory, } 24 \\
\text { items) }\end{array}$ & $\begin{array}{l}\text { Social class } \\
\text { Work role: } \\
\text { Employment status } \\
\text { Learning opportunities } \\
\text { Monotonous work } \\
\text { Work pace } \\
\text { Breaks } \\
\text { Job insecurity } \\
\text { Redundancy } \\
\text { Home roles: } \\
\text { Marital status } \\
\text { Domestic responsibili- } \\
\text { ties } \\
\text { Parental status }\end{array}$ & $\begin{array}{l}\text { Unsocial working } \\
\text { hours working } \\
\text { nights between } \\
10 \mathrm{pm} \text { and } 7 \mathrm{am} \text { ) }\end{array}$ & $\begin{array}{l}\text { Unsocial working hours was in the univariate analyses not } \\
\text { associated with psychological distress. } \\
\text { Higher psychosocial strain, monotonous work, job insecu- } \\
\text { rity, youngest child over } 6 \text {, three or more children, partner } \\
\text { not employed and low social support were all associated } \\
\text { with higher psychological distress. While being in employ- } \\
\text { ment and being married were associated with less distress. }\end{array}$ \\
\hline
\end{tabular}




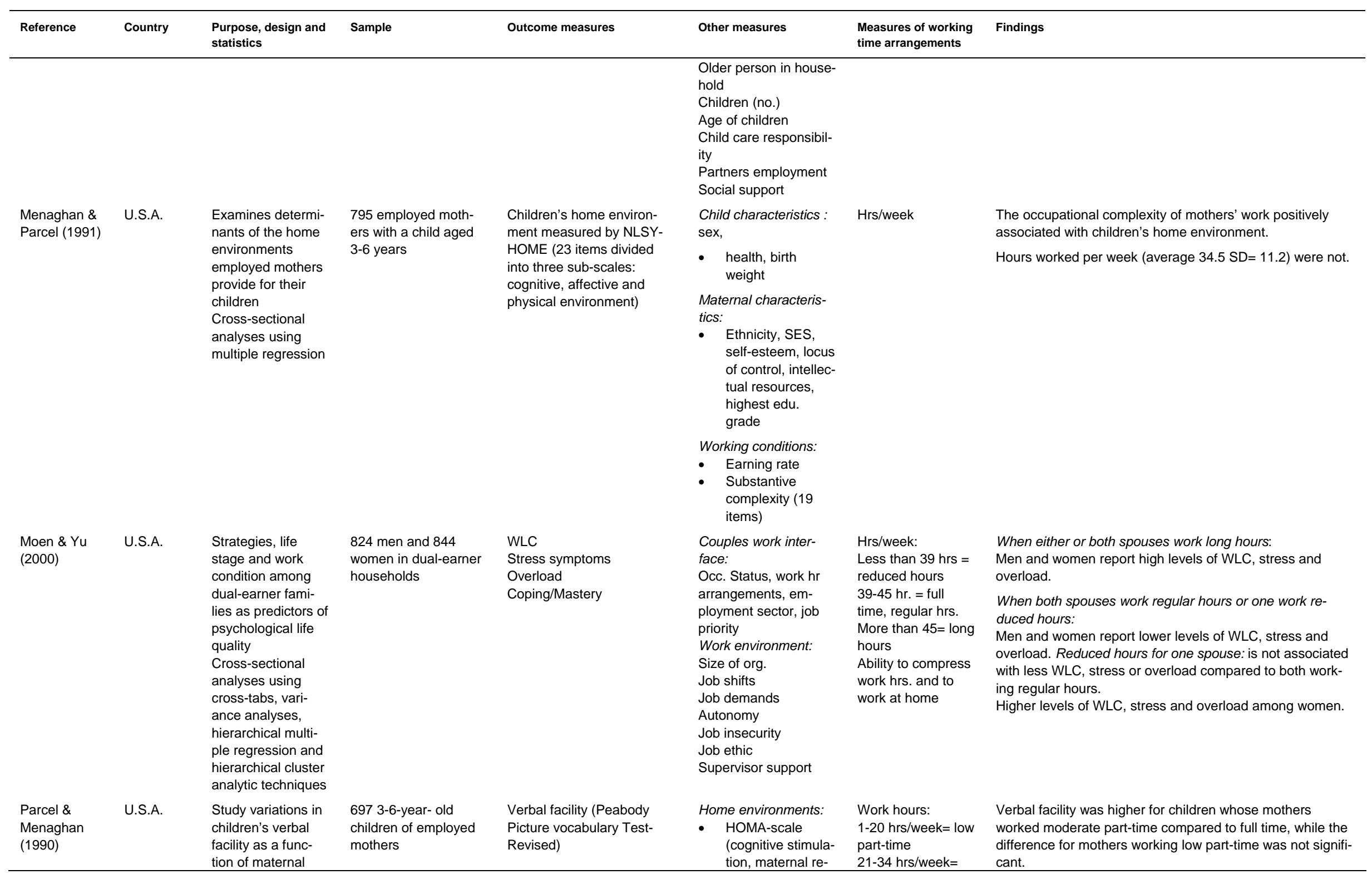




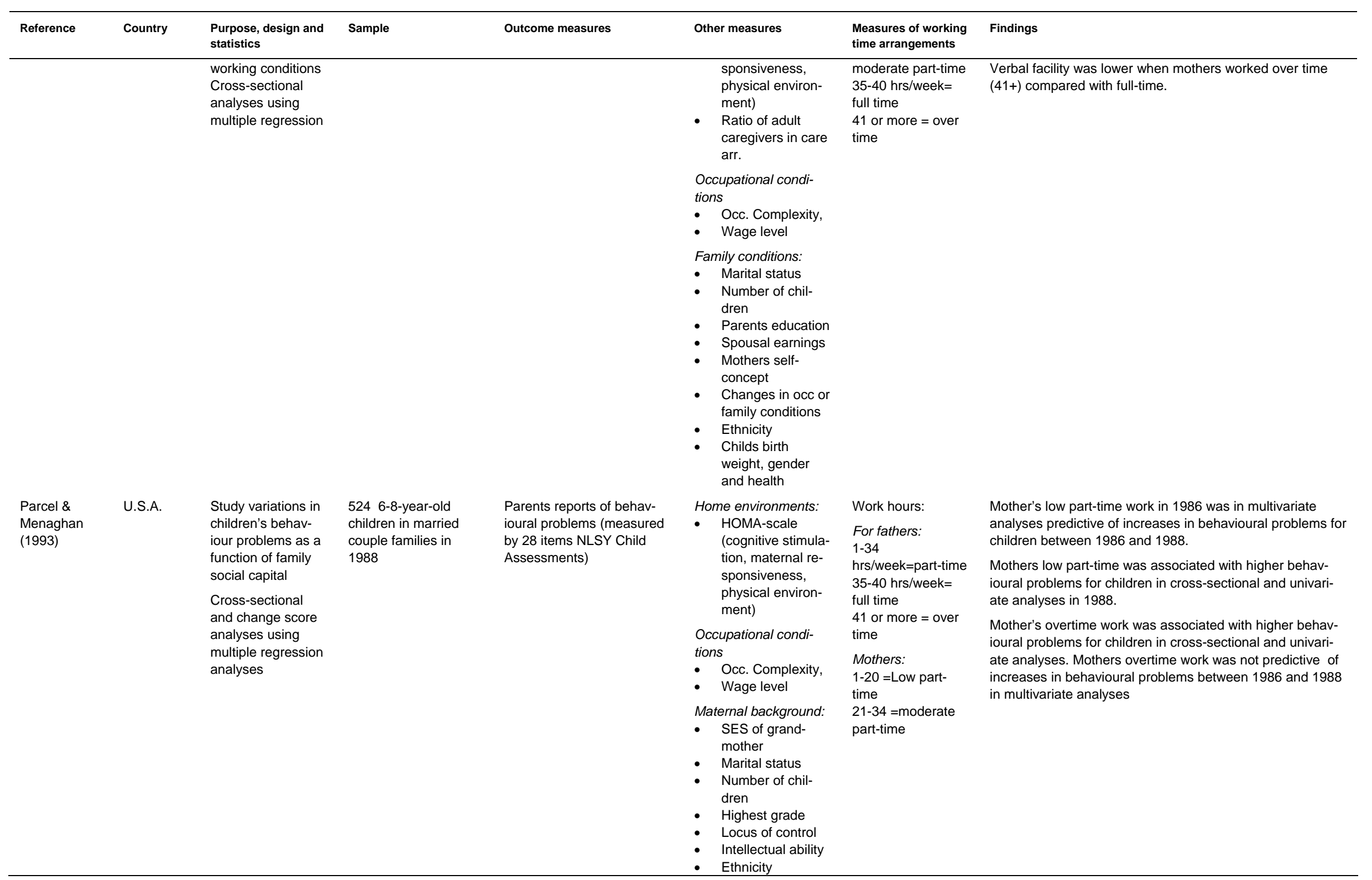




\begin{tabular}{|c|c|c|c|c|c|c|c|}
\hline Reference & Country & $\begin{array}{l}\text { Purpose, design and } \\
\text { statistics }\end{array}$ & Sample & Outcome measures & Other measures & $\begin{array}{l}\text { Measures of working } \\
\text { time arrangements }\end{array}$ & Findings \\
\hline & & & & & $\begin{array}{l}\text { Child's birth } \\
\text { weight, gender, } \\
\text { health and shy- } \\
\text { ness }\end{array}$ & & \\
\hline $\begin{array}{l}\text { Portela et al. } \\
\text { (2004) }\end{array}$ & Brazil & $\begin{array}{l}\text { Tested the hy- } \\
\text { pothesis that the } \\
\text { prevalence of } \\
\text { insufficient time for } \\
\text { non-professional } \\
\text { activities is higher } \\
\text { among night than } \\
\text { day workers } \\
\text { Analysed univari- } \\
\text { ate with estimation } \\
\text { of the prevalence } \\
\text { ratio }\end{array}$ & $\begin{array}{l}258 \text { female health } \\
\text { care personnel }\end{array}$ & $\begin{array}{l}\text { Insufficient time for non- } \\
\text { professional activities } \\
\text { (family, leisure, and rest) } \\
\text { Diseases: } \\
16 \text { kinds } \\
\text { - Migraine } \\
\text { - Severe psychological } \\
\text { problems } \\
\text { - Mild emotional disorders } \\
\text { (mild depression, tension, } \\
\text { anxiety, or insomnia) } \\
\text { Sleep complaints }\end{array}$ & $\begin{array}{l}\text { Timetables } \\
\text { No. of jobs } \\
\text { Hrs/week } \\
\text { No. of nights } \\
\text { worked/week } \\
\text { Reasons for night work } \\
\text { Reasons for quitting } \\
\text { Total work hr (domes- } \\
\text { tic and work) } \\
\text { Housework } \\
\text { Possibly nap taken } \\
\text { during the night shift }\end{array}$ & $\begin{array}{l}\text { Shift-work sched- } \\
\text { ule (no successive } \\
\text { night shifts) }\end{array}$ & $\begin{array}{l}\text { Migraine, headaches occurred less frequently among night } \\
\text { than day workers. } \\
\text { Mild emotional disorders were less frequent among night } \\
\text { and ex-night workers than day workers who never had } \\
\text { worked at night } \\
\text { No significant difference between night and dayworkers as } \\
\text { to sleep complaints } \\
\text { Working nights more than four times per 2-week span was } \\
\text { related to complaints about insufficient time for children and } \\
\text { rest/leisure. }\end{array}$ \\
\hline $\begin{array}{l}\text { Presser } \\
(2000)\end{array}$ & U.S.A. & $\begin{array}{l}\text { Examines the } \\
\text { extend to which } \\
\text { working non- } \\
\text { standard schedules } \\
\text { affects the likeli- } \\
\text { hood of separa- } \\
\text { tions or divorce } \\
\text { Prospective study } \\
\text { with } 5 \text { years of } \\
\text { follow-up } \\
\text { Using multivariate } \\
\text { logistic regression }\end{array}$ & $\begin{array}{l}3467 \text { couples married } \\
\text { at wave } 1(1987-1988) \\
\text { and re- interviewed at } \\
\text { wave } 2(1992-1994)\end{array}$ & Separation or divorce & $\begin{array}{l}\text { Employment status } \\
\text { Number of hours } \\
\text { employed preceding } \\
\text { week } \\
\text { Education } \\
\text { Previously married } \\
\text { Duration of current } \\
\text { marriage } \\
\text { No. of months be- } \\
\text { tween waves } \\
\text { Age of wife } \\
\text { Age difference be- } \\
\text { tween spouses } \\
\text { No. of children } \\
\text { Gender ideology scale } \\
\text { Couple time together }\end{array}$ & $\begin{array}{l}\text { Working shift: } \\
\text { Fixed day shift } \\
\text { Fixed evening shift } \\
\text { Fixed night shift } \\
\text { Rotating shift }\end{array}$ & $\begin{array}{l}\text { For couples with children: marital instability was increased } \\
\text { by night and rotating shifts. For men married less than } 5 \\
\text { years, working nights increased the likelihood more than six } \\
\text { times compared to fixed day work. For women married } \\
\text { more than } 5 \text { years, working nights increased the likelihood } \\
\text { by three times. } \\
\text { For couples without children: } \\
\text { No effect of non-standard work schedules } \\
\text { Working weekends did not affect marital instability }\end{array}$ \\
\hline $\begin{array}{l}\text { Shields } \\
\text { (1999) }\end{array}$ & Canada & $\begin{array}{l}\text { Examines associa- } \\
\text { tions between long } \\
\text { working hours, } \\
\text { depression and } \\
\text { changes in health } \\
\text { behaviour } \\
\text { Longitudinal analy- } \\
\text { ses from } 1994 / 95 \\
\text { to } 1996 / 97 \text { using } \\
\text { multiple logistic } \\
\text { regression }\end{array}$ & $\begin{array}{l}2181 \text { men and } 1649 \\
\text { women aged } 25-54 \\
\text { years, who worked } 35 \\
\text { hours or more per } \\
\text { week at baseline. } \\
\text { Data from the National } \\
\text { Population health } \\
\text { Survey. }\end{array}$ & $\begin{array}{l}\text { Depression (Major depres- } \\
\text { sive Episodes) } \\
\text { Body mass index } \\
\text { Smoking } \\
\text { Alcohol consumption } \\
\text { Physical activity }\end{array}$ & $\begin{array}{l}\text { Marital status } \\
\text { Education } \\
\text { Household income } \\
\text { Children under } 12 \\
\text { Occupation } \\
\text { Shift work } \\
\text { Multiple jobs } \\
\text { Job strain (decision } \\
\text { latitude x psychologi- } \\
\text { cal demands) } \\
\text { Job insecurity } \\
\text { Supervisor support }\end{array}$ & $\begin{array}{l}\text { Standard hours: } \\
35-40 \text { hrs/week } \\
\text { Long hours } 41 \text { or } \\
\text { more hrs/week }\end{array}$ & $\begin{array}{l}\text { Women who worked long hours at baseline had increased } \\
\text { odds for subsequent depression (OR 2.2). }\end{array}$ \\
\hline
\end{tabular}




\begin{tabular}{|c|c|c|c|c|c|c|c|}
\hline Reference & Country & $\begin{array}{l}\text { Purpose, design and } \\
\text { statistics }\end{array}$ & Sample & Outcome measures & Other measures & $\begin{array}{l}\text { Measures of working } \\
\text { time arrangements }\end{array}$ & Findings \\
\hline $\begin{array}{l}\text { Shields } \\
(2002)\end{array}$ & Canada & $\begin{array}{l}\text { The objective was } \\
\text { to compare stress } \\
\text { factors and health } \\
\text { behaviours of shift } \\
\text { and regular day- } \\
\text { time Workers } \\
\text { Cross tabulations } \\
\text { on } 3583 \text { men and } \\
3273 \text { women and } \\
\text { multivariate longi- } \\
\text { tudinal analyses } \\
\text { over } 4 \text { years on } \\
2151 \text { men and } \\
2150 \text { women }\end{array}$ & $\begin{array}{l}\text { Data are from the } \\
\text { Canadian Community } \\
\text { Health Survey, the } \\
\text { National Population } \\
\text { Health Survey, and } \\
\text { the Survey of Work } \\
\text { Arrangements (all } \\
\text { between } 1991 \text { and } \\
\text { 2001) }\end{array}$ & $\begin{array}{l}\text { Chronic conditions: } \\
\text { Psychological distress } \\
\text { Psychosocial problems: } \\
\text { Personal stress ( } 5 \text { items) } \\
\text { Problems with partner ( } 3 \\
\text { items) } \\
\text { Difficulties finding a partner } \\
\text { (1 item) } \\
\text { Low mastery (self-efficacy) } \\
(7 \text { items) } \\
\text { Health behaviour: } \\
\text { Smoking } \\
\text { Drinking } \\
\text { BMI } \\
\text { Physical activity }\end{array}$ & $\begin{array}{l}\text { Age } \\
\text { Education } \\
\text { Marital status } \\
\text { Household income } \\
\text { Reasons for working } \\
\text { shifts } \\
\text { Work stress } \\
\text { Physical demands } \\
\text { Supervisor support } \\
\text { Co-worker support } \\
\text { Job Insecurity }\end{array}$ & $\begin{array}{l}\text { Work schedule: } \\
\text { Regular daytime } \\
\text { Evening shift } \\
\text { Rotating shift } \\
\text { Irregular shift }\end{array}$ & $\begin{array}{l}\text { For both sexes, an evening shift was associated with } \\
\text { increases in psychological distress levels over two years. } \\
\text { After control for work stress, personal stress, health behav- } \\
\text { iour, SES and other work-related factors, men who worked } \\
\text { at evening, rotating or irregular shifts had increased odds of } \\
\text { reporting having been diagnosed with a chronic condition } \\
\text { over a four-year period. } \\
\text { In cross-sectional analyses men who worked evening shifts } \\
\text { were more likely than those with regular daytime schedule } \\
\text { to report low sense of mastery and to have relationship } \\
\text { problems. For women, an irregular shift was related to high } \\
\text { personal stress, and a rotating shift, to a low sense of } \\
\text { mastery. }\end{array}$ \\
\hline $\begin{array}{l}\text { Skipper et al. } \\
\text { (1990) }\end{array}$ & U.S.A. & $\begin{array}{l}\text { Examine the } \\
\text { relationships } \\
\text { between shift work } \\
\text { and physical health } \\
\text { and mental de- } \\
\text { pression of nurse } \\
\text { shift workers }\end{array}$ & $\begin{array}{l}465 \text { nurses on day, } \\
\text { afternoon, night and } \\
\text { rotating shifts from } \\
\text { five hospitals }\end{array}$ & $\begin{array}{l}\text { Physical health Mental } \\
\text { depression }\end{array}$ & $\begin{array}{l}\text { Social and work- } \\
\text { related variables: } \\
\text { family relations formal } \\
\text { and informal social } \\
\text { participation; solitary } \\
\text { activities; job perform- } \\
\text { ance; and job-related } \\
\text { stress }\end{array}$ & $\begin{array}{l}\text { Different kinds of } \\
\text { shifts }\end{array}$ & $\begin{array}{l}\text { Shift work was not found to be significantly related to either } \\
\text { the nurses' physical health or mental depression }\end{array}$ \\
\hline $\begin{array}{l}\text { Smith \& } \\
\text { Folkard } \\
\text { (1993) }\end{array}$ & U.K. & $\begin{array}{l}\text { Explore the views } \\
\text { and feelings of shift } \\
\text { workers' partners } \\
\text { Questionnaire data } \\
\text { analysed } \\
\text { cross-sectional }\end{array}$ & $\begin{array}{l}47 \text { partners of UK } \\
\text { nuclear power shift } \\
\text { workers }\end{array}$ & $\begin{array}{l}\text { Personal disruption (16 } \\
\text { items about intimate rela- } \\
\text { tionship, social life, child- } \\
\text { care, meals etc.) } \\
\text { Perception of shift worker } \\
\text { problems: } \\
\text { Fatigue and sleep ( } 3 \text { items) } \\
\text { Stress and health ( } 5 \text { items) } \\
\text { Social and family ( } 6 \text { items) }\end{array}$ & - & $\begin{array}{l}\text { Partners shift work: } \\
\text { continuous 5-week } \\
\text { schedule }\end{array}$ & $\begin{array}{l}\text { A sizeable proportion of partners reported being unhappy } \\
\text { with their spouse's } \\
\text { shift work and that their lives were disrupted substantially by } \\
\text { it. } \\
\text { They also reported that shift work had a significant negative } \\
\text { impact upon the lives of the partners. } \\
\text { There was a significant association between the perception } \\
\text { of disruption and the perception of the shift workers' intoler- } \\
\text { ance toward shift work. }\end{array}$ \\
\hline $\begin{array}{l}\text { Spector et al. } \\
\text { (2004) }\end{array}$ & $\begin{array}{l}\text { Cross- } \\
\text { National in } \\
\text { China and } \\
\text { Latin } \\
\text { American } \\
\text { and The } \\
\text { Anglo } \\
\text { World }\end{array}$ & $\begin{array}{l}\text { Test the hypothesis } \\
\text { that the relation } \\
\text { between work- } \\
\text { hours and stress } \\
\text { would differ in } \\
\text { collectivist and } \\
\text { individualist coun- } \\
\text { tries }\end{array}$ & $\begin{array}{l}2487 \text { participants (all } \\
\text { managers) from } 15 \\
\text { samples placed into } \\
\text { three groups accord- } \\
\text { ing to region. Data } \\
\text { from } 1997-2000\end{array}$ & $\begin{array}{l}\text { Occupational Stress Indica- } \\
\text { tor (OSI): } \\
\text {-Work-family pressure (9 } \\
\text { items) } \\
\text { - Job satisfaction (12 items) } \\
\text { - Mental well-being (12 } \\
\text { items) } \\
\text { - Psychological well-being } \\
\text { (6 items) }\end{array}$ & $\begin{array}{l}\text { Age } \\
\text { Tenure on the job } \\
\text { No of children at home } \\
\text { Management level } \\
\text { Marital status }\end{array}$ & No. hrs/week & $\begin{array}{l}\text { There was a stronger relation between the number of hours } \\
\text { worked and work-family pressure in the individualist regions } \\
\text { (Anglo) than in the collectivist regions (China and Latin). }\end{array}$ \\
\hline $\begin{array}{l}\text { Strazdins et } \\
\text { al. (2004) }\end{array}$ & Canada & $\begin{array}{l}\text { Analysed the effect } \\
\text { of parents working } \\
\text { non-standard times } \\
\text { on children's well- }\end{array}$ & $\begin{array}{l}6361 \text { children from } \\
4433 \text { households, } \\
\text { where parents lived } \\
\text { together and both }\end{array}$ & $\begin{array}{l}\text { Child well-being: } \\
\text { Presence and number of } \\
\text { child emotional and behav- } \\
\text { ioural difficulties }\end{array}$ & $\begin{array}{l}\text { SES } \\
\text { Work intensity (full- or } \\
\text { part-time) } \\
\text { child care use }\end{array}$ & $\begin{array}{l}\text { Both parents } \\
\text { working standard } \\
\text { hrs. (weekday, } \\
\text { daytime) }\end{array}$ & $\begin{array}{l}\text { Higher odds for children having difficulties, when one or } \\
\text { both parents worked non-standard schedules. } \\
\text { Compared with households where both parents worked }\end{array}$ \\
\hline
\end{tabular}




\begin{tabular}{|c|c|c|c|c|c|c|c|}
\hline Reference & Country & $\begin{array}{l}\text { Purpose, design and } \\
\text { statistics }\end{array}$ & Sample & Outcome measures & Other measures & $\begin{array}{l}\text { Measures of working } \\
\text { time arrangements }\end{array}$ & Findings \\
\hline \multirow[b]{2}{*}{$\begin{array}{l}\text { Thomas \& } \\
\text { Ganster } \\
\text { (1995) }\end{array}$} & \multirow[b]{2}{*}{ U.S.A. } & $\begin{array}{l}\text { being. } \\
\text { Cross-sectional } \\
\text { analyses using } \\
\text { logistic regression }\end{array}$ & were employed. & $\begin{array}{l}\text { 2-3 years: four scales } \\
\text { 4-11 years: five scales } \\
\text { Dichotomous outcome: } \\
\text { no/any difficulty }\end{array}$ & $\begin{array}{l}\text { Child age and gender } \\
\text { Mothers and fathers } \\
\text { age } \\
\text { Number of dependent } \\
\text { children in household }\end{array}$ & $\begin{array}{l}\text { Both non-standard } \\
\text { Father non- } \\
\text { standard } \\
\text { Mother non- } \\
\text { standard }\end{array}$ & $\begin{array}{l}\text { standard times odds ratio for emotional or behavioural } \\
\text { difficulties for the child were } 1.51 \text { when the mother worked } \\
\text { non-standard schedule, } 1.36 \text { when the father did and } 1.53 \\
\text { when both parents did. } \\
\text { Adjustment did not explain the associations. }\end{array}$ \\
\hline & & $\begin{array}{l}\text { Examined the } \\
\text { effect of family } \\
\text { supportive organ- } \\
\text { isational policies } \\
\text { and practices } \\
\text { Cross-sectional } \\
\text { analyses using } \\
\text { SEM }\end{array}$ & $\begin{array}{l}398 \text { health profes- } \\
\text { sionals from } 45 \text { acute- } \\
\text { care facilities ( } 99 \% \\
\text { women), } 44 \% \text { nurses }\end{array}$ & $\begin{array}{l}\text { Concerns about combining } \\
\text { work and parenting (16 } \\
\text { items) } \\
\text { Inter-role conflict ( } 8 \text { items) } \\
\text { Control over work- and } \\
\text { family areas ( } 14 \text { items) } \\
\text { Depression ( } 3 \text { items) } \\
\text { Job satisfaction } \\
\text { Self-reported diastolic blood } \\
\text { pressure and cholesterol } \\
\text { level } \\
\text { Somatic complaints (19 } \\
\text { symptoms) } \\
\text { Absence (SR) }\end{array}$ & $\begin{array}{l}\text { Dependent care } \\
\text { services } \\
\text { Informational referral } \\
\text { services } \\
\text { Supervisor support } \\
\text { Age } \\
\text { Education } \\
\text { Overtime work } \\
\text { Personal income } \\
\text { Family income } \\
\text { Presence of spouse or } \\
\text { relative to care for } \\
\text { children }\end{array}$ & $\begin{array}{l}\text { Flexible scheduling } \\
\text { (possibility for } \\
\text { change of schedule } \\
\text { or individualized } \\
\text { schedule) }\end{array}$ & $\begin{array}{l}\text { Flexible scheduling had direct positive effects on em- } \\
\text { ployee's perceptions of control over work and family mat- } \\
\text { ters, in turn associated with lower levels of work-family } \\
\text { conflict, job dissatisfaction, depression, somatic complaint } \\
\text { and cholesterol. Flexible scheduling had in addition also a } \\
\text { direct positive effect on Somatic complaints. } \\
\text { Supervisor support showed similar associations, while } \\
\text { dependent care services and information referral services } \\
\text { did not. }\end{array}$ \\
\hline $\begin{array}{l}\text { van Amels- } \\
\text { voort et al. } \\
\text { (2004) }\end{array}$ & $\begin{array}{l}\text { The } \\
\text { Nether- } \\
\text { lands }\end{array}$ & $\begin{array}{l}\text { Investigate the } \\
\text { effect of direction } \\
\text { of shift rotation } \\
\text { Cross-sectional } \\
\text { and prospective } \\
\text { analyses using Cox } \\
\text { regression after } 32 \\
\text { months of follow- } \\
\text { up. }\end{array}$ & $\begin{array}{l}95 \text { workers in forward } \\
\text { rotating three-shift and } \\
681 \text { in backward } \\
\text { rotating shifts from } \\
\text { The Maastricht study } \\
\text { on fatigue. }\end{array}$ & $\begin{array}{l}\text { Work-home interaction } \\
\text { (single question) } \\
\text { Fatigue (20 item) } \\
\text { Sleep quality (single ques- } \\
\text { tion) } \\
\text { SRH (single question) } \\
\text { Need for recovery (11 } \\
\text { items) }\end{array}$ & $\begin{array}{l}\text { Overtime work } \\
\text { Flexible work hours } \\
\text { Years of work experi- } \\
\text { ence } \\
\text { Psychological de- } \\
\text { mands } \\
\text { Decision latitude } \\
\text { Social support } \\
\text { Physical demands } \\
\text { Age } \\
\text { Gender } \\
\text { Education } \\
\text { Care of dependent } \\
\text { children } \\
\text { Living with a partner } \\
\text { Long-term disease }\end{array}$ & $\begin{array}{l}\text { Work schedule: } \\
\text { Forward and } \\
\text { backward rotation } \\
\text { three-shifts }\end{array}$ & $\begin{array}{l}\text { A backward rotating shift was prospectively related to work- } \\
\text { family conflict (RR> } 8.94 \text { ). Adjustment was not possible. } \\
\text { A backward rotating shift was prospectively related to an } \\
\text { increased need for recovery (RR 2.88) and poor general } \\
\text { health (RR 3.21). Adjustment did not change the relations. } \\
\text { A backward rotating shift was prospectively related to poor } \\
\text { sleep quality (RR }>7.32 \text { ). Adjustment was not possible. }\end{array}$ \\
\hline $\begin{array}{l}\text { Van der Hulst } \\
\text { \& Geurts } \\
\text { (2001) }\end{array}$ & $\begin{array}{l}\text { The } \\
\text { Nether- } \\
\text { lands }\end{array}$ & $\begin{array}{l}\text { Examined the } \\
\text { relationship be- } \\
\text { tween overtime } \\
\text { and psychological } \\
\text { health in high and } \\
\text { low reward jobs } \\
\text { Cross-sectional } \\
\text { analyses using } \\
\text { split-sample logistic } \\
\text { regression }\end{array}$ & $\begin{array}{l}535 \text { primarily male } \\
\text { postal service em- } \\
\text { ployees }\end{array}$ & $\begin{array}{l}\text { Negative WHI } \\
\text { Negative HWI (measured } \\
\text { with a } 9 \text { and a } 6 \text { item scale } \\
\text { from the SWING- } \\
\text { questionnaire) }\end{array}$ & $\begin{array}{l}\text { Age } \\
\text { Gender } \\
\text { Executive position } \\
\text { Partner status } \\
\text { Parental status }\end{array}$ & $\begin{array}{l}\text { Overtime (1-5 h, 6- } \\
10 \mathrm{~h}, 11-20 \mathrm{~h},>20 \\
\mathrm{~h}) \\
\text { Rewards ( } 7 \text { item } \\
\text { scale) } \\
\text { Pressure to work } \\
\text { overtime (single } \\
\text { item) }\end{array}$ & $\begin{array}{l}\text { No negative effect of overtime work when rewards were } \\
\text { high. } \\
\text { With low rewards, strong negative effects of overwork on } \\
\text { WHI, HWI, poor recovery, exhaustion and cynicism. } \\
\text { With low rewards and high pressure to work overtime: OR } \\
7.29 \text { for negative WHI compared to those working overtime } \\
\text { with high rewards and low pressure. } \\
\text { Low reward in combination with both high and low pressure } \\
\text { to work overtime had adverse health effects. }\end{array}$ \\
\hline
\end{tabular}




\begin{tabular}{|c|c|c|c|c|c|c|c|}
\hline Reference & Country & $\begin{array}{l}\text { Purpose, design and } \\
\text { statistics }\end{array}$ & Sample & Outcome measures & Other measures & $\begin{array}{l}\text { Measures of working } \\
\text { time arrangements }\end{array}$ & Findings \\
\hline $\begin{array}{l}\text { van Rijswijk } \\
\text { et al. (2004) }\end{array}$ & $\begin{array}{l}\text { The } \\
\text { Nether- } \\
\text { lands }\end{array}$ & $\begin{array}{l}\text { Investigate the } \\
\text { effect of part-time } \\
\text { work on WFI and } \\
\text { well-being } \\
\text { Cross-sectional } \\
\text { analyses using } \\
\text { SEM }\end{array}$ & $\begin{array}{l}160 \text { part-time and } 29 \\
\text { full-time employed } \\
\text { mothers (with children } \\
\text { at home) with a } \\
\text { partner from two } \\
\text { insurance companies. }\end{array}$ & $\begin{array}{l}\text { WFI (9 items) } \\
\text { FWI (6 items) } \\
\text { Emotional exhaustion } \\
\text { Cognitive failures } \\
\text { Perceived stress } \\
\text { Job satisfaction } \\
\text { Well-being (summary } \\
\text { variable of the four variables } \\
\text { above) }\end{array}$ & $\begin{array}{l}\text { Work demands } \\
\text { Home demands } \\
\text { Neuroticism } \\
\text { Reason for working } \\
\text { part-time }\end{array}$ & $\begin{array}{l}\text { Part-time }<32 \\
\text { hrs/week } \\
\text { Full-time }>32\end{array}$ & $\begin{array}{l}\text { For mothers: } \\
\text { Working part-time was associated with lower levels of WFI, } \\
\text { also after control for part-time as a strategy to enhance } \\
\text { WFB. No relationship between working part-time and FWI. } \\
\text { No direct effect of part-time employment on well-being. The } \\
\text { effect was mediated by WFI. Direct effect of working part- } \\
\text { time on lower level of cognitive failures }\end{array}$ \\
\hline $\begin{array}{l}\text { Voydanoff } \\
\text { (2004) }\end{array}$ & U.S.A. & $\begin{array}{l}\text { Examine the effect } \\
\text { of work demands } \\
\text { and resources on } \\
\text { WFC and facilita- } \\
\text { tion } \\
\text { Cross-sectional } \\
\text { analyses using } \\
\text { multivariate re- } \\
\text { gression }\end{array}$ & $\begin{array}{l}1938 \text { wage or salary } \\
\text { workers between } 18 \\
\text { and } 64 \text { and not living } \\
\text { alone. From the } 1997 \\
\text { National Study of } \\
\text { Changing Workforce }\end{array}$ & $\begin{array}{l}\text { WFC ( } 5 \text { items) } \\
\text { WF- facilitation ( } 2 \text { items) }\end{array}$ & $\begin{array}{l}\text { Job insecurity } \\
\text { Autonomy } \\
\text { Learning opportunities } \\
\text { Parental leave } \\
\text { Supervision work- } \\
\text { family support } \\
\text { Gender, Education, } \\
\text { Race, number of } \\
\text { children under } 6\end{array}$ & $\begin{array}{l}\text { Hrs/week } \\
\text { Extra work without } \\
\text { notice } \\
\text { Possibility for time } \\
\text { off for family } \\
\text { Perceived time } \\
\text { pressure }\end{array}$ & $\begin{array}{l}\text { Hrs/week, extra work without notice, time pressure (and job } \\
\text { insecurity) were positively associated with WFC, but only } \\
\text { weakly with WF-facilitation. } \\
\text { Possibility for time off for family was negatively associated } \\
\text { with conflict and positively with facilitation. }\end{array}$ \\
\hline $\begin{array}{l}\text { Väänänen et } \\
\text { al. (2004) }\end{array}$ & Finland & $\begin{array}{l}\text { Determine whether } \\
\text { double burden of } \\
\text { and negative spill } \\
\text { between domestic } \\
\text { and full-time work } \\
\text { are associated with } \\
\text { health problems } \\
\text { Analysed by } \\
\text { logistic and poison } \\
\text { regression }\end{array}$ & $\begin{array}{l}6442 \text { full-time munici- } \\
\text { pal employees }\end{array}$ & $\begin{array}{l}\text { Psychological distress } \\
\text { Suboptimal health } \\
\text { Sickness absence }\end{array}$ & $\begin{array}{l}\text { (Negative WF spill- } \\
\text { over } \\
\text { Negative FW - spill } \\
\text { over) } \\
\text { Age, marital status, } \\
\text { dependent children, } \\
\text { monthly income }\end{array}$ & $\begin{array}{l}\text { Paid work hours } \\
\text { Domestic work } \\
\text { hours } \\
\text { Total work hours } \\
\text { Division of domes- } \\
\text { tic responsibilities }\end{array}$ & $\begin{array}{l}\text { For men: } \\
\text { - Work hours } 41-50 \mathrm{hrs} / \text { week as compared to part-time } \\
(<38) \text {, and long total work and domestic hours were re- } \\
\text { lated to psychological distress. Long total work hours } \\
\text { and long domestic hours were related to sickness ab- } \\
\text { sence. } \\
\text { For women: } \\
\text { - Work hours } 41-50 \mathrm{hrs} / \text { week, long domestic and total } \\
\text { work hours were related to psychological distress, and } \\
\text { total work hours to suboptimal health. } \\
\text { - Working more than } 50 \text { hrs/week was not related to } \\
\text { psychological distress }\end{array}$ \\
\hline $\begin{array}{l}\text { White \& Keith } \\
\text { (1990) }\end{array}$ & & $\begin{array}{l}\text { Asses the notion } \\
\text { that shift work } \\
\text { damages marital } \\
\text { quality } \\
\text { Cross-sectional } \\
\text { and panel analyses } \\
\text { with data from } \\
1980 \text { and } 1983\end{array}$ & $\begin{array}{l}1668 \text { married men } \\
\text { and women from a } \\
\text { national random } \\
\text { sample. }\end{array}$ & $\begin{array}{l}\text { Marital happiness (11 item) } \\
\text { Marital interaction }(5 \text { item) } \\
\text { Disagreements }(4 \text { item) } \\
\text { Sexual problems }(4 \text { item }) \\
\text { Child related problems ( } 7 \\
\text { item) } \\
\text { Divorce }\end{array}$ & $\begin{array}{l}\text { Sex } \\
\text { Race } \\
\text { Age } \\
\text { Education } \\
\text { Family income } \\
\text { Wife's employment } \\
\text { Years married } \\
\text { Number of children } \\
\text { Occupational type } \\
\text { Personal income } \\
\text { Occupational prestige } \\
\text { Irregular hours } \\
\text { Job satisfaction }\end{array}$ & $\begin{array}{l}\text { Shift work within } \\
\text { the couple }(1 \text { if } \\
\text { either spouse work } \\
\text { shift and } 0 \text { if } \\
\text { neither })\end{array}$ & $\begin{array}{l}\text { Cross-sectional: } \\
\text { - Shift-work was associated with lower marital happi- } \\
\text { ness, higher sexual problems and child-related prob- } \\
\text { lems. These associations did not change after control } \\
\text { for occupational variables. } \\
\text { Prospective: } \\
\text { - Respondents in marriages that added shift worker } \\
\text { showed increased disagreements. Respondents in } \\
\text { couples who dropped shift work showed increase in in- } \\
\text { teraction and decrease in child-related problems. } \\
\text { - Couples shift work increased the probability of divorce. } \\
\text { After control of background factors from } 7 \text { to } 11 \% \text { or } \\
\text { with an increase of } 57 \% \text {. }\end{array}$ \\
\hline
\end{tabular}




\begin{tabular}{|c|c|c|c|c|c|c|c|}
\hline Reference & Country & $\begin{array}{l}\text { Purpose, design and } \\
\text { statistics }\end{array}$ & Sample & Outcome measures & Other measures & $\begin{array}{l}\text { Measures of working } \\
\text { time arrangements }\end{array}$ & Findings \\
\hline $\begin{array}{l}\text { Åkerstedt et } \\
\text { al. (2004) }\end{array}$ & Sweden & $\begin{array}{l}\text { Examined the } \\
\text { relationship be- } \\
\text { tween mental } \\
\text { fatigue and differ- } \\
\text { ent work-related } \\
\text { and background } \\
\text { factors } \\
\text { Cross-sectional } \\
\text { analysis using } \\
\text { multiple logistic } \\
\text { regression }\end{array}$ & $\begin{array}{l}5720 \text { healthy, em- } \\
\text { ployed men ( } 3250) \\
\text { and women }(2470) \\
\text { from the Stockholm } \\
\text { area }\end{array}$ & Mental Fatigue (single item) & $\begin{array}{l}\text { Non-sedentary work } \\
\text { Solitary work } \\
\text { Physical demands at } \\
\text { work } \\
\text { Demands } \\
\text { (Karasek/Theorell) } \\
\text { Immersion (occupied } \\
\text { with work in non-work } \\
\text { time) } \\
\text { Decision latitude } \\
\text { Social support } \\
\text { Age } \\
\text { Gender } \\
\text { BMI } \\
\text { Marriage status } \\
\text { Children } \\
\text { SES } \\
\text { Coffee consumption } \\
\text { Exercise } \\
\text { Disturbed sleep } \\
\text { Snoring }\end{array}$ & $\begin{array}{l}\text { Shift work } \\
\text { Overtime work } \\
\text { Part-time work } \\
\text { Having an extra job }\end{array}$ & $\begin{array}{l}\text { Mental fatigue was associated with high work demands, not } \\
\text { being a supervisor, being female, lower age, lack of exer- } \\
\text { cise, immersion (occupied with work in non-work time), } \\
\text { snoring and disturbed sleep. } \\
\text { Shift work and overtime work was not associated with } \\
\text { mental fatigue. }\end{array}$ \\
\hline
\end{tabular}

F-> W: family to work. WFB:Work family balance. WLB: Work-life balance. WIF: Work In Family. FIW: Family in Work. WHI: Work Home Interference. HWI: Home Work Interference. WFI: Work Family Interference. SOC: Selection, Optimization and Compensation. NCP: "New concept part-time", meaning part-time employment options that enhance job prestige, job satisfaction, and career opportunities associated with reducedhours employment for professional women 
Tabel 2 Examples of intervention studies in working time arrangements

\begin{tabular}{|c|c|c|c|c|c|c|c|}
\hline Reference & Country & $\begin{array}{l}\text { Purpose, design and } \\
\text { statistics }\end{array}$ & Sample & Measures of outcome & Other measures & Measures of working time arrangements & Findings \\
\hline $\begin{array}{l}\text { Andersson } \\
\& \text { Johns- } \\
\text { son (2005) }\end{array}$ & Sweden & $\begin{array}{l}\text { Evaluate the effect of } \\
\text { implementation of a 3- } \\
3 \text { model } \\
\text { Evaluated before and } \\
1 \text { year after implemen- } \\
\text { tation, no control } \\
\text { group. } \\
\text { Interviews, question- } \\
\text { naire and economical } \\
\text { data }\end{array}$ & $\begin{array}{l}133 \text { employees } \\
\text { in health care }\end{array}$ & - & - & $\begin{array}{l}\text { Three days of work followed by three days } \\
\text { off in a rolling scheme. Ignoring holidays. } \\
\text { Reduced working time compensated by } \\
\text { more work hours per day ( } 8.5 \text { ) and extra } \\
\text { days (15-20) that the employer can } \\
\text { dispose over. }\end{array}$ & $\begin{array}{l}\text { Employees experienced: Better possibili- } \\
\text { ties for recovery, better work environment } \\
\text { and climate, better possibilities for combin- } \\
\text { ing private life and work and improved } \\
\text { health. Costs to sickness absence } \\
\text { dropped } \\
\text { Costs to wages increased. } \\
\text { More work on holidays. }\end{array}$ \\
\hline $\begin{array}{l}\text { Ekstedt et } \\
\text { al. (2001) }\end{array}$ & Sweden & $\begin{array}{l}\text { Evaluate the effect of } \\
\text { compressed working } \\
\text { hours during construc- } \\
\text { tion work } \\
\text { Over one year: } \\
\text { Questionnaire at } 3 \\
\text { times } \\
\text { Sleep/wake diary (8 } \\
\text { times) } \\
\text { Artigraph } \\
\text { Saliva samples }\end{array}$ & $\begin{array}{l}83 \text { construction } \\
\text { workers on the } \\
\text { construction of a } \\
\text { road tunnel } \\
\text { system }\end{array}$ & $\begin{array}{l}\text { Attitude } \\
\text { Stress } \\
\text { Sleep } \\
\text { Fatigue } \\
\text { Health complaints }\end{array}$ & & $\begin{array}{l}\text { Introduction of a shift cycle with an } 8 \text { hrs } \\
\text { shift followed by two double shifts ( } 15.5 \\
\text { hrs) and a free weekend followed by two } \\
\text { double shifts and a week off. }\end{array}$ & $\begin{array}{l}\text { Result showed a very positive attitude } \\
\text { toward the shift among the workers. No } \\
\text { changes in stress level. Slightly increase in } \\
\text { self-reported health complaints and slightly } \\
\text { decrease in different measures of sleep } \\
\text { length and quality. }\end{array}$ \\
\hline $\begin{array}{l}\text { Enehaug } \\
\text { et al. } \\
\text { (2006) }\end{array}$ & Norway & $\begin{array}{l}\text { Evaluate et effect of a } \\
3-7,4-7 \text { model } \\
\text { Evaluated with ques- } \\
\text { tionnaire after start } \\
\text { and with follow-up } \\
\text { after one year }\end{array}$ & $\begin{array}{l}206 \text { employees } \\
\text { at baseline } 274 \\
\text { follow-up } \\
47 \text { both times }\end{array}$ & - & - & $\begin{array}{l}\text { A rota with four days and nights of work } \\
\text { followed by seven days off, and after that a } \\
\text { period with three days of work followed by } \\
\text { seven days off }\end{array}$ & $\begin{array}{l}\text { Most employees evaluated the trial posi- } \\
\text { tively with regard to the work tasks, work } \\
\text { environment, leisure time, family life and } \\
\text { health. } \\
17-18 \% \text { evaluated the roster negatively } \\
\text { with regard to family life. } \\
62 \% \text { of the respondents would choose the } \\
\text { actual roster if they could choose by } \\
\text { themselves } \\
\text { No changes in psychological or physio- } \\
\text { logical health complaints could be de- } \\
\text { tected in the group of respondents partici- } \\
\text { pating in both rounds. }\end{array}$ \\
\hline $\begin{array}{l}\text { Hornberger } \\
\text { \& Knauth } \\
\text { (1995) }\end{array}$ & Germany & $\begin{array}{l}\text { Exploring the effect of } \\
\text { changes in shift rotas } \\
\text { and shortening of } \\
\text { working time on } \\
\text { health, well-being and } \\
\text { attitudes. } \\
\text { Prospective analyses } \\
\text { of variance using pre- }\end{array}$ & $\begin{array}{l}260 \text { employees } \\
\text { in the chemical } \\
\text { industry forming } \\
5 \text { experimental } \\
\text { groups }\end{array}$ & $\begin{array}{l}\text { Subjective health and well- } \\
\text { being: } \\
\text { - } \quad \text { Fatigue } \\
\text { - } \text { Sleep } \\
\text { - } \text { Gastro comp. } \\
\text { - Neuro comp. } \\
\text { - } \quad \text { Effects on social life } \\
\text { - Utility of leisure time }\end{array}$ & $\begin{array}{l}\text { Socio demographic } \\
\text { data }\end{array}$ & 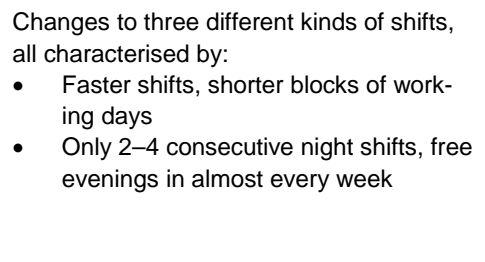 & $\begin{array}{l}\text { Improvements in three out of the five } \\
\text { experimental groups: } \\
\text { Improvements in subjective health and } \\
\text { well-being in two groups and deterioration } \\
\text { in one, reduction in social disturbances in } \\
\text { two groups, mixed results regarding } \\
\text { leisure time. }\end{array}$ \\
\hline
\end{tabular}




\begin{tabular}{|c|c|c|c|c|}
\hline Reference & Country & $\begin{array}{l}\text { Purpose, design and } \\
\text { statistics }\end{array}$ & Sample & Measures of outcome \\
\hline & & $\begin{array}{l}\text { and post- test meas- } \\
\text { ures. }\end{array}$ & & $\begin{array}{ll}\text { - Attitude toward new } \\
\text { shift }\end{array}$ \\
\hline $\begin{array}{l}\text { Kauffeld et } \\
\text { al. (2004) }\end{array}$ & Germany & $\begin{array}{l}\text { Effects of flexible } \\
\text { work-time designs on } \\
\text { employee and com- } \\
\text { pany-related aims } \\
\text { Qualitative and quanti- } \\
\text { tative measures post- } \\
\text { intervention. } \\
\text { Analysed qualitatively } \\
\text { and by MANOVA. }\end{array}$ & $\begin{array}{l}18 \text { employees } \\
\text { who had been } \\
\text { working with a } \\
\text { new work-time } \\
\text { design in } 2.5 \\
\text { years were } \\
\text { compared with } \\
15 \text { who had not }\end{array}$ & $\begin{array}{l}\text { Costumer waiting time } \\
\text { Costumer-employee ratio } \\
\text { Costumer complaints } \\
\text { Work quality } \\
\text { Absenteeism } \\
\text { Employee involvement }\end{array}$ \\
\hline $\begin{array}{l}\text { Olsson et } \\
\text { al. (1999) }\end{array}$ & Sweden & $\begin{array}{l}\text { Explored the effect of } \\
\text { a reduction of hours } \\
\text { from } 8 \text { to } 6 \text { per day } \\
\text { Measurements before } \\
\text { and 1and } 2 \text { years after } \\
\text { intervention with } \\
\text { questionnaire and } \\
\text { psycho physiological } \\
\text { measures } \\
\text { Analyses of variance }\end{array}$ & $\begin{array}{l}94 \text { employees } \\
(14 \text { men and } 80 \\
\text { women) from } \\
\text { child- and health } \\
\text { care institutions }\end{array}$ & $\begin{array}{l}\text { Experience of sufficient time } \\
\text { for social activities } \\
\text { Attitude toward working } \\
\text { hours } \\
\text { Health: Absenteeism, } \\
\text { somatic symptoms, inci- } \\
\text { dence of disease) }\end{array}$ \\
\hline $\begin{array}{l}\text { Orth- } \\
\text { Gomér } \\
\text { (1983) }\end{array}$ & Sweden & $\begin{array}{l}\text { Explored the effect of } \\
\text { a new rotating sched- } \\
\text { ule over a period of } \\
2 \times 4 \text { weeks. }\end{array}$ & $\begin{array}{l}45 \text { volunteer } \\
\text { policemen }\end{array}$ & $\begin{array}{l}\text { Serum lipids } \\
\text { Glucose } \\
\text { Uric acid } \\
\text { Blood pressure } \\
\text { Catecholamine's } \\
\text { Sleep quantity and quality } \\
\text { Tobacco consumption } \\
\text { Satisfaction with schedule, } \\
\text { leisure time and self-rated } \\
\text { health }\end{array}$ \\
\hline $\begin{array}{l}\text { Perrons } \\
\text { (2003) }\end{array}$ & UK & $\begin{array}{l}\text { Exploring the gender- } \\
\text { differentiated patterns } \\
\text { of ownership and } \\
\text { earnings among new } \\
\text { media owners and } \\
\text { whether flexible } \\
\text { working patterns, long }\end{array}$ & $\begin{array}{l}55 \text { media own- } \\
\text { ers, managers } \\
\text { and some } \\
\text { employees in } \\
\text { small and } \\
\text { medium size } \\
\text { enterprises. } 38\end{array}$ & \\
\hline
\end{tabular}

Decision latitude Peeks in costumers over a 12 month Job demands Work satisfaction Learning opportunities Coo with colleagues Supervisor conduct Communication in company Responsibility Intrinsic motivation Identification with company

Experience of sufficient time for social activities

(aln. Absenteeism, dence of disease)

Uric acid

Satisfaction with schedule,

leisure time and self-rated

health ees. 1/3 served as comparison group

period were observed, documented and
Working hour's reduction with full wage compensation among $2 / 3$ of the employ-

schedules by managers and employees.

Employees in the flex-time group viewed their work situations overall as better than the traditional group. They reported higher demands and decision latitude, work

satisfaction, learning opportunities, better addition they her ism, fewer cashier mistakes and lower rate of costumer complaints. No direct measurements of stress or wellbeing were given.

Attitude toward working hours had improved.

Experience of sufficient time for social activities had improved, particularly time for friends and relaxation.

The group with small children benefited

the most from the intervention.

Health was not significantly affected

4 weeks of clockwise rotation compared with 4 weeks of counter-clockwise rotatio

During clockwise rotation, serum lipids of triglycerides and glucose were significantly lower than during counter-clockwise rotation. Sleep quality and quantity were better, systolic blood pressure and excretion of catecholamines were lower. Satisfaction with leisure time between shifts and self-rated health was better.

Working hours varied, but were long: mean $46 \mathrm{hr} /$ week $(S D=16)$ for women and $48(S D=17)$ for men.

Flexible working hours

Responsibility for childcare
Lack of clear boundaries around project content, uncertainty about the volume of work and inflexible deadlines identified as major sources of strain.

New media creates new opportunities for people to combine interesting paid work with caring responsibilities but that a 


\begin{tabular}{|c|c|c|c|c|c|c|c|}
\hline Reference & Country & $\begin{array}{l}\text { Purpose, design and } \\
\text { statistics }\end{array}$ & Sample & Measures of outcome & Other measures & Measures of working time arrangements & Findings \\
\hline & & $\begin{array}{l}\text { hours and home } \\
\text { working are compati- } \\
\text { ble with work-life } \\
\text { balance. } \\
\text { Qualitative case study } \\
\text { using interviews. }\end{array}$ & $\begin{array}{l}\text { of these were } \\
\text { men. }\end{array}$ & & & & $\begin{array}{l}\text { marked gender imbalance remains. } \\
\text { Women more likely to have the responsi- } \\
\text { bility for childcare, but only few had. }\end{array}$ \\
\hline $\begin{array}{l}\text { Pryce et al. } \\
\text { (2006) }\end{array}$ & Denmark & $\begin{array}{l}\text { Exploring changes in } \\
\text { work environment and } \\
\text { WLB after introduction } \\
\text { of an open-roster } \\
\text { system. } \\
\text { Prospective analyses } \\
\text { with measures before } \\
\text { implementation and } \\
20 \text { month follow-up, } \\
\text { using MANOVA } \\
\text { repeated measures } \\
\text { analyses. }\end{array}$ & $\begin{array}{l}\text { Primarily female } \\
\text { employees from } \\
\text { a psychiatric } \\
\text { ward. } \\
86 \text { in interven- } \\
\text { tion group. } \\
91 \text { in control } \\
\text { group. }\end{array}$ & $\begin{array}{l}\text { WLB ( } 5 \text { items) } \\
\text { Self-rated health ( } 1 \text { item) } \\
\text { Stress symptoms ( } 3 \text { scales, } \\
\text { each of } 4 \text { items) } \\
\text { Vitality }(4 \text { items) } \\
\text { Job satisfaction }(5 \text { items) } \\
\text { Social support }(4 \text { items }) \\
\text { Sense of community ( } 3 \\
\text { items) }\end{array}$ & $\begin{array}{l}\text { Usual working hours } \\
\text { Influence over working } \\
\text { time } \\
\text { Weekend work } \\
\text { Swap of shifts } \\
\text { Attitude to swap of } \\
\text { shift from charge } \\
\text { nurse }\end{array}$ & $\begin{array}{l}\text { With and without open-rota intervention } \\
\text { (giving increased possibilities for influence } \\
\text { over own working schedule). }\end{array}$ & $\begin{array}{l}\text { Employe0es in the intervention group } \\
\text { reported compared to control group signifi- } \\
\text { cant increases in WLB, job satisfaction, } \\
\text { social support and sense of community as } \\
\text { compared to nurses in the control groups. } \\
\text { Self-rated health and stress level didn't } \\
\text { change. }\end{array}$ \\
\hline $\begin{array}{l}\text { Smith et al. } \\
\text { (1998) }\end{array}$ & Australia & $\begin{array}{l}\text { Examined the impact } \\
\text { of a change from } \\
\text { slowly to rapidly } \\
\text { rotating shifts, with } \\
\text { participative design. } \\
\text { Measures before and } \\
\text { xx month after imple- } \\
\text { mentation. }\end{array}$ & $\begin{array}{l}72 \text { shift workers } \\
\text { at three sewage } \\
\text { treatment plants. }\end{array}$ & $\begin{array}{l}\text { Impact on home-life } 6 \\
\text { items), social life ( } 7 \text { items), } \\
\text { work- life (6 items) } \\
\text { Family live } \\
\text { Social life } \\
\text { Mental Health } \\
\text { (single items) } \\
\text { Energy and vigour (10 } \\
\text { items) }\end{array}$ & $\begin{array}{l}\text { Work performance } \\
\text { Attitude toward shift } \\
\text { work. } \\
\text { Attitude toward shift } \\
\text { roster. } \\
\text { Job satisfaction ( } 5 \\
\text { items). } \\
\text { GHQ (12 items and } 6 \\
\text { item scales). } \\
\text { Health complaints, } \\
\text { Sleep quality and } \\
\text { tiredness. }\end{array}$ & $\begin{array}{l}\text { Change from a slowly rotating } 8 \text {-hour shift } \\
\text { to rapidly rotating 1) } 8 \text {-hour shift roster and } \\
\text { 2) } 12 \text {-hour shift roster. } \\
\text { Two groups changed to } 12 \mathrm{hrs} \mathrm{shift,} \mathrm{one} \\
\text { first to } 8 \text { hrs sand then to } 12 \text { hrs. }\end{array}$ & $\begin{array}{l}\text { Workers at all plants reported: Improve- } \\
\text { ments in quality of home, social and work- } \\
\text { life, increased satisfaction with roster } \\
\text { design, improved day sleep quality, less } \\
\text { tiredness, decrease in physical and psy- } \\
\text { chological circadian malaise. } \\
\text { The } 12 \text { hours shift groups reported most } \\
\text { improvement. The effects were associated } \\
\text { with the prior support for the trial. }\end{array}$ \\
\hline $\begin{array}{l}\text { Åkerstedt } \\
\text { et al. } \\
\text { (2001) }\end{array}$ & Sweden & $\begin{array}{l}\text { To study the effect of } \\
\text { a reduction of the } \\
\text { working hours. } \\
\text { Baseline and follow- } \\
\text { up after one year } \\
\text { Two- factor analyses } \\
\text { of variance } \\
\text { (time } x \text { group interac- } \\
\text { tion) }\end{array}$ & $\begin{array}{l}\text { Experimental } \\
\text { group: } 35 \\
\text { women and } 6 \\
\text { men employed } \\
\text { in child and } \\
\text { elderly care } \\
\text { Comparison } \\
\text { group: } 18 \\
\text { women and } 4 \\
\text { men in similar } \\
\text { jobs }\end{array}$ & $\begin{array}{l}\text { Attitude to work } \\
\text { Time for family and friends } \\
\text { ( } 3 \text { items) } \\
\text { Time for social activities ( } 8 \\
\text { items) } \\
\text { Health } \\
\text { Psychosomatic symptoms } \\
\text { (8 items) } \\
\text { Mental fatigue ( } 3 \text { items) } \\
\text { Nervous symptoms ( } 3 \\
\text { items) } \\
\text { Pain/ache complaints (5 } \\
\text { items) } \\
\text { Insomnia complaints ( } 4 \\
\text { items) }\end{array}$ & $\begin{array}{l}\text { Work demands ( } 5 \\
\text { items). } \\
\text { Decision latitude ( } 6 \\
\text { items). } \\
\text { Social support ( } 6 \\
\text { items). }\end{array}$ & $\begin{array}{l}\text { The experimental group had a } 9 \text { hours } \\
\text { reduction of working hrs/week to } 6 \text { hours } \\
\text { per day, and with full compensation }\end{array}$ & $\begin{array}{l}\text { The experimental group improved while } \\
\text { the control group did not change on: } \\
\text { - } \quad \text { Time for social activity } \\
\text { - } \quad \text { Time for friends and family } \\
\text { - } \quad \text { Attitude to work hours } \\
\text { - } \quad \text { Satigue } \\
\text { - } \quad \text { Heart/respiratory complaints }\end{array}$ \\
\hline
\end{tabular}


